\title{
Article \\ Knowledge-Based Fuzzy Expert System to the Condition Assessment of Historic Road Bridges
}

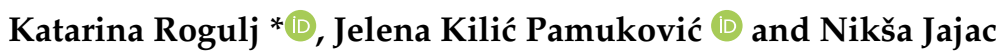 \\ Faculty of Civil Engineering, Architecture and Geodesy, University of Split, Matice Hrvatske 15, \\ 21000 Split, Croatia; jkilic@gradst.hr (J.K.P.); njajac@gradst.hr (N.J.) \\ * Correspondence: katarina.rogulj@gradst.hr
}

check for

updates

Citation: Rogulj, K.; Kilić Pamuković, J.; Jajac, N. KnowledgeBased Fuzzy Expert System to the Condition Assessment of Historic Road Bridges. Appl. Sci. 2021, 11 , 1021. https://doi.org/10.3390/ app11031021

Received: 23 December 2020

Accepted: 20 January 2021

Published: 23 January 2021

Publisher's Note: MDPI stays neutral with regard to jurisdictional claims in published maps and institutional affiliations.

Copyright: (C) 2021 by the authors Licensee MDPI, Basel, Switzerland. This article is an open access article distributed under the terms and conditions of the Creative Commons Attribution (CC BY) license (https:// creativecommons.org/licenses/by/ $4.0 /)$.

\begin{abstract}
A systematic methodology for condition assessment of the historic road bridges was needed because of the poor and inadequate condition of bridges which cannot satisfy everydayday dynamic loads and deteriorations due to the aging process. Thus in this study, a new expert system based on the knowledge approach has been proposed to develop a systematic procedure for condition assessment of these bridges using fuzzy logic and sets of $\alpha$-cuts. Each bridge is divided into three components: superstructure, substructure, and equipment, and each component is divided into relevant elements. These elements are evaluated by an expert and their ratings are fuzzified according to defined fuzzy sets, their membership functions, and linguistic values. Furthermore, fuzzy structural importance is given to ratings of each element. Combinations of these two values are calculated to obtain a fuzzy rating of the component using the Fuzzy Weighted Geometric Mean (FWGM). Finally, for the defuzzification of the component rating, the centroid method is proposed. The Analytic Hierarchy Process (AHP) is used for comparison of the components. The bridge condition rating is achieved by summering all the components ratings multiplied by their relative importance, and it is presented as a value of the Historic Road Bridge Condition Assessment Index (HRBCAI). The validation is conducted on the bridges built until the end of the Austro-Hungarian Monarchy in Split-Dalmatia County, Croatia.
\end{abstract}

Keywords: historic road bridges; visual assessment; fuzzy logic; expert systems; FWGM; AHP; HRBCAI

\section{Introduction}

Road infrastructure is one of the main social resources that contains specific characteristics and whose planning should be approached in a special way. The key components of road infrastructure are road bridges which, due to their function of connecting roads and their strategic position, require special attention. Of particular importance is a systematic assessment of bridges as an essential activity of monitoring and managing the transport system [1]. The shortcomings related to the aging of the bridge have become a major concern for managers, but also society as a whole. The degradation of bridges mainly begins with processes whose action is manifested only in an advanced stage, phenomena visible on the surface of the building [2]. Serious damage to bridges can be caused by exposure to aggressive environmental conditions, increased traffic volume, neglect of durability problems, performance errors, and underestimation of the importance of maintenance [3]. Determining the level of repairs needed to achieve the most cost-effective life of a bridge has been a source of dilemma for managers for many years. Following the limited resources for the management, maintenance and reconstruction of bridges, certain strategies must be defined. However, on the other hand, any carelessness and delayed actions of maintaining bridges can lead to large future costs or significant degradation of the building [4].

For bridges to be effectively maintained and renovated, experts must have knowledge of their design as well as their maintenance history which is unknown to most bridges. Maintenance of bridges implies a set of activities to establish a sustainable condition to 
ensure the basic values of the building (mechanical resistance and stability, safety in use, etc.) such as renovation, adaptation, and reconstruction to enable safety and usability of the bridge [2]. Inspection and maintenance of road bridges is a very sensitive and complex task due to the increased volume of traffic, degradation and various damages of existing bridges. The management of road bridges is entrusted to public institutions and is shaped by technical, political, environmental, and historical aspects. It deals with all activities during the life of the bridge from construction to replacement, intending to ensure its safety and functionality. It also provides the necessary protection, maintenance planning, and minimization of bridge life cycle costs [5]. The lifespan of a bridge can be divided into four different phases [6]: design and construction, slight deterioration, obvious damage, and the occurrence of extensive degradation. The most effective way to select an adequate maintenance strategy, including replacement, repair, restoration, and preventive maintenance, is to apply mathematical modelling of computer systems [7].

With the advancement of technology, the combination of bridge inspection and maintenance or restoration methods has been controlled by a computer-assisted Bridge Management System (BMS) used worldwide to address the complexity of bridge management decision-making [5]. However, each BMS differs from state to state because of the use of different ways of inspecting bridges and strategies for maintaining, rebuilding, and repairing bridges within a distributed budget [8]. Road bridge management in Croatia began to be studied more intensively in the 1980s, when the first systematic inspections of road network bridges were conducted [9].

The main activities of the bridge management system are: database module, condition assessment and decision-making process [10]. The database module consists of bridge documentation and a computer database. One of the basic requirements of a bridge management system is a comprehensive and accessible list of bridge data. The list should include maintenance information, a set of descriptive data used for various purposes, such as managing large bridge networks, evaluating the overall condition of bridges, bridge location, bridge type, materials, costs and maintenance history, etc. Records of any shortcomings, changes to original bridge designs and maintenance actions need to be accurately memorized for future knowledge. Maintenance history not only provides information for an individual bridge, but can lead, when analyzing all information, to an understanding of common problems that require more than solutions at the project or network level [11].

\subsection{Assessment of Bridge Condition}

The assessment of the bridge condition is based on data from periodic field inspections of bridges. The purpose of the condition assessment is to assess the degree and extent of deterioration and deficiencies. The bridge is divided into elements or components, and the condition of each element or component is expressed using a condition assessment. Condition estimates are defined by numerical or linguistic variables as measures of the degree and extent of deterioration. The condition is assessed through an inspection process that involves the use of specific techniques to assess the physical condition of the bridge. A detailed visual inspection is carried out on a routine or planned basis to detect serious deficiencies and assess the degree of deterioration of the bridge elements. Additionally, ad hoc inspections should be carried out after natural disasters such as earthquakes and emergency inspections after accidents due to specific failures. If serious damage is found during the visual inspection, a detailed test using non-destructive testing (NDT) methods is needed to determine the extent of damage to the bridge element. It is also necessary to inspect the condition of the bridge after the maintenance, refurbishment or repair work to ensure that damage or malfunction has been rectified, after which routine inspections and maintenance should continue to be performed on the bridge [12].

The bridge inspection system controls the entire bridge life cycle process and provides the information needed for a decision-making system that is responsible for all activities during the life of the bridge, such as routine maintenance and repair, upgrading and 
replacement. Watson and Everett [13] state that the usual bridge inspection process involves four levels:

(1) routine checks to confirm the general safety and usability of the structure for road users;

(2) a comprehensive visual inspection carried out by a qualified expert to assess the condition of each bridge;

(3) detailed inspections carried out when further tests during level 2 are required and carried out by qualified engineers;

(4) load assessment due to changes in dynamic load, i.e., due to the application of new types of vehicles or due to the need to confirm the structural capacity of bridges.

As a result, the responsibility of managers in charge of bridge reconstruction is crucial to make transparent decisions with the lowest projected losses [14]. Most decisions related to bridge maintenance are made based on assessments based on visual inspections performed by trained engineers whose task is to see, identify, and record phenomena relevant to assessing the condition of bridge construction and equipment, or indications leading to damage. Visual inspection, along with all other test methods, is considered to be the most important means of assessing the condition of a bridge. How high quality and accurate the visual inspection will depend on the training and equipment of the experts conducting the inspection. The effectiveness of management in maintenance and renovation planning significantly depends on the uniformity of the results of the visual inspection, i.e., on the assessment of the type of damage [9]. After the visual inspection, assessments of the condition of the element are assigned, and are further incorporated into a unique assessment of the entire building [2]. Assessing the condition of structures can be defined as a process that determines how reliably a structure can take on current and future actions, while fulfilling the task of its existence in the planned time of use. Simple methods (such as reviewing documentation) are most commonly used for lower levels of assessment, while for higher levels of assessment it is necessary to reduce uncertainties by inspecting the structure and testing the material. As an option, wherever possible, it is better to choose non-destructive testing methods [15].

Different methodologies were proposed for the concrete and reinforced-concrete bridge condition assessment such as wireless sensor network monitoring system [16], a hierarchical evidential reasoning [17], technical and non-technical performance indicators to Bridge Quality Control [18], comparisons of different non-destructive testing techniques [19], multi-level approach to bridge condition assessment [20], Automatic Detection of Bridge Deck Condition [21], introduction of Priority Index to bridge evaluation [22], structural health monitoring of concrete bridges [23], Visual Inspection and Analytical Models of Bridge Deterioration [24], low cost condition assessment [25], Decision Support System [26], and multi-attribute decision-making for assessment of bridge quality [27,28].

\subsection{Expert Systems and Fuzzy Logic}

Expert systems (ES) are computer programs within a particular domain that involve a certain amount of artificial intelligence mimicking human thinking to reach the same conclusions as experts. The main goal of the ES is to provide expert advice in specific situations [29]. They are part of artificial intelligence, which is a broader research area that, in addition to ES, also includes natural language management systems and a computer perception system for sight, speech, and touch [30]. The advantage of ESs is that they can use incomplete and unreliable data in conclusions and contain explanations of their review process [31]. The knowledge base in the ES contains expert knowledge on a particular issue. It stores knowledge of a specific field and heuristic-based rules to minimize the complete search of the field of knowledge. Knowledge can be shaped by formal theories or normative models and is presented in the form of rules, semantic networks, frameworks, or cases [30].

Fuzzy logic was presented by Zadeh [32] and even then this approach attracted a lot of attention. Although for simpler systems fuzzy logic has proven to be very effective and adapted to human understanding. For more complicated systems, it has proven to be very 
demanding. Namely, there are situations in which knowledge about the system cannot be presented in an absolutely precise way. To present knowledge about such systems, one must reject the classical (binary) logic in which something is either true or false and use fuzzy logic. Classical set theory starts from the fact that some element $x$ from the observed (universal) set $X$ belongs or does not belong to a specific set $A$. A similar division exists in classical logic: a statement is true or false and the third possibility is excluded. Belonging is conditioned by the characteristic of the element, i.e., the condition that the element of the set $X$ must meet in order to belong to the set $A$. The theory of fuzzy sets introduces the membership function $\mu_{A}(x)$. This function shows how much $x \in X$ satisfies the condition of belonging to the set $A$. In classical theory it can have one of two values, 1 and 0 , i.e., the element belongs or does not belong to the set $A$. In the theory of fuzzy sets, the membership function can have any value between 0 and 1 . The value of $\mu_{A}(x)$ determines how much truth is in the statement that the element $x$ belongs to the set $A$, i.e., the element $x$ in a greater degree meets the conditions of belonging to the set $A$. For the membership function there is: $0 \leq \mu_{A}(x) \leq 1, \forall x \in A$, i.e., $\mu_{A}: X \rightarrow[0,1]$. A fuzzy set $A$ is defined as a set of ordered pairs: $A=\left\{\left(x, \mu_{A}(x)\right) \mid x \in X, 0 \leq \mu_{A}(x) \leq 1\right\}$. $X$ is a universal set or set of observations on which a fuzzy set $A$ is defined, and $\mu_{A}(x)$ is a function of the membership of an element $x$ to the set $A$. Each fuzzy set is completely and uniquely determined by its membership function.

Fuzzy logic is most commonly used to model complex systems in which, by applying other methods, it is very difficult to determine the interdependencies that exist between individual variables. It was also introduced in various studies of the assessment of concrete and reinforced-concrete bridge condition assessment [33-40]. Models based on fuzzy logic consist of "If-Then" rules. The "If-Then" rules are interrelated with the expression "Else". In the vast majority of cases, the input values are most often represented by a number, where the output value is also obtained in numerical form. On the other hand, in a fuzzy system, a given system is described linguistically (qualitatively) through given rules. Therefore, numerical values are first fuzzified in a certain way. Thereafter, the reasoning mechanism processes them in a fuzzy system through the phases of aggregation, activation, and accumulation [41]. The output value is obtained by the defuzzification process.

The aim of this research was to develop a knowledge-based expert system approach using fuzzy logic theoretical background and fuzzy weighted geometric mean (FWGM) to provide ratings of historic road bridges condition built until the end of the AustroHungarian Monarchy and located in Split-Dalmatia County (SDC). The FWGM approach has been used in different areas of science such as lean failure modes in manufacturing industries [42], comparison with others fuzzy weighted means [43,44], engine risk priority analysis [45], and risk evaluation of the NC machine tools [46].

The visual inspection, in this research, was used to collect data of bridge condition as an input for further process of newly developed expert system approach. Because of the uncertain, subjective, and vague nature of collected data, fuzzy logic showed out to be very useful and practical in obtaining the ratings of bridge condition assessment. As a result of the model a historic road bridge condition assessment index (HRBCAI) is proposed as a final rating of the bridges.

\section{Materials and Methods}

The purpose of assessing the condition of the bridge is to assess the mechanical resistance, stability, and safety at the time of the visual inspection of the bridge. The theory of fuzzy logic is often used in the field of construction engineering, and thus in the assessment of the condition of bridges. Fuzzy logic in combination with the Analytic Hierarchy Process (AHP) method is used to obtain a historic road bridge condition assessment index (HRBCAI). A modified form of fuzzy logic is given because the structural importance of the elements will also be analyzed in the methodology. The current method of assessing the condition of bridges (and exclusively concrete ones) by visual inspection has been done using either classical fuzzy logic or the fuzzy weighted average (FWA) approach. 
This paper will present the use of the FWGM approach, which has not been used so far in assessing the condition of bridges.

The fuzzy logic is briefly explained in Section 2.1 and therefore the methodology of the FWGM approach is described in more detail. For fuzzy logic, it is important to define if-then rules, which can be thousands (depending on the amount of input and output data) and for their correct definition it is important to have as much knowledge and experience as experts, and finances. The greater the number of rules, the more judgments the experts must make. Reducing the if-then rule can lead to a reduction in the required knowledge, and thus to inaccurate and incomplete conclusions. To avoid defining a large number of rules, and their reduction, it is recommended to use the FWGM approach [42]. Therefore, there is a clear need to develop a new approach of fuzzy logic in which there will be no need for lengthy expert examination. Below is a detailed description of the entire process of obtaining a bridge rating using FWGM, as well as an overview of the required mathematical models.

\subsection{Fuzzy Logic and Fuzzy Weighted Geometric Mean-Theoretical Background}

A fuzzy set is a set of elements in a universal set whose boundaries are ambiguous, vagueness, and uncertain. Each element of the set is assigned a membership function $\mu_{\widetilde{A}}(x)$, with the value within the interval $[0,1]$. The assigned value is called the degree of membership and it specifies the extent to which the element belongs to a particular fuzzy set. If the value is 0 , then the element does not belong to the set, and if it is 1 , then the element belongs entirely to the specified set. If the value "lies" within the interval $(0,1)$, the element partly belongs to the fuzzy set [33]. Therefore, each fuzzy set can be determined by a unique membership function. They can also be expressed as intervals called $\alpha$-cuts.

Definition 1. Let $\widetilde{A}$ be a fuzzy set within the universal set X. Then the $\alpha$-cuts of $\widetilde{A}$ are defined as:

$$
A_{\alpha}=\left\{x \in X \mid \mu_{\widetilde{A}}(x) \geq \alpha\right\}=\left[\min \left\{x \in X \mid \mu_{\widetilde{A}}(x) \geq \alpha\right\}, \max \left\{x \in X \mid \mu_{\widetilde{A}}(x) \geq \alpha\right\}\right]
$$

According to Zadeh's additional principle [30], the fuzzy set $\widetilde{A}$ can be represented as:

$$
\widetilde{A}=\cup_{\alpha} \alpha A_{\alpha}, \quad 0<\alpha \leq 1
$$

Fuzzy numbers are main segments of fuzzy sets. A fuzzy number is a convex fuzzy set described by a given interval of real numbers, each with a degree of membership between 0 and 1 . The membership functions of fuzzy numbers are partially continuous and satisfy the following conditions:

(1) $\mu_{\widetilde{A}}(x)=0$ for each $x \notin[a, c]$;

(2) $\mu_{\widetilde{A}}(x)$ is non-decreasing (monotonically increasing) on the interval $[a, b]$ and nonincreasing (monotonically decreasing) on the interval $[b, c]$;

(3) $\mu_{\widetilde{A}}(x)=1$ for each $x \in b$,

where $a \leq b \leq c$ are real numbers $\mathrm{R}=(-\infty,+\infty)$.

Hereby, triangular fuzzy numbers are used, whose membership functions is defined as:

$$
\mu_{\widetilde{A}}(x)=\left\{\begin{array}{lc}
(x-a) /(b-a), & a \leq x \leq b \\
(c-x) /(c-b), & b \leq x \leq c \\
0, & \text { other }
\end{array}\right.
$$

They are often written as $(a, b, c)$.

Definition 2. Let $\widetilde{A}=\left(a_{1}, a_{2}, a_{3}\right)$ and $\widetilde{B}=\left(b_{1}, b_{2}, b_{3}\right)$ be two positive triangular fuzzy numbers. Then the basic fuzzy operations are defined as [47]: 
Addition: $\widetilde{A}+\widetilde{B}=\left(a_{1}+b_{1}, a_{2}+b_{2}, a_{3}+b_{3}\right)$;

Subtraction: $\widetilde{A}-\widetilde{B}=\left(a_{1}-b_{3}, a_{2}-b_{2}, a_{3}-b_{1}\right)$;

Multiplication: $\widetilde{A} \times \widetilde{B} \approx\left(a_{1} b_{1}, a_{2} b_{2}, a_{3} b_{3}\right)$;

Division: $\widetilde{A} \div \widetilde{B} \approx\left(\frac{a_{1}}{b_{3}}, \frac{a_{2}}{b_{2}}, \frac{a_{3}}{b_{1}}\right)$.

Fuzzy numbers often have to be transformed into a crisp value for the comparison or ranking. Such a transformation process is called defuzzification, which can be carried out in several ways. The most commonly used defuzzification process is the centroid method, also known as the center of gravity or the center of the surface of the defuzzification. The centroid method defines a centroid of fuzzy number $\widetilde{A}$ as its defuzzified value, and according to [48] it is defined as follows:

$$
\overline{x_{0}}(\widetilde{A})=\frac{\int_{a}^{c} x \mu_{\widetilde{A}}(x) \mathrm{dx}}{\int_{a}^{c} \mu_{\widetilde{A}}(x) \mathrm{dx}}
$$

where $\overline{x_{0}}(\widetilde{A})$ is a defuzzified value. To defuzzify triangular fuzzy number $\widetilde{A}=(a, b, c)$ centroid expression is used as follows:

$$
\overline{x_{0}}(\widetilde{A})=\frac{a+b+c}{3}
$$

When fuzzy number $\widetilde{A}$ is presented by $\alpha$-cuts, i.e., $\widetilde{A}=\cup_{\alpha} \alpha \cdot A_{\alpha}=\cup_{\alpha} \alpha \cdot\left[\left(x_{L}\right)_{\alpha^{\prime}}\left(x_{U}\right)_{\alpha}\right]$, $(0<\alpha \leq 1)$, its defuzzifyed centroid form can be expressed as follows [49]:

$$
\begin{gathered}
\int_{a}^{c} \mu_{\widetilde{A}}(x) \mathrm{dx}=\frac{\left(x_{U}\right)_{\alpha_{0}}-\left(x_{L}\right)_{\alpha_{0}}}{2} \\
\int_{a}^{c} x \mu_{\widetilde{A}}(x) \mathrm{dx}=\frac{\left(x_{U}\right)_{\alpha_{0}}^{2}-\left(x_{L}\right)_{\alpha_{0}}^{2}+\left(x_{U}\right)_{\alpha_{i}} \cdot\left(x_{U}\right)_{\alpha_{i+1}}-\left(x_{L}\right)_{\alpha_{i}} \cdot\left(x_{L}\right)_{\alpha_{i+1}}}{6} \\
\bar{x}_{0}(\widetilde{A})=\frac{\left(x_{U}\right)_{\alpha_{0}}^{2}-\left(x_{L}\right)_{\alpha_{0}}^{2}+\left(x_{U}\right)_{\alpha_{i}} \cdot\left(x_{U}\right)_{\alpha_{n}}-\left(x_{L}\right)_{\alpha_{i}} \cdot\left(x_{L}\right)_{\alpha_{n}}}{3\left(\left(x_{U}\right)_{\alpha_{0}}-\left(x_{L}\right)_{\alpha_{0}}\right)}=\frac{\left(x_{U}\right)_{\alpha_{0}}+\left(x_{U}\right)_{\alpha_{n}}+\left(x_{L}\right)_{\alpha_{0}}}{3}
\end{gathered}
$$

Expression (8) represents the defuzzzification by the centroid method for a triangular fuzzy number. The average weight of $n$ fuzzy numbers has so far been obtained using the fuzzy weighted average (FWA) when assessing the condition of concrete bridges [33]. To assess the condition of historic road bridges, the FWGM approach will be used for $n$ fuzzy numbers expressed as follows:

$$
\begin{aligned}
& \widetilde{y_{G}}=f_{G}\left(\widetilde{x_{1}}, \ldots, \widetilde{x_{n}} ; \widetilde{w_{1}}, \ldots, \widetilde{w_{n}}\right)
\end{aligned}
$$

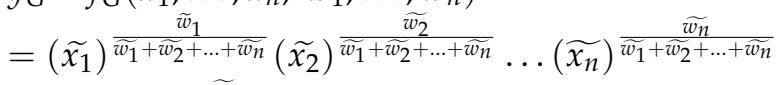

$$
\begin{aligned}
& =\prod_{i=1}^{n}\left(\widetilde{x}_{i}\right)^{\frac{\widetilde{w}_{i=1}^{n}}{\sum_{i=1}^{n}}}
\end{aligned}
$$

where $\widetilde{x_{1}}, \ldots, \widetilde{x_{n}} n$ are positive fuzzy numbers, and $\widetilde{w_{1}}, \ldots, \widetilde{w_{n}}$ are their fuzzy weights. It is obvious that $\widetilde{y_{G}}$ is also fuzzy number and it can be calculated using $\alpha$ - cuts and Zadeh's additional principle.

Let $\left(y_{G}\right)_{\alpha}=\left[\left(y_{L}\right)_{\alpha^{\prime}}\left(y_{U}\right)_{\alpha}\right]$, where $\alpha$-cut is a set of $\widetilde{y_{G}}$, then lower and upper value of set can be determined according to following mathematical models:

$$
\begin{gathered}
\left(y_{L}\right)_{\alpha}=\operatorname{Min} \prod_{i=1}^{n}\left(x_{i}\right)^{\frac{w_{i}}{\sum_{i=1}^{n} w_{i}}} \\
{\left[\left(w_{L}\right)_{i}\right]_{\alpha} \leq w_{i} \leq\left[\left(w_{U}\right)_{i}\right]_{\alpha^{\prime}} \quad i=1, \ldots, n} \\
{\left[\left(x_{L}\right)_{i}\right]_{\alpha} \leq x_{i} \leq\left[\left(x_{U}\right)_{i}\right]_{\alpha^{\prime}} \quad i=1, \ldots, n}
\end{gathered}
$$




$$
\begin{gathered}
\left(y_{U}\right)_{\alpha}=\operatorname{Max} \prod_{i=1}^{n}\left(x_{i}\right)^{\frac{w_{i}}{\sum_{i=1}^{n} w_{i}}} \\
{\left[\left(w_{L}\right)_{i}\right]_{\alpha} \leq w_{i} \leq\left[\left(w_{U}\right)_{i}\right]_{\alpha^{\prime}} \quad i=1, \ldots, n} \\
{\left[\left(x_{L}\right)_{i}\right]_{\alpha} \leq x_{i} \leq\left[\left(x_{U}\right)_{i}\right]_{\alpha^{\prime}} \quad i=1, \ldots, n}
\end{gathered}
$$

Considering that:

$$
f_{G}\left(x_{1}, \ldots, x_{n} ; w_{1}, \ldots, w_{n}\right)=\prod_{i=1}^{n}\left(x_{i}\right)^{\frac{i_{i}}{\sum_{i=1}^{n} w_{i}}}
$$

is increasing function of variables $x_{i}(i=1, \ldots, n)$, the above mathematical models can therefore be expressed as:

$$
\begin{aligned}
\left(y_{L}\right)_{\alpha} & =\operatorname{Min} \exp \left(\frac{\sum_{i=1}^{n} w_{i} \ln \left[\left(x_{L}\right)_{i}\right]_{\alpha}}{\sum_{i=1}^{n} w_{i}}\right) \\
{\left[\left(w_{L}\right)_{i}\right]_{\alpha} } & \leq w_{i} \leq\left[\left(w_{U}\right)_{i}\right]_{\alpha^{\prime}} \quad i=1, \ldots, n \\
\left(y_{U}\right)_{\alpha} & =\operatorname{Max} \exp \left(\frac{\sum_{i=1}^{n} w_{i} \ln \left[\left(x_{U}\right)_{i}\right]_{\alpha}}{\sum_{i=1}^{n} w_{i}}\right) \\
{\left[\left(w_{L}\right)_{i}\right]_{\alpha} } & \leq w_{i} \leq\left[\left(w_{U}\right)_{i}\right]_{\alpha^{\prime}} \quad i=1, \ldots, n
\end{aligned}
$$

where $\exp ()$ is an exponential function.

Let $z=\frac{1}{\sum_{i=1}^{n} w_{i}}$ and $u_{i}=z w_{i}$ for $i=1, \ldots, n$, models (13) and (14) can be transformed into:

$$
\begin{gathered}
\operatorname{Min} z_{1}=\sum_{i=1}^{n} u_{i} \ln \left[\left(x_{L}\right)_{i}\right]_{\alpha} \\
u_{1}+u_{2}+\ldots+u_{n}=1 \\
{\left[\left(w_{L}\right)_{i}\right]_{\alpha} \cdot z \leq u_{i} \leq\left[\left(w_{U}\right)_{i}\right]_{\alpha} \cdot z, \quad i=1, \ldots, n} \\
z \geq 0 \\
\operatorname{Max} z_{2}=\sum_{i=1}^{n} u_{i} \ln \left[\left(x_{U}\right)_{i}\right]_{\alpha} \\
u_{1}+u_{2}+\ldots+u_{n}=1 \\
{\left[\left(w_{L}\right)_{i}\right]_{\alpha} \cdot z \leq u_{i} \leq\left[\left(w_{U}\right)_{i}\right]_{\alpha} \cdot z, \quad i=1, \ldots, n} \\
z \geq 0
\end{gathered}
$$

Models (15) and (16) are calculated using linear modelling which was easily conducted in Matlab.

Let $z_{1}^{*} \mathrm{i} z_{2}^{*}$ be optimal objective values of models (15) and (16), than $\left(y_{L}\right)_{\alpha}=\exp \left(z_{1}^{*}\right)$ and $\left(y_{U}\right)_{\alpha}=\exp \left(z_{2}^{*}\right)$. By defining different $\alpha$-cuts, different sets of $\alpha$-cuts for $\widetilde{y_{G}}$ can be generalized based on which $\widetilde{y_{G}}$ can be expressed as follows:

$$
\widetilde{y_{G}}=\cup_{\alpha} \alpha \cdot\left(y_{G}\right)_{\alpha}=\cup_{\alpha} \alpha\left[\left(y_{L}\right)_{\alpha},\left(y_{U}\right)_{\alpha}\right], \quad 0<\alpha \leq 1
$$

Suppose a bridge component has $n$ elements, $E L_{i}(i=1, \ldots, n)$, and each element is undergoing under visual evaluation of an expert. Let $\widetilde{R}_{E L_{i}}=\left(\left(R_{E L_{i}}\right)_{L^{\prime}}\left(R_{E L_{i}}\right)_{M^{\prime}}\left(R_{E L_{i}}\right)_{U}\right)$ be a fuzzy grade of $i$-th element, and $\widetilde{w}_{E L_{i j}}=\left(\left(w_{E L_{i}}\right)_{L^{\prime}}\left(w_{E L_{i}}\right)_{M^{\prime}}\left(w_{E L_{i}}\right)_{U}\right) j=1, \ldots, n$, is a fuzzy weight of $i$-th element by $j$-th expert, according to defined fuzzy grade of the element. $L$ is lower boundary of set, $M$ is middle value and $U$ is upper boundary of set. Based on the assumptions, grades of bridge components (superstructure, substructure, and equipment) can be defined using the following steps.

\subsection{Proposed Model to Historic Road Bridge Condition Rating}

Hereby, the model to historic road bridge condition rating is explained in ten steps, and its illustrative presentation is given in Figure 1. 


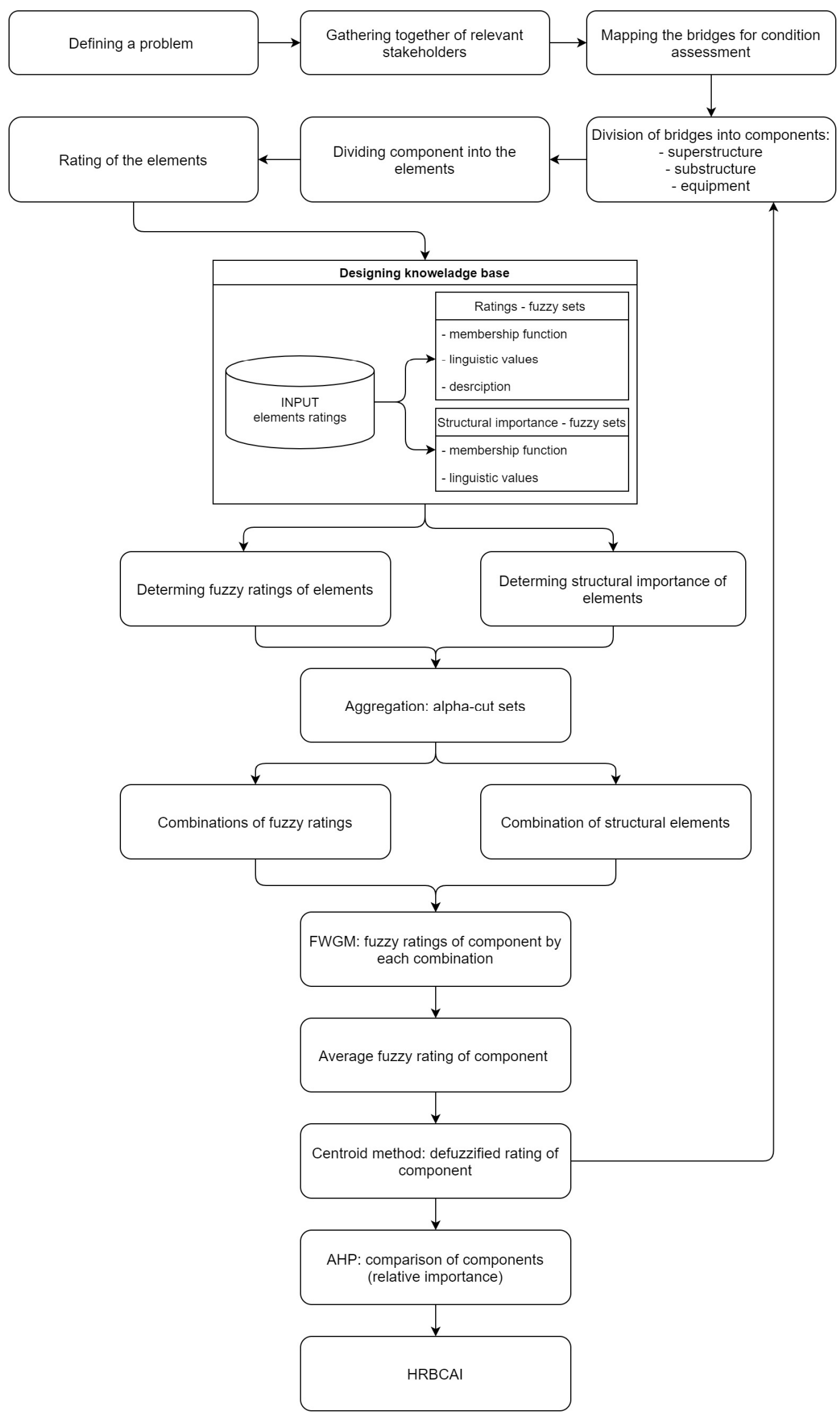

Figure 1. Model to historic road bridge condition rating. 
Step 1. Assigning a crisp grade to elements ranging from 0 to 100 .

The grading of bridge condition is set by the structural expert. Given the subjectivity that occurs when assessing the condition of the bridge, in order to achieve accuracy and objectivity, division into 11 fuzzy sets is proposed. According to the defined rating, the fuzzy sets within which the rating is located are singled out as follows:

Definition 3. Let crisp value of grade $x$ be a part of set $S=\{10,20,30,40,50,60,70,80,90\}$, then for each $x \in S$ there is: $\left(\widetilde{R}_{E L_{i}}\right)_{k}=\left(\left(\left(R_{E L_{i}}\right)_{k}\right)_{L^{\prime}}\left(\left(R_{E L_{i}}\right)_{k}\right)_{M^{\prime}}\left(\left(R_{E L_{i}}\right)_{k}\right)_{U}\right), k=1,2$ and 3; $i=1, \ldots, n$, where $\left(\widetilde{R}_{E L_{i}}\right)_{k^{\prime}}{ }^{\prime}$-th fuzzy set of $i$-th element. For each $x \notin S$, there is:

$$
\left(\widetilde{R}_{E L_{i}}\right)_{k}=\left(\left(\left(R_{E L_{i}}\right)_{k}\right)_{L^{\prime}}\left(\left(R_{E L_{i}}\right)_{k}\right)_{M^{\prime}}\left(\left(R_{E L_{i}}\right)_{k}\right)_{U}\right), k=1 \text { and } 2 ; i=1, \ldots, n \text {. }
$$

Demonstrated fuzzy sets present all possible conditions of elements according to the expert's grade.

Step 2. Assigning structural importance to elements with respect to all possible conditions given according to determined crisp grade.

Importance are assigned by experts as follows:

$$
\left(\widetilde{w}_{E L_{i}}\right)_{j}=\left(\frac{1}{n} \sum_{j=1}^{n}\left(\left(w_{E L_{i}}\right)_{j}\right)_{L^{\prime}} \frac{1}{n} \sum_{j=1}^{n}\left(\left(w_{E L_{i}}\right)_{j}\right)_{M^{\prime}} \frac{1}{n} \sum_{j=1}^{n}\left(\left(w_{E L_{i}}\right)_{j}\right)_{U}\right), i=1, \ldots, n,
$$

where $\left(\widetilde{w}_{E L_{i}}\right)_{j}$ is a structural importance of $i$-th element given by $j$-th expert.

Step 3. Determining the total number of combinations of all elements in all graded conditions defined by crisp values:

$$
N_{k o m b}=\prod_{i=1}^{n}\left(\left(\widetilde{R}_{E L_{i}}\right)_{k^{\prime}}\left(\widetilde{w}_{E L_{i}}\right)_{j}\right)
$$

Step 4. Determining the fuzzy grade of component by all combinations as follows:

$$
\left(\widetilde{R}_{K O M P}\right)_{l}=\prod_{i=1}^{n}\left(\widetilde{R}_{E L_{i}}\right)_{k}^{\frac{\left(\widetilde{w}_{\left.E L_{i}\right)_{j}}\right.}{\sum_{j=1}^{n}\left(\widetilde{w}_{\left.E L_{i}\right)_{j}}\right.}}
$$

To calculate the resultant fuzzy grade of component $\left(\widetilde{R}_{K O M P}\right)_{l}$, the FWGM approach is used, defined by (19). Given the values of $\left(\widetilde{R}_{K O M P}\right)_{l}$ are fuzzy numbers, they can be easily calculated using $\alpha$ - cuts.

Step 5. Determining $\alpha$ - cuts for fuzzy values of grades of component by all combinations using linear programing model as follows:

$$
\begin{gathered}
\operatorname{Min} z_{1}=u_{1} \ln \left(\left(R_{E L_{1}}\right)_{\alpha}\right)_{L}+u_{2} \ln \left(\left(R_{E L_{2}}\right)_{\alpha}\right)_{L}+\ldots+u_{n} \ln \left(\left(R_{E L_{n}}\right)_{\alpha}\right)_{L} \\
u_{1}+u_{2}+\ldots+u_{n}=1 \\
\left(\left(w_{E L_{1}}\right)_{\alpha}\right)_{L} \cdot z \leq u_{1} \leq\left(\left(w_{E L_{1}}\right)_{\alpha}\right)_{U} \cdot z \\
\left(\left(w_{E L_{2}}\right)_{\alpha}\right)_{L} \cdot z \leq u_{2} \leq\left(\left(w_{E L_{2}}\right)_{\alpha}\right)_{U} \cdot z \\
\vdots \\
\left(\left(w_{E L_{n}}\right)_{\alpha}\right)_{L} \cdot z \leq u_{n} \leq\left(\left(w_{E L_{n}}\right)_{\alpha}\right)_{U} \cdot z \\
z \geq 0
\end{gathered}
$$




$$
\begin{gathered}
\operatorname{Max} z_{2}=u_{1} \ln \left(\left(R_{E L_{1}}\right)_{\alpha}\right)_{U}+u_{2} \ln \left(\left(R_{E L_{2}}\right)_{\alpha}\right)_{U}+\ldots+u_{n} \ln \left(\left(R_{E L_{n}}\right)_{\alpha}\right)_{U} \\
u_{1}+u_{2}+\ldots+u_{n}=1 \\
\left(\left(w_{E L_{1}}\right)_{\alpha}\right)_{L} \cdot z \leq u_{1} \leq\left(\left(w_{E L_{1}}\right)_{\alpha}\right)_{U} \cdot z \\
\left(\left(w_{E L_{2}}\right)_{\alpha}\right)_{L} \cdot z \leq u_{2} \leq\left(\left(w_{E L_{2}}\right)_{\alpha}\right)_{U} \cdot z \\
\vdots \\
\left(\left(w_{E L_{n}}\right)_{\alpha}\right)_{L} \cdot z \leq u_{n} \leq\left(\left(w_{E L_{n}}\right)_{\alpha}\right)_{U} \cdot z \\
z \geq 0
\end{gathered}
$$

where $\left[\ln \left(\left(R_{E L_{1}}\right)_{\alpha}\right)_{L^{\prime}}, \ln \left(\left(R_{E L_{1}}\right)_{\alpha}\right)_{U}\right], \ldots,\left[\ln \left(\left(R_{E L_{n}}\right)_{\alpha}\right)_{L^{\prime}} \ln \left(\left(R_{E L_{n}}\right)_{\alpha}\right)_{U}\right]$ are logarithmic values of $\left[\left(\left(R_{E L_{i}}\right)_{\alpha}\right)_{L^{\prime}}\left(\left(R_{E L_{i}}\right)_{\alpha}\right)_{U}\right], i=1, \ldots, n$, which represent sets of $\alpha$ - cuts for fuzzy values of elements ratings by all combinations, and $\left[\left(\left(w_{E L_{1}}\right)_{\alpha}\right)_{L^{\prime}}\left(\left(w_{E L_{1}}\right)_{\alpha}\right)_{U}\right], \ldots$, $\left[\left(\left(w_{E L_{n}}\right)_{\alpha}\right)_{L^{\prime}}\left(\left(w_{E L_{n}}\right)_{\alpha}\right)_{U}\right]$ are sets of $\alpha$-cuts for fuzzy values of structural importance of elements. Above mentioned models of linear programming are applications of models (15) and (16) for fuzzy value of grade of component according to all combinations for all $\alpha$-cuts.

Step 6. Let $z_{1}^{*} \mathrm{i} z_{2}^{*}$ be optimal objective values of models (20) and (21), respectively, then $\left(\left(R_{K O M P_{l}}\right)_{\alpha}\right)_{L}=\exp \left(z_{1}^{*}\right)$ and $\left(\left(R_{K O M P_{l}}\right)_{\alpha}\right)_{U}=\exp \left(z_{2}^{*}\right)$, where $R_{K O M P_{l}}$ is fuzzy grade of component by all combinations. Different sets of $\alpha$-cuts for $R_{K O M P_{l}}$ can be generalized and according to them $R_{K O M P_{l}}$ can be expressed as follows:

$$
R_{\text {KOMP }}=\cup_{\alpha} \alpha \cdot\left[\left(\left(R_{K O M P_{l}}\right)_{\alpha}\right)_{L^{\prime}}\left(\left(R_{K O M P_{l}}\right)_{\alpha}\right)_{U}\right], 0<\alpha \leq 1
$$

Step 7. Determining the average value of all combinations of component fuzzy grade according to the calculated $\alpha$-cuts as follows:

$$
R_{\text {KOMP }}=\frac{1}{n} \sum_{l=1}^{n}\left[\left(\left(R_{K O M P_{l}}\right)_{\alpha}\right)_{L^{\prime}}\left(\left(R_{K O M P_{l}}\right)_{\alpha}\right)_{U}\right]
$$

Step 8 . Defuzzification of fuzzy grade of component $R_{K O M P}$ by centroid method.

$$
\bar{x}_{0}(\widetilde{A})=\frac{1}{3}\left(\left(x_{U}\right)_{\alpha_{0}}+\left(x_{U}\right)_{\alpha_{n}}+\left(x_{L}\right)_{\alpha_{0}}\right)
$$

Since $R_{K O M P}$ is expressed by sets of $\alpha$-cuts, its defuzzified centroid can be obtained by (6). In the special case, when the interval $[0,1]$ is divided into equal parts by different $\alpha$-cuts, the defuzzified centroid can be determined using Equations (7) and (8).

Step 9. Determining relative importance of bridge components.

After the defuzzified grades of components have been calculated, the relative importance (weight) of the components is assigned by the AHP method. Using the Saaty's scale [50] to compare bridge components (superstructure, substructure, and equipment), weights of component are obtained. In the upper triangle of the comparison matrix, also known as real continuous pairwise (RCP), the values of weights are entered, and their reciprocal values are in the lower triangle, as shown in the following matrix:

$$
R C P=\left[\begin{array}{ccccc}
A_{11} & A_{12} & A_{13} & \ldots & A_{1 n} \\
A_{21} & A_{22} & A_{23} & \ldots & A_{2 n} \\
A_{31} & A_{32} & A_{33} & \ldots & A_{3 n} \\
\ldots & \ldots & \ldots & \ldots & \ldots \\
A_{n 1} & A_{n 2} & A_{n 3} & \ldots & A_{n n}
\end{array}\right]
$$

The values on the diagonal are always one. Assuming that the group of elements $A$ consists of $A_{1}, A_{2}, \ldots, A_{n}$, a comparison matrix can be constructed and the relative 
importance of the elements $\left(A_{i j}\right)$ is obtained by comparing the element $i$ with the element $j$. The relationship $\alpha_{i j}$ and the comparison matrix of the order $p \times p$ can be represented as [51]:

$$
A_{p \times p}=\left[\alpha_{i j}\right]=\left[\frac{w_{i}}{w_{j}}\right], i, j=1, p
$$

Each data of matrix $[A]$ represents an expert judgment by comparison. The consistency of the matrix $[A]$ satisfies the condition:

$$
A_{i j}=A_{i k} A_{k j} \quad i, j, k=1,2, \ldots, n
$$

The consistency of matrix has rank 1 with an eigenvector $(\lambda)=n$. Then there is:

$$
[A]\langle w\rangle=n\langle w\rangle
$$

where $w$ is eigenvector.

In most cases, element comparisons are not ideal, i.e., the comparison matrix does not always have to achieve consistency. Expression (28) does not have to be satisfied for all possible assigned weights. The maximum eigenvalue of the matrix is close to $n$ (number of elements), while the other values are close to 0 . Therefore, in inconsistent cases it is necessary to determine the eigenvector corresponding to the largest eigenvalue $\lambda_{\max }$, i.e., the eigenvector $w$ must be defined to satisfy the following:

$$
A\langle w\rangle=\lambda_{\max }\langle w\rangle
$$

where $\lambda_{\max } \approx n$.

The consistency of the matrix is achieved if the value of the consistency ratio (CR) is less than or equal to 0.1 . The $C R$ is obtained by dividing the consistency index $(\mathrm{CI})$ by the random consistency index (RCI) proposed by Saaty [50]. The CI is obtained by calculating $\lambda_{\max }$. Saaty [50] defines the consistency index of the matrix $[A]$ as:

$$
\mathrm{CI}=\frac{\lambda_{\max }-n}{n-1}
$$

Step 10. Defining Historic Road Bridge Condition Assessment Index (HRBCAI).

The obtained weights are multiplied by the defuzzified values of the component ratings in order to obtain the final rating of the historic road bridge, i.e., to calculate Historic Road Bridge Condition Index (HRBCI) as follows:

$$
\mathrm{IPSPCM}=R_{S P} * w_{S P}+R_{S B} * w_{S B}+R_{E Q} * w_{E Q}
$$

where $R_{S P}, R_{S B}$, and $R_{E Q}$ are ratings of bridge components calculated by defuzzification, and $w_{S P}, w_{S B}$, and $w_{E Q}$ are relative importance of components.

The model of assessing the condition of historic road bridges serves to solve poorly structured tasks at the strategic level of historic road bridges reconstruction planning. The result of the model is the Historic Road Bridge Condition Assessment Index (HRBCAI), which will also be a criterion in the future study needed to rank historic road bridges according to the priority for the reconstruction activity. This index is based on the Bridge Condition Index (BCI) defined by [5] in his dissertation. The BCI index was used to assess the condition of concrete modern bridges. However, the methodology for obtaining the HRBCI has been improved from that outlined for obtaining the BCI, which will be discussed later.

Bridges, as key components of the road, degrade over time due to traffic congestion, environmental impact, fatigue, etc. Historic road bridges in the area of SDC "suffer" loads that are not foreseen in the design process. Therefore, it is necessary to approach a thorough review and analyze their condition. To ensure continued safety and stability of 
bridges, periodic field inspections involving visual assessment, non-destructive or partially destructive testing should be performed. Field inspections could decide on the selection of necessary activities such as repairs, renovations, reinforcements, or, if necessary, removal of the bridge, all concerning their condition at the time of the inspection. Bridge managers are required to draw up plans for financing such activities. The development of such plans requires a rational and sustainable approach to organizing and implementing activities related to the planning, design, construction, maintenance, reconstruction, and replacement of bridges. To make a valid decision on all these activities, a sustainable and logical way of assessing the condition of bridges is needed. Assessing the condition of a bridge is very important for any bridge management system. They are based on data that represent the subjective judgment and opinion of a bridge expert. Therefore, the procedure as fuzzy logic can be useful to address vagueness and uncertain judgment. The flow diagram of the condition assessment model of historic road bridges is presented in Figure 1. The realization of the model begins with the formation of the expert group consisting of a bridge expert and five experts from other areas of structural engineering. Exclusively visual assessment is used to assess the condition of these bridges. Assessment starts from the elements of bridges (arches, front walls, abutments, pillars, fences, curtains, ... ) which are given crisp values of the assessment grade. Before assigning grades to elements, fuzzy sets of grades and structural importance as well as their membership functions are defined. More specifically, estimates of bridges and structural importance are fuzzified. The ratings of the elements are assigned by the bridge expert, and based on his assessment, the other five experts from other areas of structural engineering define the structural importance using determined fuzzy sets. After the assigned fuzzy ratings and structural importance, the fuzzy ratings of the components (superstructure, substructure, and equipment) are calculated, and furthermore, they are defuzzified by the centroid method. The defuzzified grades of the components are then compared with each other using the principles of the AHP method and the Saaty comparison scale. The results of the comparison are of relative importance. Multiplying the relative importance and the rating of component, and then adding up the products gives an estimate of the condition of the bridge, i.e., the value of the HRBCAI.

Structural importance determines the negative importance element has on the condition of a component concerning the element rating relative to the rating of other elements. Since the elements are given crisp values of grades, it is necessary to find fuzzy sets that the given grade belongs to. For this reason, all conditions in which the element can be according to a given grade are determined. This way, combinations of all elements in all conditions are created and each of the combination gains average structural importance. The average structural importance is obtained by summing the importance of construction experts and dividing by the total number of experts. Once the ratings and importance of the elements have been defined, their aggregation is approached, which further uses the fuzzy weighted geometric mean (FWGM) approach to obtain a bridge component fuzzy grade for all combinations. Given its fuzzy value, $\alpha$-cuts are defined which determine the upper and lower values of fuzzy sets of component evaluation. The average value of the upper and lower boundary is then calculated and a crisp evaluation of the bridge component is determined by the defuzzification process using the centroid method. The process is repeated until all components receive their crisp grade. After that, using the multicriteria AHP method, the importance (weights) are defined for each component. Using the Saaty scale, the components are compared with each other, followed by normalization of the assigned weights and checking the consistency of the comparison matrix. If the matrix is consistent, the defined weights are adopted and the calculation of the condition of the bridge is calculated. The bridge condition assessment is defined as the HRBCAI and is calculated by multiplying the obtained component ratings by the assigned weights and summing them together. 


\section{Results}

To rank historic road bridges according to the priority for reconstruction activity, it is necessary to determine the condition of the bridges at the time of inspection, which examines the mechanical stability and resistance, but also safety for vehicles and pedestrians. The condition of the bridge can be assessed by visual inspection or in-situ testing which can be destructive or non-destructive. For this research, i.e., to assess the condition of historic road bridges, the only visual expert assessment was conducted. First, the scope of the test had to be defined. So, the assessment started from the elements to obtain the rating of the bridge components, and then the overall rating of each bridge, which is also the result of the proposed model (HRBCAI). Each bridge is subdivided into three components: superstructure, substructure, and equipment. How many elements each component has depends on the bridge. However, as these are massive stone bridges, they are characterized by arched construction, so the elements were observed for the superstructure: arches and spandrel walls, for the substructure: piers and abutments, and for equipment: pavement, fence, drainage, and lighting. In Table 1 the total number of elements of each component is given. The spandrel walls are observed in groups. The bridge expert gave the ratings to the elements based on a visual inspection. Structural importance was then assigned by five construction experts based on element ratings. Although these are very experienced experts with rich knowledge and expertise, their opinions (assessments and structural importance) can sometimes be subjective and thus give uncertain and inaccurate estimates. Therefore, as a solution to such a problem, fuzzy logic is imposed, which has been discussed more in the previous subchapter. The beginning of any fuzzy logic starts with defining fuzzy sets. Thus, the experts agreed to take values of ratings from 0 to 100 for the evaluation of the element and distribute their vagueness in 11 sets, to achieve the most accurate evaluation of the component, and finally to obtain a precise rating of the bridge. To each set, a membership function is assigned. The same is done for structural importance which is divided into 5 sets, from 0 to 1 . Each defined fuzzy set has linguistic value. The ratings of the elements were assigned a crisp value to single out the fuzzy sets to which that rating belongs. Each singled out the fuzzy set was assigned fuzzy structural importance. Five experts assigned importance to elements using defined fuzzy sets of structural importance. The average value of the experts' assigned structural importance is used for further calculation. In Tables 2 and 3, sets with linguistic values of ratings and structural importance are shown, respectively. Figures 2 and 3 show the assigned membership functions for fuzzy sets of element ratings and structural importance, respectively. The experts opted for a triangular membership function to describe the sets for ratings and the importance of the elements. The experts found the triangular membership function more useful because of the narrow peak of the absolute membership, unlike the trapezoidal membership function where the peak (absolute membership) is presented through the interval.

The bridge Blato on the river Cetina has no arches and front walls, but its superstructure is composed of longitudinal and transverse girders and a deck. It is a similar situation with the Bridge on the river Grab, which contains arches and spandrel walls, and a deck, while the Bridge at the entrance to the "Majdan" factory, cross beams, and a deck.

Furthermore, the defined fuzzy numbers and their belonging linguistic values for the structural importance of elements are given in Table 3. Experts decided to define them in the range from 0 to 1 .

As already mentioned, since triangular fuzzy sets are defined, each set is assigned a triangular membership function for grades and structural importance. In Figures 2 and 3 the listed membership functions are shown, where the abscissa axis contains membership functions for fuzzy sets of ratings and structural importance, respectively, and the ordinate axis shows the degree of membership, i.e., the membership of the assigned rating and structural importance, respectively, to each set. The entire calculation for obtaining the component rating was made with the help of Matlab. As the procedure for obtaining the rating of each component, and finally the rating of the bridge, is very comprehensive, the detailed calculation for all bridges is not given, but only the final ratings are presented. 
Hereby, the whole model calculation is presented on the bridge at river Jaruga near Mračaj in Imotski filed, labeled B10.

In the group of photographs in Figure 4, the bridge at the river Jaruga near Mračaj in Imotski filed is shown, where damage to the bridge can be easily observed, such as dense vegetation and seepage, cracks in the bridge elements, landslides and falling off parts of the elements. In Figure 5 the elements of the assessment bridge are marked, provided that the group of spandrel walls 2 is not visible because it is on the other (east) side of the bridge.

Table 1. Historic road bridges with a total number of elements per component.

\begin{tabular}{|c|c|c|c|c|c|c|}
\hline \multirow[b]{2}{*}{$\begin{array}{l}\text { Bridge } \\
\text { Label }\end{array}$} & \multirow[b]{2}{*}{ Name of the Bridge } & \multicolumn{2}{|c|}{ Superstructure } & \multicolumn{2}{|c|}{ Substructure } & \multirow{2}{*}{$\begin{array}{c}\text { Equipment } \\
\begin{array}{c}\text { Fence, Lightening, Pavement } \\
\text { and Drainage }\end{array}\end{array}$} \\
\hline & & Arches & $\begin{array}{l}\text { Spandrel } \\
\text { Walls }\end{array}$ & Piers & Abutments & \\
\hline B1 & Jovića bridge & 4 & 2 & 3 & 2 & 3 \\
\hline B2 & Bridge over the river Matica & 6 & 2 & 5 & 2 & 2 \\
\hline B3 & Bridge in Rastoke & 4 & 2 & 3 & 2 & 3 \\
\hline B4 & Bridge Brvina on the river Vrljika & 4 & 2 & 3 & 2 & 3 \\
\hline B5 & Bridge on Bublin on the river Vrljika & 6 & 2 & 5 & 2 & 3 \\
\hline B6 & Zmijavački bridge on the river Vrljika & 6 & 2 & 5 & 2 & 3 \\
\hline B7 & $\begin{array}{l}\text { Bridge on the stream } \\
\text { Suvaja/Karalipeov bridge }\end{array}$ & 4 & 2 & 3 & 2 & 3 \\
\hline B8 & Bridge Šumet over the channel Jaruga & 3 & 2 & 2 & 2 & 3 \\
\hline B9 & Bridge Jasenovac on the river Jaruga & 3 & 2 & 2 & 2 & 3 \\
\hline B10 & $\begin{array}{l}\text { Bridge on the river Jaruga nearby } \\
\text { Mračaj in Imotski field. }\end{array}$ & 2 & 2 & 1 & 2 & 3 \\
\hline B11 & Bridge at the quarry "Lavčević" & 3 & 2 & 2 & 2 & 4 \\
\hline B12 & Žrnovački bridge & 4 & 2 & 3 & 2 & 4 \\
\hline B13 & Bridge over the river Jadro & 5 & 2 & 4 & 2 & 4 \\
\hline B14 & $\begin{array}{l}\text { Bridge at the entrance to the factory } \\
\text { "Majdan" }\end{array}$ & 3 & 2 & 2 & 2 & 3 \\
\hline B15 & Rera/Vetmin bridge & 6 & 2 & 5 & 2 & 3 \\
\hline B16 & Bridge on the river Grab & 5 & 2 & 4 & 2 & 4 \\
\hline B17 & Bridge on the river Kosinac & 12 & 2 & 11 & 2 & 3 \\
\hline B18 & Bridge Blato on the river Cetina & 0 & 0 & 4 & 2 & 4 \\
\hline B19 & Pavića bridge & 7 & 2 & 6 & 2 & 4 \\
\hline $\mathrm{B} 20$ & Bridge on Panj & 8 & 2 & 6 & 2 & 4 \\
\hline B21 & Balečki bridge & 3 & 2 & 2 & 2 & 4 \\
\hline
\end{tabular}

Table 2. Fuzzy sets of element ratings with linguistic values and description.

\begin{tabular}{ccc}
\hline Fuzzy Set & $\begin{array}{c}\text { Linguistic } \\
\text { Value }\end{array}$ & Description \\
\hline$(0,0,10)$ & $\begin{array}{c}\text { Extreme } \\
\text { bad }\end{array}$ & $\begin{array}{r}\text { The bridge is in extremely poor condition. Parts of the element are eroded or fallen off, cracks of } \\
\text { maximum width along the entire element, abundant vegetation and seepage. }\end{array}$ \\
\hline$(0,10,20)$ & Very bad & $\begin{array}{r}\text { Cracks of maximum width can be seen on the elements of the bridge, parts of the elements (blocks) } \\
\text { are damaged or partially fallen off. Dense vegetation and seepage. }\end{array}$ \\
\hline$(10,20,30)$ & Quite bad & $\begin{array}{r}\text { The elements of the bridge contain cracks of maximum to medium width, as well as parts of the } \\
\text { elements (blocks). Vegetation and percolation are of considerable intensity. }\end{array}$ \\
\hline
\end{tabular}


Table 2. Cont.

\begin{tabular}{ccc}
\hline Fuzzy Set & $\begin{array}{c}\text { Linguistic } \\
\text { Value }\end{array}$ & Description \\
\hline$(20,30,40)$ & Bad & The bridge is in poor condition, several cracks of medium width along the elements, vegetation and \\
seepage are very well visible.
\end{tabular}

Table 3. Fuzzy sets of structural importance of elements with linguistic values.

\begin{tabular}{cc}
\hline Fuzzy Set & Linguistic Value \\
\hline$(0,0,0,25)$ & Extreme bad \\
\hline$(0,0.25,0.5)$ & Very bad \\
\hline$(0.25,0.5,0.75)$ & Bad \\
\hline$(0.5,0.75,1)$ & Medium good \\
\hline$(0.75,1,1)$ & Good \\
\hline
\end{tabular}

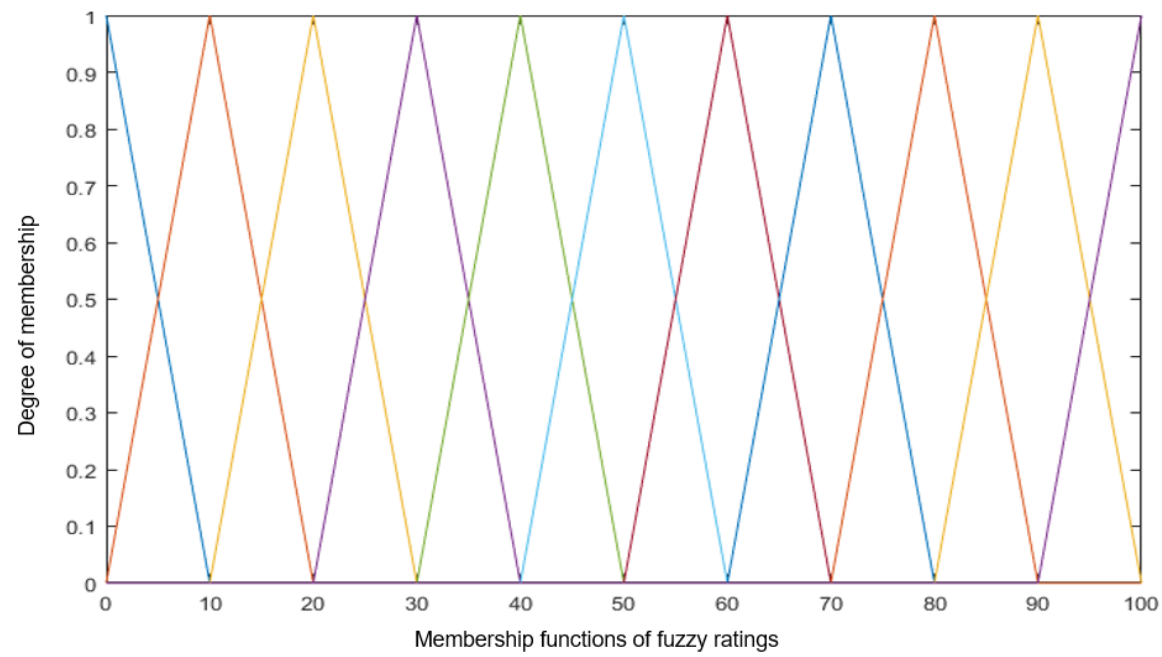

Figure 2. Membership functions of fuzzy sets of elements ratings. 


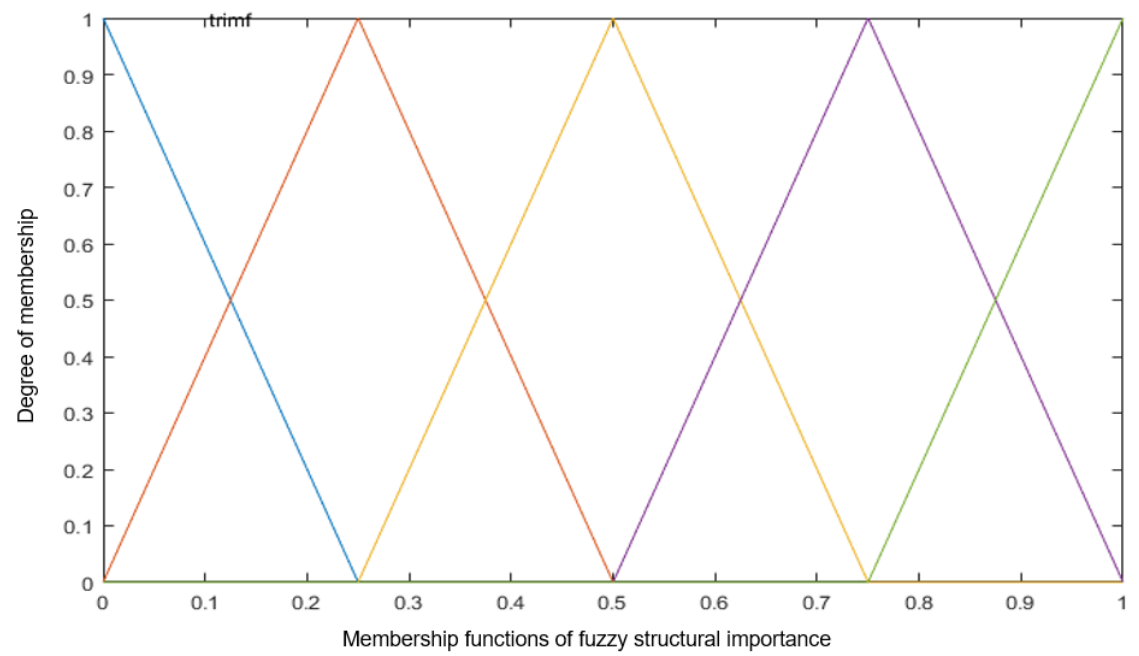

Figure 3. Membership functions of fuzzy sets of elements structural importance.
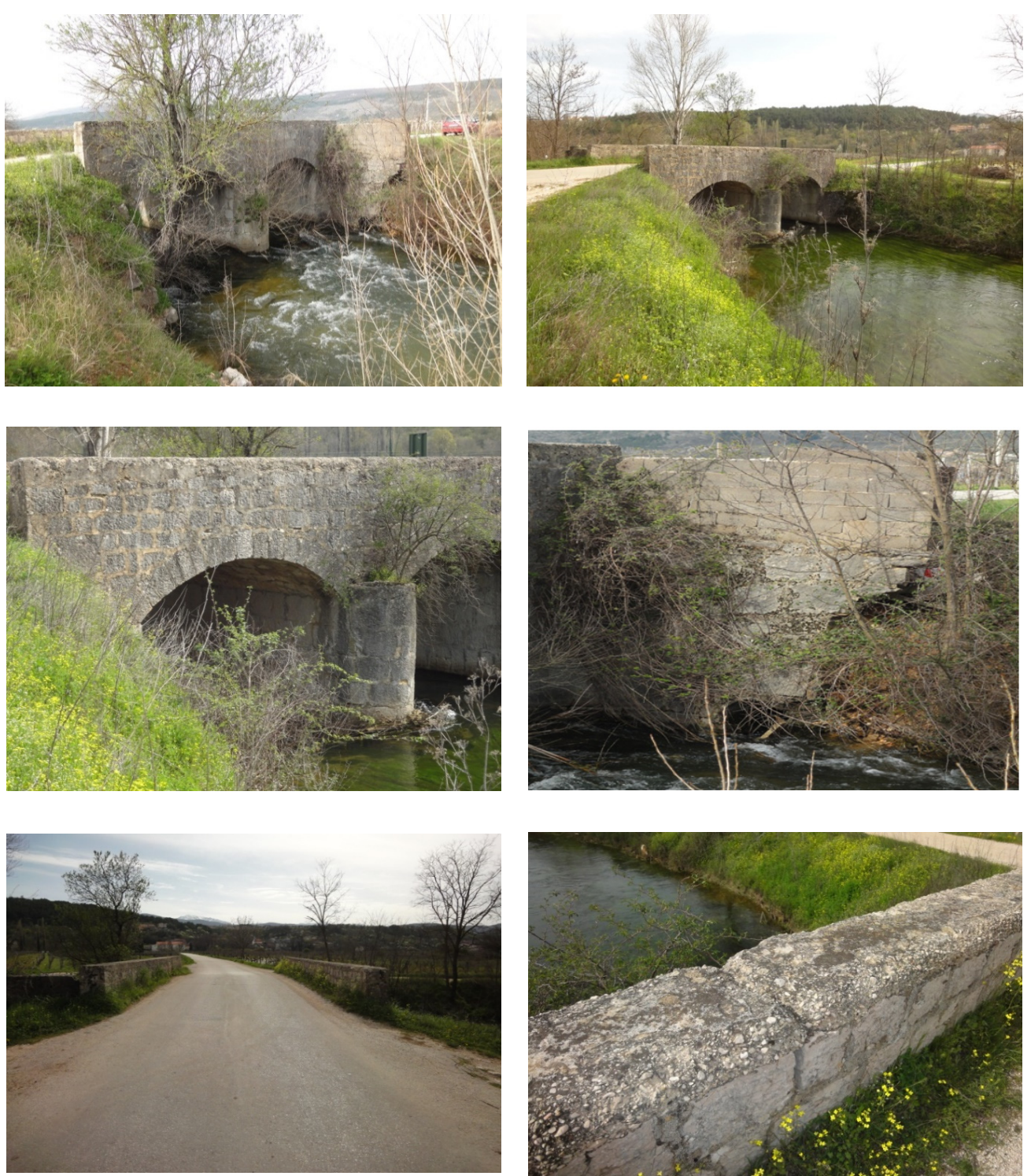

Figure 4. Bridge on the river Jaruga nearby Mračaj in Imotski field (figures in order from above left: bridge from east side, bridge from west side, abutment wing, pier, access road, fence). 


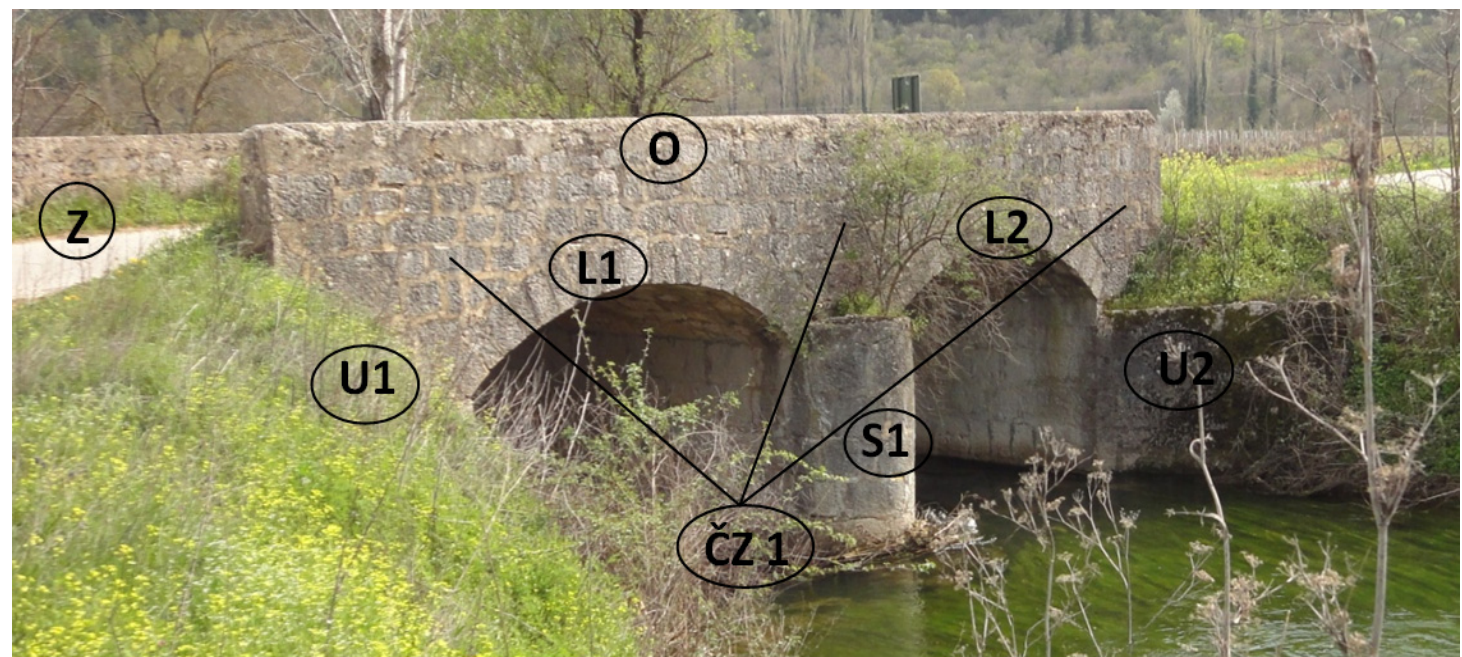

Figure 5. Labels of bridge elements for assessment (L1—arch1; L2—arch2; S—pier; U1—abutment1; U2—abutment2; ČZ1—the group1 of spandrel walls (a view from west side); $\mathrm{Z}$-pavement; $\mathrm{O}$-fence).

Evaluations of the elements for the bridge components and their structural importance are given below. First, it is started with the component superstructure, which contains 4 elements: arch 1, arch 2, spandrel walls 1, and spandrel walls 2 . In Table 4, crisp values of the elements ratings of the superstructure are given, and fuzzy sets to which these values belong are singled out. Fuzzy sets represent fuzzy ratings of elements and each set gets its fuzzy structural importance expressed as the average value of all fuzzy structural importance given by the experts. Additionally, each fuzzy set of element rating values is a description of the condition of the elements at the time of the expert visual assessment. According to the given crisp values of ratings, it can be noticed that two or three conditions are singled out for each element.

Table 4. Crisp and fuzzy values of the superstructure component elements.

\begin{tabular}{|c|c|c|c|}
\hline Element & Crisp Value of Rating & Fuzzy Value of Rating & $\begin{array}{l}\text { Fuzzy Structural Importance by } \\
\text { Each Expert (Average Value) }\end{array}$ \\
\hline \multirow{2}{*}{ Arc1 } & \multirow{2}{*}{75} & $60,70,80$ & $0.30 ; 0.55 ; 0.80$ \\
\hline & & $70,80,90$ & $0.15 ; 0.40 ; 0.65$ \\
\hline \multirow{3}{*}{ Arc2 } & \multirow{3}{*}{70} & $50,60,70$ & $0.60 ; 0.85 ; 1.00$ \\
\hline & & $60,70,80$ & $0.30 ; 0.55 ; 0.80$ \\
\hline & & $70,80,90$ & $0.15 ; 0.40 ; 0.65$ \\
\hline \multirow{2}{*}{ The group 1 of spandrel walls } & \multirow{2}{*}{75} & $60,70,80$ & $0.30 ; 0.55 ; 1.00$ \\
\hline & & $70,80,90$ & $0.15 ; 0.40 ; 0.65$ \\
\hline \multirow{2}{*}{ The group 2 of spandrel walls } & \multirow{2}{*}{75} & $60,70,80$ & $0.30 ; 0.55 ; 0.10$ \\
\hline & & $70,80,90$ & $0.15 ; 0.40 ; 0.65$ \\
\hline
\end{tabular}

After rating the elements of the superstructure, and determining their fuzzy values and the average values of fuzzy structural importance of the elements, the total number of combinations of elements in all possible conditions with given structural importance to calculate the final rating of the component is defined. Each component has a different number of combinations, so the algorithm is only applicable to combinations of superstructure elements. What the algorithm will look like depends on the number of elements and their conditions that are singled out based on the rating. The input data a1, a2, b1, b2, b3, $\mathrm{c} 1, \mathrm{c} 2, \mathrm{~d} 1$, and $\mathrm{d} 2$ represent the conditions of the elements, so the data a1 and a2 are the conditions for the element arch 1, b1, b2, and b3 are the conditions for the element arch 2, c1 
and c2 for the spandrel walls 1 , and $\mathrm{d} 1$ and $\mathrm{d} 2$ for spandrel walls 2 . The above data contain a fuzzy set of element ratings and the corresponding average value of fuzzy structural importance. That is why each condition contains six numbers, the first three represent the lower, middle, and upper value of the fuzzy set of rating, and the other three numbers, the lower, middle, and upper value of the fuzzy set of structural importance. The elements of the superstructure are shown in matrix form $A=[\mathrm{a} 1 ; \mathrm{a} 2], B=[\mathrm{b} 1 ; \mathrm{b} 2 ; \mathrm{b} 3], C=[\mathrm{c} 1 ; \mathrm{c} 2]$ and $D=[\mathrm{d} 1 ; \mathrm{d} 2]$. Then, the allcombs() function allows all elements in different states to be combined with each other.

The total number of combinations of superstructure elements is matrix $N_{k}=[24 \times 4]$. The number $N_{k}$ is expressed in a matrix form in which all possible combinations of four elements in different states are written ( 24 in total). The matrix form of the above combinations is shown below.

$$
N_{k}=\left[\begin{array}{llll}
0 & 0 & 0 & 0 \\
0 & 0 & 0 & 1 \\
0 & 0 & 1 & 0 \\
0 & 0 & 1 & 1 \\
0 & 1 & 0 & 0 \\
0 & 1 & 0 & 1 \\
0 & 1 & 1 & 0 \\
0 & 1 & 1 & 1 \\
0 & 2 & 0 & 0 \\
0 & 2 & 0 & 1 \\
0 & 2 & 1 & 0 \\
0 & 2 & 1 & 1 \\
1 & 0 & 0 & 0 \\
1 & 0 & 0 & 1 \\
1 & 0 & 1 & 0 \\
1 & 0 & 1 & 1 \\
1 & 1 & 0 & 0 \\
1 & 1 & 0 & 1 \\
1 & 1 & 1 & 0 \\
1 & 1 & 1 & 1 \\
1 & 2 & 0 & 0 \\
1 & 2 & 0 & 1 \\
1 & 2 & 1 & 0 \\
1 & 2 & 1 & 1
\end{array}\right]
$$

The values 0,1 and 2 represent the conditions of the elements, in such a way that 0 is valid for the first condition, i.e., a1, b1, $\mathrm{c} 1$, and $\mathrm{d} 1,1$ is valid for the second condition, a2, $\mathrm{b} 2, \mathrm{c} 2$, and $\mathrm{d} 2$, and 2 is valid for the condition b3. In Table 5 (shortened version-the first and the last two combinations) these values are transformed into fuzzy ratings and fuzzy structural importance of the elements, for the example, a1, b1, $\mathrm{c} 1$, and $\mathrm{d} 1$ are equivalent to the first row of the matrix $N_{k}$. Full data are provided in Table A1, in the Appendix A.

Using the $\alpha$-cuts, the lower and upper boundaries of the membership function are determined to obtain the combinations. Sets of $\alpha$-cuts range from 0 to 1 with the increment of 0.1. In Table 6 sets of $\alpha$-cuts of element fuzzy ratings for all combinations are given. The 22 values can be observed, of which 11 are for the ascending part of the fuzzy set, i.e., for the values of $\alpha$-cuts from 0 to 1 , and the other 11 for the descending part of the fuzzy set, for $\alpha$-cuts from 1 to 0 . Values 11 and 12 are the same for each set because in these values the membership degree is 1 . These 22 values form the membership functions of all fuzzy evaluations of the elements of each combination. Hereby, in Table 6 the shortened version (the first and the last two combinations) is presented, the full data is provided in the Appendix A (Table A2).

The same procedure for obtaining $\alpha$-cuts was applied for fuzzy structural importance. In Table 7 (shortened version-the first and the last two combinations), a representation of 
all $\alpha$-cuts of the structural importance of the superstructure elements is given. Full data are presented in the Appendix A (Table A3).

After calculating the sets of $\alpha$-cuts of fuzzy ratings and fuzzy structural importance, the determination of the component rating is obtained using the FWGM approach, in which the exponential value of the component rating is sought. As the evaluation of a component is a fuzzy value, it is also necessary to determine the sets of $\alpha$-cuts obtained from the previously calculated sets of ratings and the structural importance of the elements. In Table 8 (shortened version), the values of $\alpha$-cuts of fuzzy component ratings of the combinations are shown. Table A4, in the Appendix A, presents $\alpha$-cuts of fuzzy component ratings for all 24 combinations.

Figure 6 shows the $\alpha$-cuts of the membership functions of fuzzy component ratings for all combinations. The range of sets on the abscissa axis from 55 to 90 are presented, which corresponds to the range of obtained ratings, and on the ordinate axis the values of $\alpha$ are given.

After defining the fuzzy ratings of the superstructure component by all combinations, the final fuzzy rating of the component is determined using the arithmetic mean of all combinations ratings. The value of the $\alpha$-cuts for the final fuzzy component rating is given in Table 9. Figure 7 shows the membership function of the final fuzzy component rating.

The obtained membership function ranges from 61.28 to 83.11, and the degree of membership of 1 is reached at 72.37 .

The result of the final fuzzy rating of the component is required to obtain the final defuzzified rating, which is achieved by defuzzifiation. The defuzzification of the fuzzy component rating is obtained using the centroid method, expressed by (24).

Table 5. Combinations of all elements with fuzzy ratings and fuzzy structural importance (shortened version-the first and the last two combinations).

\begin{tabular}{|c|c|c|c|c|c|c|c|}
\hline \multirow{5}{*}{$\begin{array}{c}\text { No. of Combination } \\
1\end{array}$} & \multirow{5}{*}{$\begin{array}{c}\text { Element Combinations } \\
\mathrm{a} 1 \\
\mathrm{~b} 1 \\
\mathrm{c} 1 \\
\mathrm{~d} 1\end{array}$} & \multicolumn{3}{|c|}{ Fuzzy Ratings } & \multicolumn{3}{|c|}{ Fuzzy Structural Importance } \\
\hline & & 60.0000 & 70.0000 & 80.0000 & 0.3000 & 0.5500 & 0.8000 \\
\hline & & 50.0000 & 60.0000 & 70.0000 & 0.6000 & 0.8500 & 1.0000 \\
\hline & & 60.0000 & 70.0000 & 80.0000 & 0.3000 & 0.5500 & 1.0000 \\
\hline & & 60.0000 & 70.0000 & 80.0000 & 0.3000 & 0.5500 & 0.1000 \\
\hline \multirow{4}{*}{2} & a1 & 60.0000 & 70.0000 & 80.0000 & 0.3000 & 0.5500 & 0.8000 \\
\hline & b1 & 50.0000 & 60.0000 & 70.0000 & 0.6000 & 0.8500 & 1.0000 \\
\hline & $\mathrm{c} 1$ & 60.0000 & 70.0000 & 80.0000 & 0.3000 & 0.5500 & 1.0000 \\
\hline & $\mathrm{d} 2$ & 70.0000 & 80.0000 & 90.0000 & 0.1500 & 0.4000 & 0.6500 \\
\hline$\cdots$ & $\cdots$ & \multicolumn{3}{|c|}{$\ldots$} & \multicolumn{3}{|c|}{$\cdots$} \\
\hline \multirow{4}{*}{23} & a2 & 70.0000 & 80.0000 & 90.0000 & 0.1500 & 0.4000 & 0.6500 \\
\hline & b3 & 70.0000 & 80.0000 & 90.0000 & 0.1500 & 0.4000 & 0.6500 \\
\hline & c2 & 70.0000 & 80.0000 & 90.0000 & 0.1500 & 0.4000 & 0.6500 \\
\hline & $\mathrm{d} 1$ & 60.0000 & 70.0000 & 80.0000 & 0.3000 & 0.5500 & 0.1000 \\
\hline \multirow{4}{*}{24} & a2 & 70.0000 & 80.0000 & 90.0000 & 0.1500 & 0.4000 & 0.6500 \\
\hline & b3 & 70.0000 & 80.0000 & 90.0000 & 0.1500 & 0.4000 & 0.6500 \\
\hline & c2 & 70.0000 & 80.0000 & 90.0000 & 0.1500 & 0.4000 & 0.6500 \\
\hline & $\mathrm{d} 2$ & 70.0000 & 80.0000 & 90.0000 & 0.1500 & 0.4000 & 0.6500 \\
\hline
\end{tabular}


Table 6. The $\alpha$-cut sets of elements fuzzy ratings according to each combination (shortened version-the first and the last two combinations).

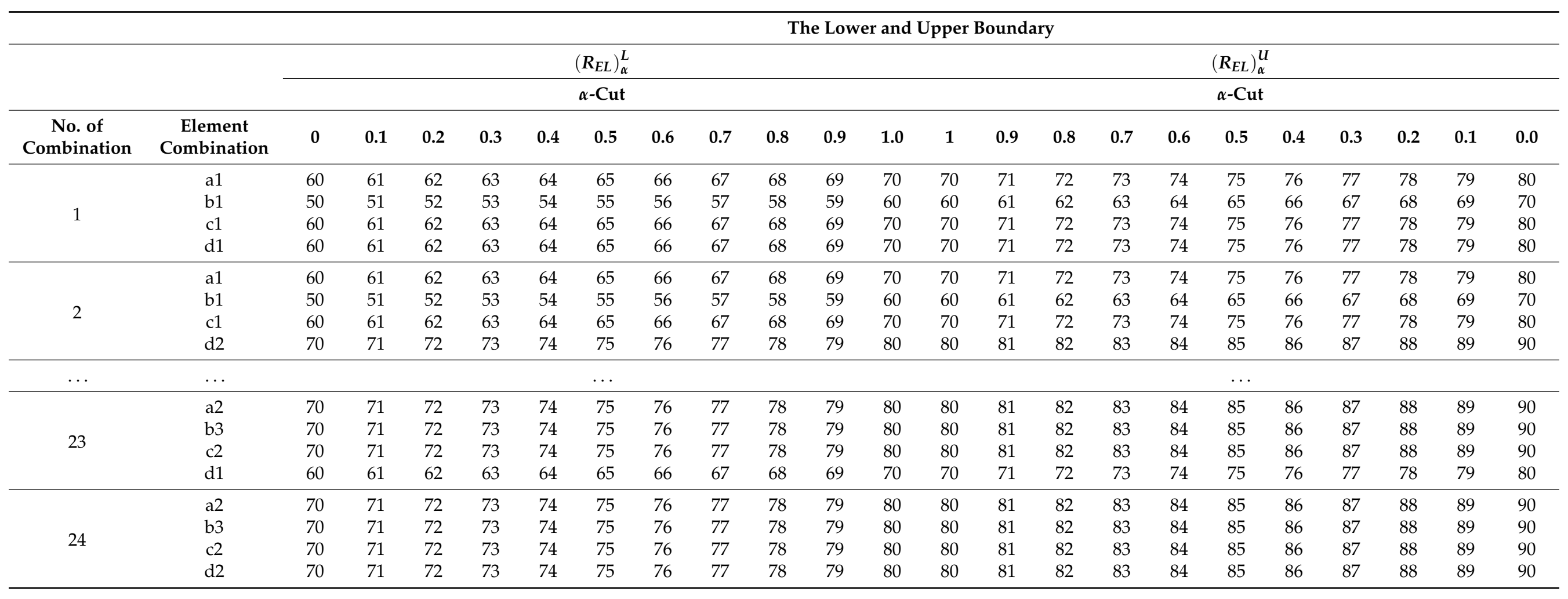

Table 7. The $\alpha$-cut sets of elements fuzzy structural importance according to each combination (shortened version-the first and the last two combinations).

\begin{tabular}{|c|c|c|c|c|c|c|c|c|c|c|c|c|c|}
\hline & & Boundary & & & & & & $\alpha$-Cut & & & & & \\
\hline \multirow{2}{*}{$\begin{array}{c}\text { No. of } \\
\text { Combination }\end{array}$} & \multirow{2}{*}{$\begin{array}{c}\text { Element } \\
\text { Combination }\end{array}$} & $\left(w_{E L}\right)_{\alpha}^{L}$ & 0 & 0.1 & 0.2 & 0.3 & 0.4 & 0.5 & 0.6 & 0.7 & 0.8 & 0.9 & 1 \\
\hline & & $\left(w_{E L}\right)_{\alpha}^{U}$ & 1 & 0.9 & 0.8 & 0.7 & 0.6 & 0.5 & 0.4 & 0.3 & 0.2 & 0.1 & 0 \\
\hline \multirow{3}{*}{1} & b1 & \multirow{3}{*}{$\left(w_{E L}\right)_{\alpha}^{L}$} & 0.6000 & 0.6250 & 0.6500 & 0.6750 & 0.7000 & 0.7250 & 0.7500 & 0.7750 & 0.8000 & 0.8250 & 0.8500 \\
\hline & $\mathrm{c} 1$ & & 0.3000 & 0.3250 & 0.3500 & 0.3750 & 0.4000 & 0.4250 & 0.4500 & 0.4750 & 0.5000 & 0.5250 & 0.5500 \\
\hline & $\mathrm{d} 1$ & & 0.3000 & 0.3250 & 0.3500 & 0.3750 & 0.4000 & 0.4250 & 0.4500 & 0.4750 & 0.5000 & 0.5250 & 0.5500 \\
\hline
\end{tabular}


Table 7. Cont.

\begin{tabular}{|c|c|c|c|c|c|c|c|c|c|c|c|c|c|}
\hline \multirow{3}{*}{$\begin{array}{c}\text { No. of } \\
\text { Combination }\end{array}$} & \multirow{3}{*}{$\begin{array}{c}\text { Element } \\
\text { Combination }\end{array}$} & \multirow{2}{*}{$\frac{\text { Boundary }}{\left(w_{E L}\right)_{\alpha}^{L}}$} & \multicolumn{11}{|c|}{$\alpha$-Cut } \\
\hline & & & 0 & 0.1 & 0.2 & 0.3 & 0.4 & 0.5 & 0.6 & 0.7 & 0.8 & 0.9 & 1 \\
\hline & & $\left(w_{E L}\right)_{\alpha}^{U}$ & 1 & 0.9 & 0.8 & 0.7 & 0.6 & 0.5 & 0.4 & 0.3 & 0.2 & 0.1 & 0 \\
\hline & $\mathrm{b} 1$ & & 0.8500 & 0.8650 & 0.8800 & 0.8950 & 0.9100 & 0.9250 & 0.9400 & 0.9550 & 0.9700 & 0.9850 & 1.0000 \\
\hline & $\mathrm{c} 1$ & $\left(w_{E L}\right)_{\alpha}$ & 0.5500 & 0.5950 & 0.6400 & 0.6850 & 0.7300 & 0.7750 & 0.8200 & 0.8650 & 0.9100 & 0.9550 & 1.0000 \\
\hline & $\mathrm{d} 1$ & & 0.5500 & 0.5050 & 0.4600 & 0.4150 & 0.3700 & 0.3250 & 0.2800 & 0.2350 & 0.1900 & 0.1450 & 0.1000 \\
\hline \multirow{8}{*}{2} & a1 & \multirow{4}{*}{$\left(w_{E L}\right)_{\alpha}^{L}$} & 0.3000 & 0.3250 & 0.3500 & 0.3750 & 0.4000 & 0.4250 & 0.4500 & 0.4750 & 0.5000 & 0.5250 & 0.5500 \\
\hline & b1 & & 0.6000 & 0.6250 & 0.6500 & 0.6750 & 0.7000 & 0.7250 & 0.7500 & 0.7750 & 0.8000 & 0.8250 & 0.8500 \\
\hline & c1 & & 0.3000 & 0.3250 & 0.3500 & 0.3750 & 0.4000 & 0.4250 & 0.4500 & 0.4750 & 0.5000 & 0.5250 & 0.5500 \\
\hline & $\mathrm{d} 2$ & & 0.1500 & 0.1750 & 0.2000 & 0.2250 & 0.2500 & 0.2750 & 0.3000 & 0.3250 & 0.3500 & 0.3750 & 0.4000 \\
\hline & a1 & \multirow{4}{*}{$\left(w_{E L}\right)_{\alpha}^{U}$} & 0.5500 & 0.5750 & 0.6000 & 0.6250 & 0.6500 & 0.6750 & 0.7000 & 0.7250 & 0.7500 & 0.7750 & 0.8000 \\
\hline & $\mathrm{b} 1$ & & 0.8500 & 0.8650 & 0.8800 & 0.8950 & 0.9100 & 0.9250 & 0.9400 & 0.9550 & 0.9700 & 0.9850 & 1.0000 \\
\hline & $\mathrm{c} 1$ & & 0.5500 & 0.5950 & 0.6400 & 0.6850 & 0.7300 & 0.7750 & 0.8200 & 0.8650 & 0.9100 & 0.9550 & 1.0000 \\
\hline & $\mathrm{d} 2$ & & 0.400 & 0.4250 & 0.4500 & 0.4750 & 0.5000 & 0.5250 & 0.5500 & 0.5750 & 0.6000 & 0.6250 & 0.6500 \\
\hline$\cdots$ & $\ldots$ & $\left(w_{E L}\right)_{\alpha}^{L}$ & \multicolumn{11}{|c|}{$\ldots$} \\
\hline \multirow{8}{*}{23} & $\mathrm{a} 2$ & \multirow{4}{*}{$\left(w_{E L}\right)_{\alpha}^{L}$} & 0.1500 & 0.1750 & 0.2000 & 0.2250 & 0.2500 & 0.2750 & 0.3000 & 0.3250 & 0.3500 & 0.3750 & 0.4000 \\
\hline & b3 & & 0.1500 & 0.1750 & 0.2000 & 0.2250 & 0.2500 & 0.2750 & 0.3000 & 0.3250 & 0.3500 & 0.3750 & 0.4000 \\
\hline & c2 & & 0.1500 & 0.1750 & 0.2000 & 0.2250 & 0.2500 & 0.2750 & 0.3000 & 0.3250 & 0.3500 & 0.3750 & 0.4000 \\
\hline & $\mathrm{d} 1$ & & 0.3000 & 0.3250 & 0.3500 & 0.3750 & 0.4000 & 0.4250 & 0.4500 & 0.4750 & 0.5000 & 0.5250 & 0.5500 \\
\hline & a2 & \multirow{4}{*}{$\left(w_{E L}\right)_{\alpha}^{U}$} & 0.4000 & 0.4250 & 0.4500 & 0.4750 & 0.5000 & 0.5250 & 0.5500 & 0.5750 & 0.6000 & 0.6250 & 0.6500 \\
\hline & b3 & & 0.4000 & 0.4250 & 0.4500 & 0.4750 & 0.5000 & 0.5250 & 0.5500 & 0.5750 & 0.6000 & 0.6250 & 0.6500 \\
\hline & c2 & & 0.4000 & 0.4250 & 0.4500 & 0.4750 & 0.5000 & 0.5250 & 0.5500 & 0.5750 & 0.6000 & 0.6250 & 0.6500 \\
\hline & $\mathrm{d} 1$ & & 0.5500 & 0.5050 & 0.4600 & 0.4150 & 0.3700 & 0.3250 & 0.2800 & 0.2350 & 0.1900 & 0.1450 & 0.1000 \\
\hline \multirow{8}{*}{24} & a2 & \multirow{4}{*}{$\left(w_{E L}\right)_{\alpha}^{L}$} & 0.1500 & 0.1750 & 0.2000 & 0.2250 & 0.2500 & 0.2750 & 0.3000 & 0.3250 & 0.3500 & 0.3750 & 0.4000 \\
\hline & b3 & & 0.1500 & 0.1750 & 0.2000 & 0.2250 & 0.2500 & 0.2750 & 0.3000 & 0.3250 & 0.3500 & 0.3750 & 0.4000 \\
\hline & $\mathrm{c} 2$ & & 0.1500 & 0.1750 & 0.2000 & 0.2250 & 0.2500 & 0.2750 & 0.3000 & 0.3250 & 0.3500 & 0.3750 & 0.4000 \\
\hline & $\mathrm{d} 2$ & & 0.1500 & 0.1750 & 0.2000 & 0.2250 & 0.2500 & 0.2750 & 0.3000 & 0.3250 & 0.350 & 0.3750 & 0.4000 \\
\hline & a2 & \multirow{4}{*}{$\left(w_{E L}\right)_{\alpha}^{U}$} & 0.4000 & 0.4250 & 0.4500 & 0.4750 & 0.5000 & 0.5250 & 0.5500 & 0.5750 & 0.6000 & 0.6250 & 0.6500 \\
\hline & b3 & & 0.4000 & 0.4250 & 0.4500 & 0.4750 & 0.5000 & 0.5250 & 0.5500 & 0.5750 & 0.6000 & 0.6250 & 0.6500 \\
\hline & c2 & & 0.4000 & 0.4250 & 0.4500 & 0.4750 & 0.5000 & 0.5250 & 0.5500 & 0.5750 & 0.6000 & 0.6250 & 0.6500 \\
\hline & $\mathrm{d} 2$ & & 0.4000 & 0.4250 & 0.4500 & 0.4750 & 0.5000 & 0.5250 & 0.5500 & 0.5750 & 0.6000 & 0.6250 & 0.6500 \\
\hline
\end{tabular}


Table 8. The rating value of the superstructure component for all combinations (shortened version).

\begin{tabular}{|c|c|c|c|c|c|c|c|c|c|c|c|c|}
\hline \multirow[b]{2}{*}{$\alpha$-Cut } & \multicolumn{12}{|c|}{ Number of Combination } \\
\hline & 1 & 2 & 3 & 4 & 5 & 6 & 7 & 8 & 9 & 10 & 11 & 12 \\
\hline 0.0 & 55.78 & 56.29 & 56.29 & 56.92 & 60.00 & 61.34 & 61.34 & 63.16 & 61.34 & 63.16 & 63.16 & 65.81 \\
\hline 0.1 & 56.88 & 57.51 & 57.51 & 58.30 & 61.00 & 62.43 & 62.43 & 64.33 & 62.43 & 64.33 & 64.33 & 67.00 \\
\hline \multicolumn{13}{|c|}{$\ldots$} \\
\hline 0.9 & 65.38 & 66.64 & 66.64 & 68.10 & 69.00 & 70.82 & 70.82 & 73.00 & 70.82 & 73.00 & 73.00 & 75.67 \\
\hline 1.0 & 66.43 & 67.73 & 67.73 & 69.23 & 70.00 & 71.85 & 71.85 & 74.05 & 71.85 & 74.05 & 74.05 & 76.71 \\
\hline 1.0 & 66.43 & 67.73 & 67.73 & 69.23 & 70.00 & 71.85 & 71.85 & 74.05 & 71.85 & 74.05 & 74.05 & 76.71 \\
\hline 0.9 & 67.42 & 68.86 & 68.78 & 70.40 & 71.00 & 72.86 & 72.94 & 75.09 & 72.92 & 75.05 & 75.24 & 77.75 \\
\hline \multicolumn{13}{|c|}{$\ldots$} \\
\hline 0.1 & 75.40 & 77.62 & 77.18 & 79.41 & 79.00 & 80.90 & 81.58 & 83.32 & 81.39 & 83.05 & 84.61 & 85.95 \\
\hline 0.0 & 76.40 & 78.69 & 78.23 & 80.51 & 80.00 & 81.91 & 82.65 & 84.34 & 82.44 & 84.05 & 85.77 & 86.97 \\
\hline \multicolumn{13}{|c|}{ Number of Combination } \\
\hline$\alpha$-Cut & 13 & 14 & 15 & 16 & 17 & 18 & 19 & 20 & 21 & 22 & 23 & 24 \\
\hline 0.0 & 56.29 & 56.92 & 56.92 & 57.76 & 61.34 & 63.16 & 63.16 & 65.81 & 63.16 & 65.81 & 65.81 & 70.00 \\
\hline 0.1 & 57.51 & 58.30 & 58.30 & 59.32 & 62.43 & 64.33 & 64.33 & 67.00 & 64.33 & 67.00 & 67.00 & 71.00 \\
\hline \multicolumn{13}{|c|}{$\ldots$} \\
\hline 0.9 & 66.64 & 68.10 & 68.10 & 69.82 & 70.82 & 73.00 & 73.00 & 75.67 & 73.00 & 75.67 & 75.67 & 79.00 \\
\hline 1.0 & 67.73 & 69.23 & 69.23 & 71.00 & 71.85 & 74.05 & 74.05 & 76.71 & 74.05 & 76.71 & 76.71 & 80.00 \\
\hline 1.0 & 67.73 & 69.23 & 69.23 & 71.00 & 71.85 & 74.05 & 74.05 & 76.71 & 74.05 & 76.71 & 76.71 & 80.00 \\
\hline 0.9 & 68.80 & 70.41 & 70.39 & 72.23 & 72.92 & 75.05 & 75.24 & 77.75 & 75.20 & 77.67 & 78.03 & 81.00 \\
\hline 0.1 & 77.30 & 79.39 & 79.52 & 81.53 & 81.39 & 83.05 & 84.61 & 85.95 & 84.17 & 85.49 & 88.24 & 89.00 \\
\hline 0.0 & 78.36 & 80.48 & 80.66 & 82.65 & 82.44 & 84.05 & 85.77 & 86.97 & 85.27 & 86.48 & 89.48 & 90.00 \\
\hline
\end{tabular}

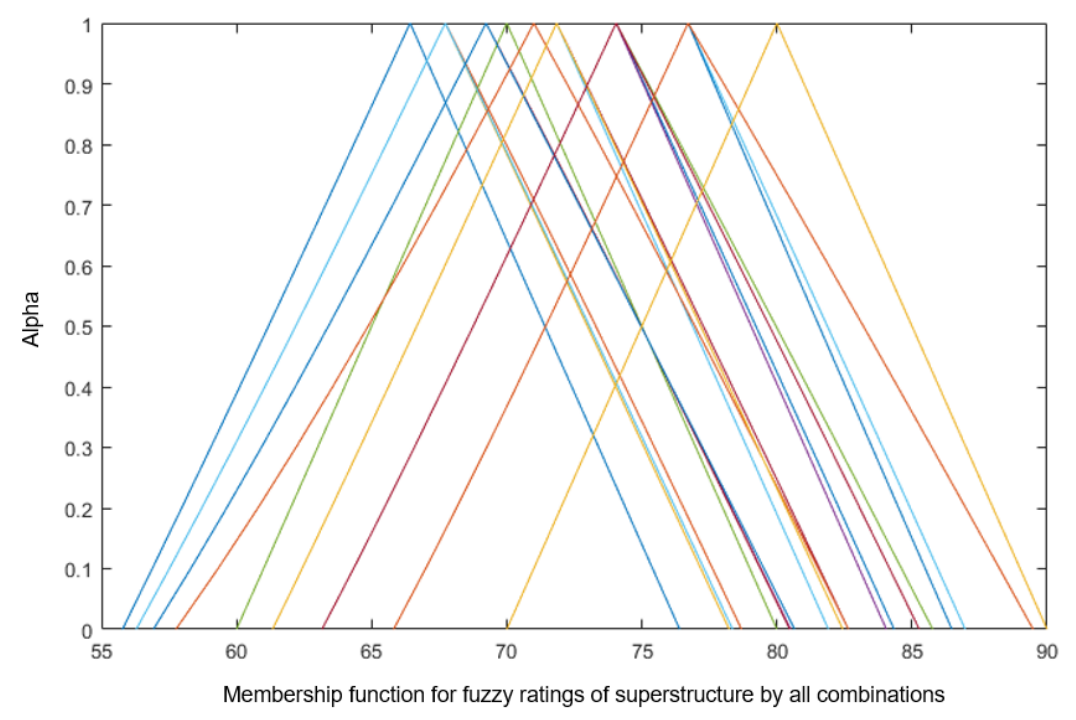

Figure 6. Graphical representation of the superstructure component rating values for all combinations. 
Table 9. The average of all combinations—-the final fuzzy value of the superstructure component rating.

\begin{tabular}{ccccccccccccc}
\hline$\alpha$-cut & 0.0 & 0.1 & 0.2 & 0.3 & 0.4 & 0.5 & 0.6 & 0.7 & 0.8 & 0.9 & 1.0 \\
\hline$\left(R_{\text {КОМР }}\right)_{\alpha}^{L}$ & 61.28 & 62.47 & 63.63 & 64.77 & 65.89 & 66.99 & 68.08 & 69.17 & 70.24 & 71.31 & 72.37 \\
\hline$\alpha$-cut & 1.0 & 0.9 & 0.8 & 0.7 & 0.6 & 0.5 & 0.4 & 0.3 & 0.2 & 0.1 & 0.0 \\
\hline$\left(R_{\text {КОМР }}\right)_{\alpha}^{U}$ & 72.37 & 73.46 & 74.54 & 75.62 & 76.70 & 77.78 & 78.85 & 79.92 & 80.98 & 82.04 & 83.11 \\
\hline
\end{tabular}

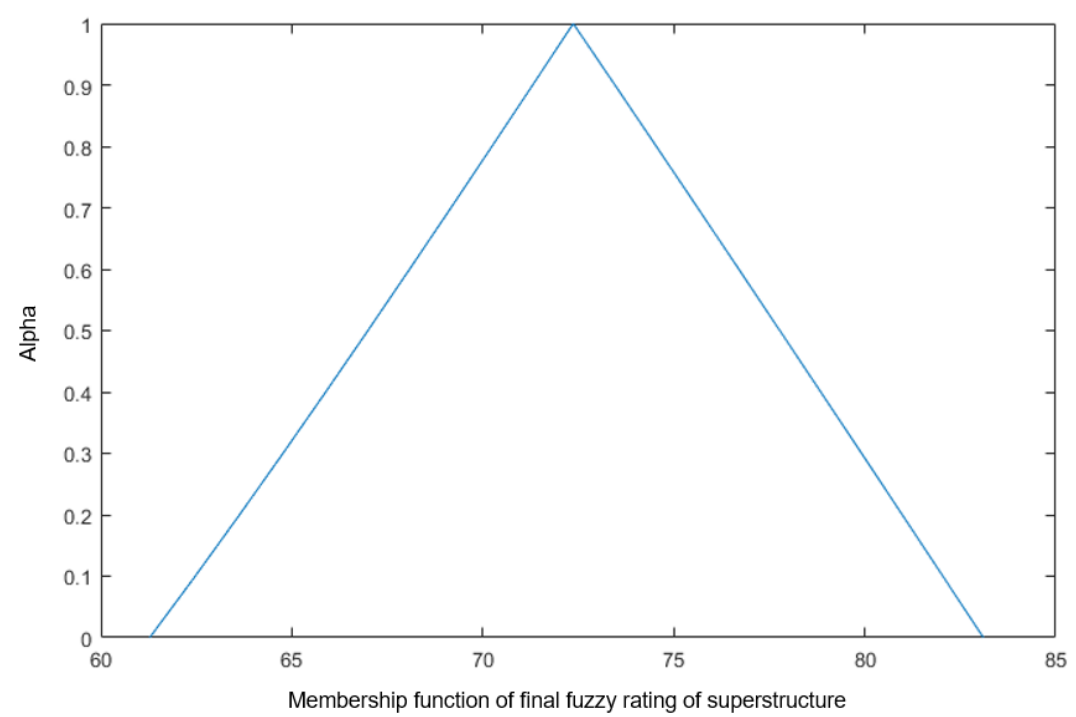

Figure 7. Graphical representation of the membership function of superstructure component final rating for all combinations.

The algorithm for obtaining the defuzzified value of the component rating is given below, where $m$ represents the value of the upper boundary of the fuzzy value in which the degree of membership is $1, n$ also represents the upper boundary but with the degree of membership is 0 . The degree of membership is also 0 for the lower boundary of the fuzzy value of the component rating which is denoted by $o$. The defuzzified value of the superstructure component rating is denoted by $\mathrm{P}$. The alphaCuts() function is used to obtain $\alpha$-cut sets.

$$
\begin{aligned}
& m=\text { alphaCuts(12); } \\
& n=\text { alphaCuts(22); } \\
& o=\text { alphaCuts }(1) ; \\
& \mathrm{P}=(m+n+o) / 3
\end{aligned}
$$

The final defuzzified rating of the superstructure component is calculated as follows:

$$
\bar{x}_{0}(\widetilde{A})=\frac{1}{3}(83.11+72.37+61.28)=72.25
$$

The same procedure is applied to the substructure component and to the equipment component, therefore the whole procedure will not be repeated but only the final fuzzy and defuzzified values of the component ratings will be given. The input data for the substructure component are given in Table 10.

The number of obtained combinations based on the total number of elements and fuzzy sets to which the crisp value of the element rating belongs for the substructure component is the matrix $N_{k}=[12 \times 3]$. Fuzzy values of the element ratings of the substructure for all combinations are shown in Figure 8.

The final fuzzy value of the component rating is shown in Table 11, whit the lower and upper boundaries of the $\alpha$-cuts are given, and in Figure 9, a graphical representation of the membership function with all its $\alpha$-cuts is given. 
Table 10. Crisp and fuzzy values of ratings of the substructure component elements.

\begin{tabular}{|c|c|c|c|}
\hline Element & Crisp Value of Rating & Fuzzy Value of Rating & $\begin{array}{c}\text { Fuzzy Structural Importance by Each } \\
\text { Expert (Average Value) }\end{array}$ \\
\hline \multirow{3}{*}{ Pier } & \multirow{3}{*}{70} & $50,60,70$ & $0.65 ; 0.90 ; 1.00$ \\
\hline & & $60,70,80$ & $0.30 ; 0.55 ; 0.80$ \\
\hline & & $70,80,90$ & $0.10 ; 0.35 ; 0.60$ \\
\hline \multirow{2}{*}{ Abutment 1} & \multirow{2}{*}{75} & $60,70,80$ & $0.30 ; 0.55 ; 0.80$ \\
\hline & & $70,80,90$ & $0.10 ; 0.35 ; 0.60$ \\
\hline \multirow{2}{*}{ Abutment 2} & \multirow{2}{*}{75} & $60,70,80$ & $0.30 ; 0.55 ; 0.80$ \\
\hline & & $70,80,90$ & $0.10 ; 0.35 ; 0.60$ \\
\hline
\end{tabular}

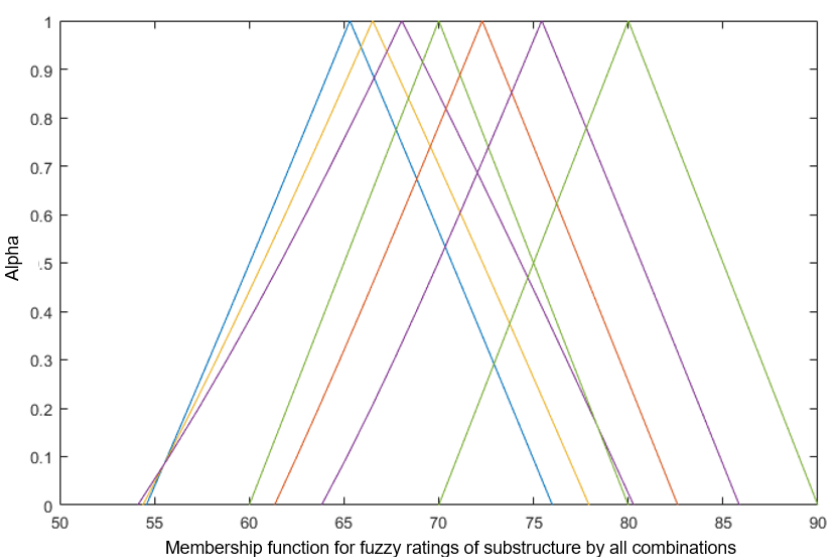

Figure 8. Graphical representation of the substructure component rating values for all combinations.

Table 11. The average of all combinations—the final fuzzy value of the substructure component rating.

\begin{tabular}{ccccccccccccc}
\hline$\alpha$-cut & 0.0 & 0.1 & 0.2 & 0.3 & 0.4 & 0.5 & 0.6 & 0.7 & 0.8 & 0.9 & 1.0 \\
\hline$\left(R_{\text {КОМР }}\right)_{\alpha}^{L}$ & 60.24 & 61.49 & 62.70 & 63.88 & 65.03 & 66.16 & 67.27 & 68.38 & 69.47 & 70.55 & 71.63 \\
\hline$\alpha$-cut & 1.0 & 0.9 & 0.8 & 0.7 & 0.6 & 0.5 & 0.4 & 0.3 & 0.2 & 0.1 & 0.0 \\
\hline$\left(R_{\text {КОМР }}\right)_{\alpha}^{U}$ & 71.63 & 72.72 & 73.80 & 74.88 & 75.95 & 77.02 & 78.08 & 79.14 & 80.19 & 81.25 & 82.30 \\
\hline
\end{tabular}

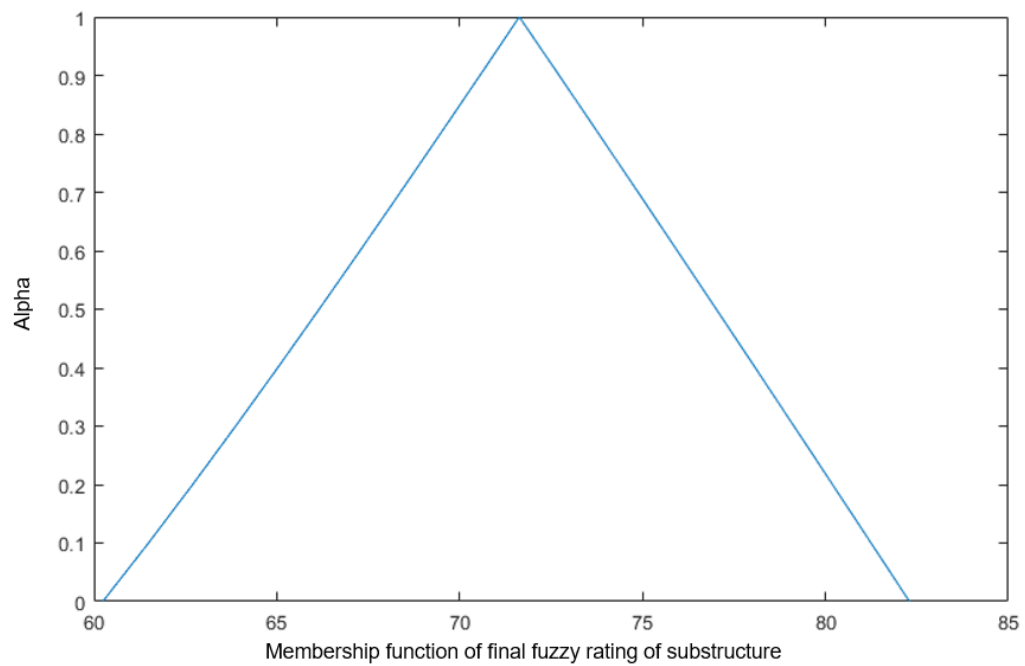

Figure 9. Graphical representation of the membership function of substructure component final rating for all combinations. 
The defuzzification of rating values of substructure is obtained using the centroid method, and the final rating of the component is:

$$
\bar{x}_{0}(\widetilde{A})=\frac{1}{3}(82.30+71.63+60.24)=71.39
$$

Elements of the equipment component are curtain, fence, drainage and lighting. As there is no lighting for the observed bridge, it could not be assessed. The input data for the equipment component are given in Table 12.

Table 12. Crisp and fuzzy values of ratings of the equipment component elements.

\begin{tabular}{|c|c|c|c|}
\hline Element & Crisp Value of Rating & Fuzzy Value of Rating & $\begin{array}{c}\text { Fuzzy Structural Importance by Each } \\
\text { Expert (Average Value) }\end{array}$ \\
\hline \multirow{2}{*}{ Pavement } & \multirow{2}{*}{75} & $60,70,80$ & $0.30 ; 0.55 ; 0.80$ \\
\hline & & $70,80,90$ & $0.10 ; 0.35 ; 0.60$ \\
\hline \multirow{2}{*}{ Fence } & \multirow{2}{*}{75} & $60,70,80$ & $0.30 ; 0.55 ; 0.80$ \\
\hline & & $70,80,90$ & $0.15 ; 0.40 ; 0.65$ \\
\hline \multirow{2}{*}{ Drainage } & \multirow{2}{*}{75} & $60,70,80$ & $0.30 ; 0.55 ; 0.80$ \\
\hline & & $70,80,90$ & $0.15 ; 0.40 ; 0.65$ \\
\hline
\end{tabular}

The number of obtained combinations based on the total number of elements and fuzzy sets to which the crisp value of the rating of an element belongs for the equipment component is a matrix $N_{k}=[8 \times 3]$.

Fuzzy values of ratings of equipment elements for all combinations are shown in Figure 10.

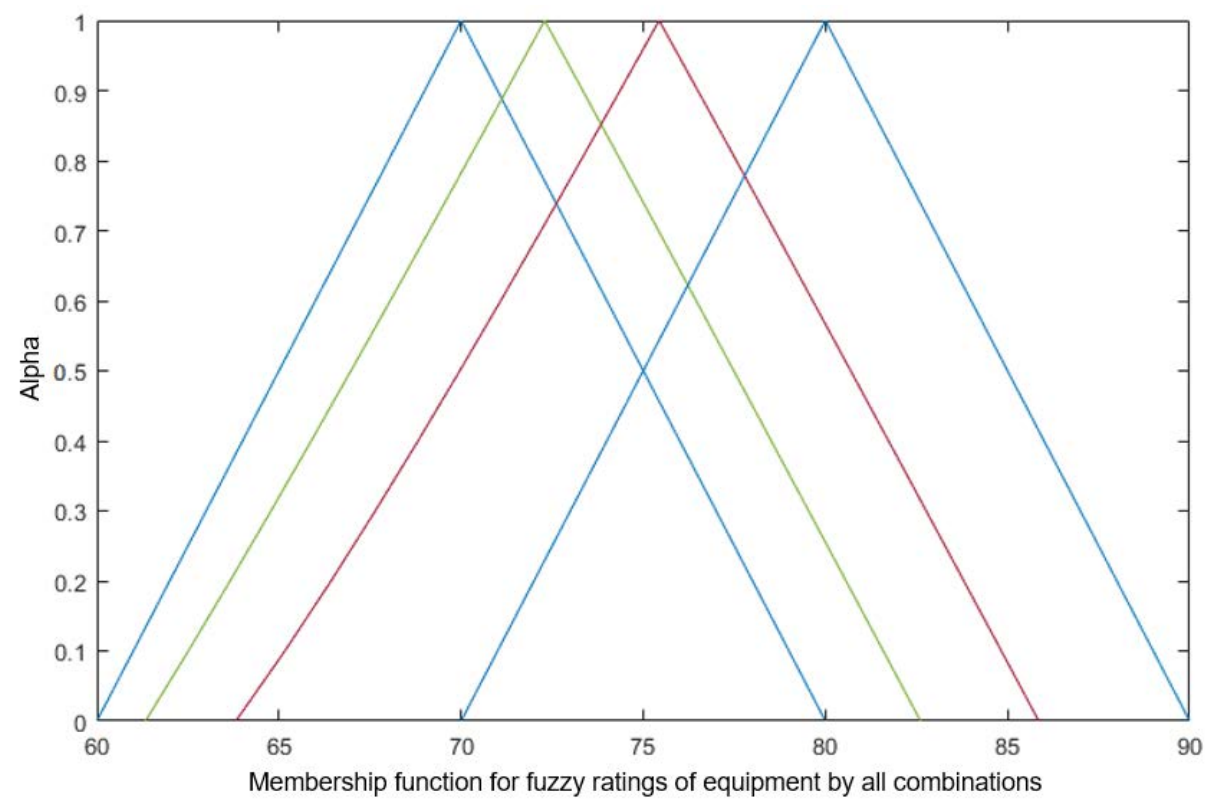

Figure 10. Graphical representation of the equipment component rating values for all combinations.

The final fuzzy value of the equipment component rating is shown in Table 13 with the lower and upper boundaries of the $\alpha$-cuts, and in Figure 11, a graphical representation of the membership function with all $\alpha$-cuts is given. 
Table 13. The average of all combinations—-the final fuzzy value of the equipment component rating.

\begin{tabular}{ccccccccccccc}
\hline$\alpha$-cut & 0.0 & 0.1 & 0.2 & 0.3 & 0.4 & 0.5 & 0.6 & 0.7 & 0.8 & 0.9 & 1.0 \\
\hline$\left(R_{\text {КОМР }}\right)_{\alpha}^{L}$ & 63.18 & 64.38 & 65.53 & 66.66 & 67.76 & 68.85 & 69.93 & 70.99 & 72.05 & 73.10 & 74.15 \\
\hline$\alpha$-cut & 1.0 & 0.9 & 0.8 & 0.7 & 0.6 & 0.5 & 0.4 & 0.3 & 0.2 & 0.1 & 0.0 \\
\hline$\left(R_{\text {КОМР }}\right)_{\alpha}^{U}$ & 74.15 & 75.19 & 76.23 & 77.26 & 78.29 & 79.32 & 80.34 & 81.37 & 82.39 & 83.41 & 84.43 \\
\hline
\end{tabular}

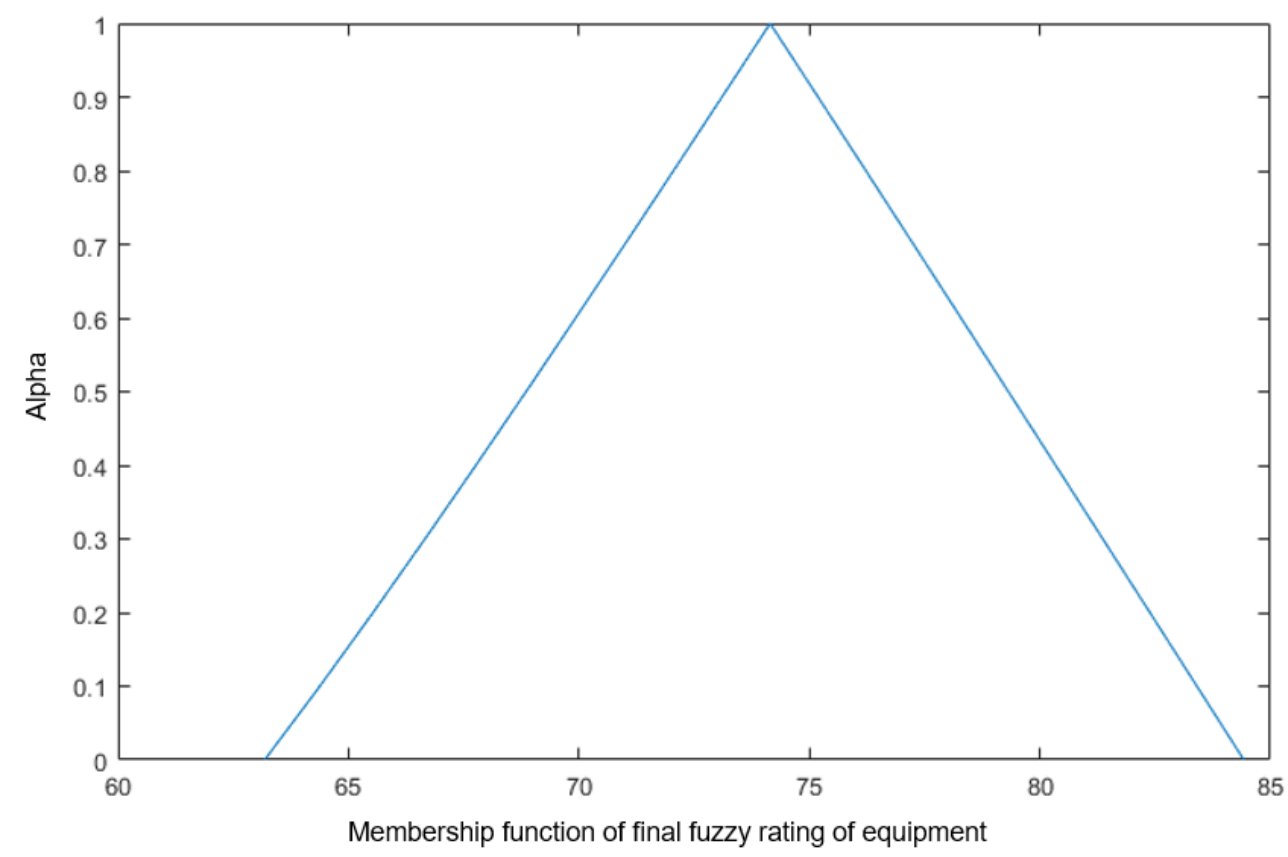

Figure 11. Graphical representation of the membership function of equipment component final rating for all combinations.

The defuzzification of rating values of equipment is obtained using the centroid method, and the final rating of the component is:

$$
\bar{x}_{0}(\widetilde{A})=\frac{1}{3} \cdot(84.43+74.15+63.18)=73.92
$$

After the defuzzfied values of the ratings of the components are calculated, the relative importance (weights) of components are determined using the AHP method. Rashidi et al. [52] used simplified AHP to evaluate the major rehabilitation strategies for the concrete bridge to maintain bridge assets within acceptable limits of safety, serviceability, and sustainability. Additionally, Rashidi et al. [53] applied simplified AHP to the threelevel hierarchy structure, identifying the main goal, criteria, subcriteria, and alternatives, for the remediation of the steel bridges. Hereby, the AHP method is used to the define relative importance of the bridge components according to their calculated ratings. This way, the impact of each component rating on the overall bridge condition is expressed. If the components, for example, all have the same rating each of them may not have the same impact, also if one component is rated higher than the other it still, according to an expert opinion, may have a negative impact on the overall bridge condition. First, a comparison matrix of components is established by an expert according to the Saaty's scale, as shown in Table 14. In Table 15, normalization and calculated final weights of components are presented. 
The last column in Table 15 represents the final weights of the components. After the assigned weights, the consistency of the matrix is checked as follows:

$$
\begin{gathered}
\lambda_{\text {max }}=2.5 \times 0.4+2.5 \times 0.4+5 \times 0.2=3 \\
\mathrm{CI}=\frac{\lambda_{\max }-n}{n-1}=\frac{3-3}{3-1}=0 \\
\mathrm{RI}=0.52 \text { for } n=3 \\
\mathrm{CR}=\frac{\mathrm{CI}}{\mathrm{RI}}=\frac{0}{0,52}=0
\end{gathered}
$$

The value of the consistency ratio is 0 , and the consistency of the matrix is achieved, i.e., the weights are correctly assigned.

Table 14. Comparison matrix of bridge component.

\begin{tabular}{cccc}
\hline & Superstructure & Substructure & Equipment \\
\hline Superstructure & 1 & 1 & 2 \\
\hline Substructure & 1 & 1 & 2 \\
\hline Equipment & $1 / 2$ & $1 / 2$ & 1 \\
\hline$\sum$ & 2.5 & 2.5 & 5 \\
\hline
\end{tabular}

Table 15. Normalization of matrix and final weights of components.

\begin{tabular}{lccccc}
\hline & Superstructure & Substructure & Equipment & $\sum$ & $\boldsymbol{w}$ \\
\hline Superstructure & 0.4 & 0.4 & 0.4 & 1.2 & $1.2 / 3=0.4$ \\
\hline Substructure & 0.4 & 0.4 & 0.4 & 1.2 & $1.2 / 3=0.4$ \\
\hline Equipment & 0.2 & 0.2 & 0.2 & 0.6 & $0.6 / 3=0.2$ \\
\hline
\end{tabular}

The HRBCAI is obtained by summing the defuzzified ratings of the components multiplied by their relative importance, which is also a rating of the Bridge on the river Jaruga nearby Mračaj in Imotski field:

$$
\mathrm{HRBCAI}=72.25 \times 0.4+71.39 \times 0.4+73.92 \times 0.2=72.24
$$

The HRBCAI values for all bridges are given in Table 16. According to Table 16, the lowest value has the Bridge over the river Matica in Kokorići, 38.59, and the highest Balački bridge in Vinalići, 98.18. Concerning the visual inspection of bridges, the values obtained are justified, which is confirmed by an expert opinion on the condition of the bridges. After the procedure of model validation, the expert is asked to rate bridges from 0 to 100 . In Table 16, a comparison of the bridge condition assessment obtained by the proposed model with the expert's assessment is given.

From Table 16 it can be seen that the differences in the values obtained by the model and those obtained by the expert are very small, and with a very high correlation $r=0.99$. Therefore, it can be concluded that the newly developed model is efficient and effective when it comes to assessing the condition of historic road bridges. This model can be also used for other types of bridges and structures, the only thing that is crucial for the whole process is the collection of adequate knowledge or data (estimates, percentages, weights, etc.) that will get the most correct and realistic output value. Additionally, the quality selection of the membership function as well as the division into appropriate fuzzy sets is important. The obtained ratings of bridges will be further used as input values for one of the criteria in the historic road bridges priority ranking model, which will be discussed and demonstrated in future research. 
Table 16. Historic Road Bridge Condition Assessment Index (HRBCAI) values for historic road bridges values obtained by the proposed model and their comparison with the values given by the expert.

\begin{tabular}{|c|c|c|c|}
\hline Bridge Label & Name of the Bridge & HRBCAI & Expert \\
\hline B1 & Jovića bridge & 73.602 & 75 \\
\hline B2 & Bridge over the river Matica & 38.594 & 40 \\
\hline B3 & Bridge in Rastoke & 60.532 & 60 \\
\hline B4 & Bridge Brvina on the river Vrljika & 91.249 & 95 \\
\hline B5 & Bridge on Bublin on the river Vrljika & 77.641 & 80 \\
\hline B6 & Zmijavački bridge on the river Vrljika & 80.131 & 80 \\
\hline B7 & Bridge on the stream Suvaja/Karalipeov bridge & 80.310 & 80 \\
\hline B8 & Bridge Šumet over the channel Jaruga & 71.199 & 70 \\
\hline B9 & Bridge Jasenovac on the river Jaruga & 86.621 & 90 \\
\hline $\mathrm{B} 10$ & $\begin{array}{c}\text { Bridge on the river Jaruga nearby Mračaj in } \\
\text { Imotski field }\end{array}$ & 72.240 & 75 \\
\hline B11 & Bridge at the quarry "Lavčević & 80.917 & 80 \\
\hline B12 & Žrnovački bridge & 89.254 & 90 \\
\hline B13 & Bridge over the river Jadro & 88.035 & 90 \\
\hline B14 & Bridge at the entrance to the factory "Majdan" & 79.176 & 80 \\
\hline B15 & Rera/Vetmin bridge & 73.871 & 75 \\
\hline B16 & Bridge on the river Grab & 78.817 & 80 \\
\hline B17 & Bridge on the river Kosinac & 87.833 & 90 \\
\hline B18 & Bridge Blato on the river Cetina & 59.649 & 60 \\
\hline B19 & Pavića bridge & 98.167 & 100 \\
\hline $\mathrm{B} 20$ & Bridge on Panj & 98.166 & 100 \\
\hline B21 & Balečki bridge & 98.184 & 100 \\
\hline
\end{tabular}

\section{Conclusions}

Given the complexity of the overall problems of assessing the condition of historic road bridges, a systematic analysis was performed, which resulted in the development of an expert system. The proposed model is a tool to improve and enhance the assessment of historic road bridges. The implementation of the expert system, using the proposed methodology, enables the involvement of all relevant experts in the assessment process and provides a precise and objective assessment of the condition of historic road bridges. For the model of the condition assessment of a historic road bridge, a fuzzy logic procedure was used, more precisely an FWGM approach based on obtaining a bridge rating using a fuzzy geometric mean and the centroid method. For the purpose of this model, data of each bridge were collected based on the visual expert assessment of the bridge elements. Thus, the component ratings (superstructure, substructure, and equipment) were obtained, which were then assigned relative importance using the AHP method, and the sum of the weighted component ratings gave the final bridge rating expressed as the HRBCAI value. This way, the assumption was proved that the newly formed expert system, with the collected adequate data and knowledge, provides outputs of the historic road bridges that the expert himself made. It has been proved that the results of the expert system are quite similar to the expert's assessments, and the formation of the system is not only practicable but also suitable.

A computer algorithm has been developed based on the proposed methodology for condition assessment through the rating of the bridges. From the obtained results it can 
be concluded that the methodology can handle a various number of bridges with all considered components, elements, and scales of rating. Thus, the proposed methodology would surely help the structural engineering experts and decision-makers concerned with the management of bridges to achieve a systematic and suitable judgment and to design a methodical approach for the recovery, rehabilitation, or demolition of the bridge in future years. Until now, no systematic approach has been developed for historic road bridges conditions assessment that includes a detailed evaluation of its elements throughout combinations of $\alpha$-cut sets. Historic road bridges assessment is not only important for infrastructure functionality and mechanical stability of the bridges, but also because of the cultural and environmental importance of these bridges.

In conclusion, it can be established that the proposed newly designed expert system for assessing the condition of historic road bridges is an efficient and adequate tool for experts and policy makers. The system is functional, adaptable, and can be easily upgraded as needed, providing objectivity to the assessment, and thus ensuring the quality of assessment which is provided by model validation. The implementation of the system itself is quite demanding and complex, however, at the same time, it ensures an organized and systematic implementation of the assessment of the current condition of historic road bridges in the SDC area. The result of the model, HRBCAI, will be used in future research as a criterion needed for the priority ranking of historic road bridges according to the activity of rehabilitation.

Author Contributions: Conceptualization, K.R., J.K.P. and N.J.; methodology, K.R., J.K.P. and N.J.; software, K.R., J.K.P. and N.J.; validation, K.R., J.K.P. and N.J.; formal analysis, K.R., J.K.P. and N.J.; investigation, K.R., J.K.P. and N.J.; resources, K.R., J.K.P. and N.J.; data curation, K.R., J.K.P. and N.J.; writing-original draft preparation, K.R., J.K.P. and N.J.; writing-review and editing, K.R., J.K.P. and N.J.; visualization, K.R., J.K.P. and N.J.; supervision, K.R., J.K.P. and N.J.; project administration, K.R., J.K.P. and N.J.; funding acquisition, K.R., J.K.P. and N.J. All authors have read and agreed to the published version of the manuscript.

Funding: This research is partially supported through project KK.01.1.1.02.0027, a project co-financed by the Croatian Government and the European Union through the European Regional Development Fund-the Competitiveness and Cohesion Operational Programme.

Institutional Review Board Statement: Not applicable.

Informed Consent Statement: Not applicable.

Data Availability Statement: Data available on request due to restrictions eg privacy or ethical. The data presented in this study are available on request from the corresponding author. The data are not publicly available due to further research to be published.

Conflicts of Interest: The authors declare no conflict of interest. 


\section{Appendix A}

Table A1. Combinations of all elements with fuzzy ratings and fuzzy structural importance (extended version of Table 5).

\begin{tabular}{|c|c|c|c|c|c|c|c|}
\hline \multirow{5}{*}{$\begin{array}{c}\text { No. of Combination } \\
1\end{array}$} & \multirow{5}{*}{$\begin{array}{c}\text { Element Combinations } \\
\mathrm{a} 1 \\
\mathrm{~b} 1 \\
\mathrm{c} 1 \\
\mathrm{~d} 1\end{array}$} & \multicolumn{3}{|c|}{ Fuzzy Rating } & \multicolumn{3}{|c|}{ Fuzzy Structural Importance } \\
\hline & & 60.0000 & 70.0000 & 80.0000 & 0.3000 & 0.5500 & 0.8000 \\
\hline & & 50.0000 & 60.0000 & 70.0000 & 0.6000 & 0.8500 & 1.0000 \\
\hline & & 60.0000 & 70.0000 & 80.0000 & 0.3000 & 0.5500 & 1.0000 \\
\hline & & 60.0000 & 70.0000 & 80.0000 & 0.3000 & 0.5500 & 0.1000 \\
\hline \multirow{4}{*}{2} & a1 & 60.0000 & 70.0000 & 80.0000 & 0.3000 & 0.5500 & 0.8000 \\
\hline & b1 & 50.0000 & 60.0000 & 70.0000 & 0.6000 & 0.8500 & 1.0000 \\
\hline & $\mathrm{c} 1$ & 60.0000 & 70.0000 & 80.0000 & 0.3000 & 0.5500 & 1.0000 \\
\hline & $\mathrm{d} 2$ & 70.0000 & 80.0000 & 90.0000 & 0.1500 & 0.4000 & 0.6500 \\
\hline \multirow{4}{*}{3} & a1 & 60.0000 & 70.0000 & 80.0000 & 0.3000 & 0.5500 & 0.8000 \\
\hline & b1 & 50.0000 & 60.0000 & 70.0000 & 0.6000 & 0.8500 & 1.0000 \\
\hline & c2 & 70.0000 & 80.0000 & 90.0000 & 0.1500 & 0.4000 & 0.6500 \\
\hline & $\mathrm{d} 1$ & 60.0000 & 70.0000 & 80.0000 & 0.3000 & 0.5500 & 0.1000 \\
\hline \multirow{4}{*}{4} & a1 & 60.0000 & 70.0000 & 80.0000 & 0.3000 & 0.5500 & 0.8000 \\
\hline & b1 & 50.0000 & 60.0000 & 70.0000 & 0.6000 & 0.8500 & 1.0000 \\
\hline & $\mathrm{c} 2$ & 70.0000 & 80.0000 & 90.0000 & 0.1500 & 0.4000 & 0.6500 \\
\hline & $\mathrm{d} 2$ & 70.0000 & 80.0000 & 90.0000 & 0.1500 & 0.4000 & 0.6500 \\
\hline \multirow{4}{*}{5} & a1 & 60.0000 & 70.0000 & 80.0000 & 0.3000 & 0.5500 & 0.8000 \\
\hline & b2 & 60.0000 & 70.0000 & 80.0000 & 0.3000 & 0.5500 & 0.8000 \\
\hline & c1 & 60.0000 & 70.0000 & 80.0000 & 0.3000 & 0.5500 & 1.0000 \\
\hline & $\mathrm{d} 1$ & 60.0000 & 70.0000 & 80.0000 & 0.3000 & 0.5500 & 0.1000 \\
\hline \multirow{4}{*}{6} & a1 & 60.0000 & 70.0000 & 80.0000 & 0.3000 & 0.5500 & 0.8000 \\
\hline & $\mathrm{b} 2$ & 60.0000 & 70.0000 & 80.0000 & 0.3000 & 0.5500 & 0.8000 \\
\hline & c1 & 60.0000 & 70.0000 & 80.0000 & 0.3000 & 0.5500 & 1.0000 \\
\hline & $\mathrm{d} 2$ & 70.0000 & 80.0000 & 90.0000 & 0.1500 & 0.4000 & 0.6500 \\
\hline \multirow{4}{*}{7} & a1 & 60.0000 & 70.0000 & 80.0000 & 0.3000 & 0.5500 & 0.8000 \\
\hline & b2 & 60.0000 & 70.0000 & 80.0000 & 0.3000 & 0.5500 & 0.8000 \\
\hline & c2 & 70.0000 & 80.0000 & 90.0000 & 0.1500 & 0.4000 & 0.6500 \\
\hline & $\mathrm{d} 1$ & 60.0000 & 70.0000 & 80.0000 & 0.3000 & 0.5500 & 0.1000 \\
\hline \multirow{4}{*}{8} & a1 & 60.0000 & 70.0000 & 80.0000 & 0.3000 & 0.5500 & 0.8000 \\
\hline & b2 & 60.0000 & 70.0000 & 80.0000 & 0.3000 & 0.5500 & 0.8000 \\
\hline & c2 & 70.0000 & 80.0000 & 90.0000 & 0.1500 & 0.4000 & 0.6500 \\
\hline & $\mathrm{d} 2$ & 70.0000 & 80.0000 & 90.0000 & 0.1500 & 0.4000 & 0.6500 \\
\hline \multirow{4}{*}{9} & a1 & 60.0000 & 70.0000 & 80.0000 & 0.3000 & 0.5500 & 0.8000 \\
\hline & b3 & 70.0000 & 80.0000 & 90.0000 & 0.1500 & 0.4000 & 0.6500 \\
\hline & $\mathrm{c} 1$ & 60.0000 & 70.0000 & 80.0000 & 0.3000 & 0.5500 & 1.0000 \\
\hline & $\mathrm{d} 1$ & 60.0000 & 70.0000 & 80.0000 & 0.3000 & 0.5500 & 0.1000 \\
\hline \multirow{4}{*}{10} & a1 & 60.0000 & 70.0000 & 80.0000 & 0.3000 & 0.5500 & 0.8000 \\
\hline & b3 & 70.0000 & 80.0000 & 90.0000 & 0.1500 & 0.4000 & 0.6500 \\
\hline & c1 & 60.0000 & 70.0000 & 80.0000 & 0.3000 & 0.5500 & 1.0000 \\
\hline & $\mathrm{d} 2$ & 70.0000 & 80.0000 & 90.0000 & 0.1500 & 0.4000 & 0.6500 \\
\hline \multirow{4}{*}{11} & a1 & 60.0000 & 70.0000 & 80.0000 & 0.3000 & 0.5500 & 0.8000 \\
\hline & b3 & 70.0000 & 80.0000 & 90.0000 & 0.1500 & 0.4000 & 0.6500 \\
\hline & c2 & 70.0000 & 80.0000 & 90.0000 & 0.1500 & 0.4000 & 0.6500 \\
\hline & $\mathrm{d} 1$ & 60.0000 & 70.0000 & 80.0000 & 0.3000 & 0.5500 & 0.1000 \\
\hline \multirow{4}{*}{12} & a1 & 60.0000 & 70.0000 & 80.0000 & 0.3000 & 0.5500 & 0.8000 \\
\hline & b3 & 70.0000 & 80.0000 & 90.0000 & 0.1500 & 0.4000 & 0.6500 \\
\hline & c2 & 70.0000 & 80.0000 & 90.0000 & 0.1500 & 0.4000 & 0.6500 \\
\hline & $\mathrm{d} 2$ & 70.0000 & 80.0000 & 90.0000 & 0.1500 & 0.4000 & 0.6500 \\
\hline
\end{tabular}


Table A1. Cont.

\begin{tabular}{|c|c|c|c|c|c|c|c|}
\hline \multirow{5}{*}{$\begin{array}{c}\text { No. of Combination } \\
13\end{array}$} & \multirow{5}{*}{$\begin{array}{c}\text { Element Combinations } \\
\mathrm{a} 2 \\
\mathrm{~b} 1 \\
\mathrm{c} 1 \\
\mathrm{~d} 1\end{array}$} & \multicolumn{3}{|c|}{ Fuzzy Rating } & \multicolumn{3}{|c|}{ Fuzzy Structural Importance } \\
\hline & & 70.0000 & 80.0000 & 90.0000 & 0.1500 & 0.4000 & 0.6500 \\
\hline & & 50.0000 & 60.0000 & 70.0000 & 0.6000 & 0.8500 & 1.0000 \\
\hline & & 60.0000 & 70.0000 & 80.0000 & 0.3000 & 0.5500 & 1.0000 \\
\hline & & 60.0000 & 70.0000 & 80.0000 & 0.3000 & 0.5500 & 0.1000 \\
\hline \multirow{4}{*}{14} & $\mathrm{a} 2$ & 70.0000 & 80.0000 & 90.0000 & 0.1500 & 0.4000 & 0.6500 \\
\hline & b1 & 50.0000 & 60.0000 & 70.0000 & 0.6000 & 0.8500 & 1.0000 \\
\hline & $\mathrm{c} 1$ & 60.0000 & 70.0000 & 80.0000 & 0.3000 & 0.5500 & 1.0000 \\
\hline & $\mathrm{d} 2$ & 70.0000 & 80.0000 & 90.0000 & 0.1500 & 0.4000 & 0.6500 \\
\hline \multirow{4}{*}{15} & a2 & 70.0000 & 80.0000 & 90.0000 & 0.1500 & 0.4000 & 0.6500 \\
\hline & b1 & 50.0000 & 60.0000 & 70.0000 & 0.6000 & 0.8500 & 1.0000 \\
\hline & c2 & 70.0000 & 80.0000 & 90.0000 & 0.1500 & 0.4000 & 0.6500 \\
\hline & $\mathrm{d} 1$ & 60.0000 & 70.0000 & 80.0000 & 0.3000 & 0.5500 & 0.1000 \\
\hline \multirow{4}{*}{16} & $\mathrm{a} 2$ & 70.0000 & 80.0000 & 90.0000 & 0.1500 & 0.4000 & 0.6500 \\
\hline & b1 & 50.0000 & 60.0000 & 70.0000 & 0.6000 & 0.8500 & 1.0000 \\
\hline & $\mathrm{c} 2$ & 70.0000 & 80.0000 & 90.0000 & 0.1500 & 0.4000 & 0.6500 \\
\hline & $\mathrm{d} 2$ & 70.0000 & 80.0000 & 90.0000 & 0.1500 & 0.4000 & 0.6500 \\
\hline \multirow{4}{*}{17} & $\mathrm{a} 2$ & 70.0000 & 80.0000 & 90.0000 & 0.1500 & 0.4000 & 0.6500 \\
\hline & $\mathrm{b} 2$ & 60.0000 & 70.0000 & 80.0000 & 0.3000 & 0.5500 & 0.8000 \\
\hline & c1 & 60.0000 & 70.0000 & 80.0000 & 0.3000 & 0.5500 & 1.0000 \\
\hline & d1 & 60.0000 & 70.0000 & 80.0000 & 0.3000 & 0.5500 & 0.1000 \\
\hline \multirow{4}{*}{18} & $\mathrm{a} 2$ & 70.0000 & 80.0000 & 90.0000 & 0.1500 & 0.4000 & 0.6500 \\
\hline & $\mathrm{b} 2$ & 60.0000 & 70.0000 & 80.0000 & 0.3000 & 0.5500 & 0.8000 \\
\hline & c1 & 60.0000 & 70.0000 & 80.0000 & 0.3000 & 0.5500 & 1.0000 \\
\hline & $\mathrm{d} 2$ & 70.0000 & 80.0000 & 90.0000 & 0.1500 & 0.4000 & 0.6500 \\
\hline \multirow{4}{*}{19} & $\mathrm{a} 2$ & 70.0000 & 80.0000 & 90.0000 & 0.1500 & 0.4000 & 0.6500 \\
\hline & $\mathrm{b} 2$ & 60.0000 & 70.0000 & 80.0000 & 0.3000 & 0.5500 & 0.8000 \\
\hline & c2 & 70.0000 & 80.0000 & 90.0000 & 0.1500 & 0.4000 & 0.6500 \\
\hline & $\mathrm{d} 1$ & 60.0000 & 70.0000 & 80.0000 & 0.3000 & 0.5500 & 0.1000 \\
\hline \multirow{4}{*}{20} & $\mathrm{a} 2$ & 70.0000 & 80.0000 & 90.0000 & 0.1500 & 0.4000 & 0.6500 \\
\hline & $\mathrm{b} 2$ & 60.0000 & 70.0000 & 80.0000 & 0.3000 & 0.5500 & 0.8000 \\
\hline & $\mathrm{c} 2$ & 70.0000 & 80.0000 & 90.0000 & 0.1500 & 0.4000 & 0.6500 \\
\hline & $\mathrm{d} 2$ & 70.0000 & 80.0000 & 90.0000 & 0.1500 & 0.4000 & 0.6500 \\
\hline \multirow{4}{*}{21} & $\mathrm{a} 2$ & 70.0000 & 80.0000 & 90.0000 & 0.1500 & 0.4000 & 0.6500 \\
\hline & b3 & 70.0000 & 80.0000 & 90.0000 & 0.1500 & 0.4000 & 0.6500 \\
\hline & $\mathrm{c} 1$ & 60.0000 & 70.0000 & 80.0000 & 0.3000 & 0.5500 & 1.0000 \\
\hline & $\mathrm{d} 1$ & 60.0000 & 70.0000 & 80.0000 & 0.3000 & 0.5500 & 0.1000 \\
\hline \multirow{4}{*}{22} & a2 & 70.0000 & 80.0000 & 90.0000 & 0.1500 & 0.4000 & 0.6500 \\
\hline & b3 & 70.0000 & 80.0000 & 90.0000 & 0.1500 & 0.4000 & 0.6500 \\
\hline & c1 & 60.0000 & 70.0000 & 80.0000 & 0.3000 & 0.5500 & 1.0000 \\
\hline & $\mathrm{d} 2$ & 70.0000 & 80.0000 & 90.0000 & 0.1500 & 0.4000 & 0.6500 \\
\hline \multirow{4}{*}{23} & $\mathrm{a} 2$ & 70.0000 & 80.0000 & 90.0000 & 0.1500 & 0.4000 & 0.6500 \\
\hline & b3 & 70.0000 & 80.0000 & 90.0000 & 0.1500 & 0.4000 & 0.6500 \\
\hline & $\mathrm{c} 2$ & 70.0000 & 80.0000 & 90.0000 & 0.1500 & 0.4000 & 0.6500 \\
\hline & $\mathrm{d} 1$ & 60.0000 & 70.0000 & 80.0000 & 0.3000 & 0.5500 & 0.1000 \\
\hline \multirow{4}{*}{24} & $\mathrm{a} 2$ & 70.0000 & 80.0000 & 90.0000 & 0.1500 & 0.4000 & 0.6500 \\
\hline & b3 & 70.0000 & 80.0000 & 90.0000 & 0.1500 & 0.4000 & 0.6500 \\
\hline & c2 & 70.0000 & 80.0000 & 90.0000 & 0.1500 & 0.4000 & 0.6500 \\
\hline & $\mathrm{d} 2$ & 70.0000 & 80.0000 & 90.0000 & 0.1500 & 0.4000 & 0.6500 \\
\hline
\end{tabular}


Table A2. The $\alpha$-cut sets of elements fuzzy ratings according to each combination (extended version of Table 6).

\begin{tabular}{|c|c|c|c|c|c|c|c|c|c|c|c|c|c|c|c|c|c|c|c|c|c|c|c|}
\hline \multirow[b]{4}{*}{$\begin{array}{c}\text { No. of } \\
\text { Combination }\end{array}$} & \multirow[b]{4}{*}{$\begin{array}{c}\text { Element } \\
\text { Combination }\end{array}$} & \multicolumn{22}{|c|}{ The Lower and Upper Boundary } \\
\hline & & \multicolumn{11}{|c|}{$\left(R_{E L}\right)_{\alpha}^{L}$} & \multicolumn{11}{|c|}{$\left(\boldsymbol{R}_{E L}\right)_{\alpha}^{U}$} \\
\hline & & \multicolumn{11}{|c|}{$\alpha$-Cut } & \multicolumn{11}{|c|}{$\alpha$-Cut } \\
\hline & & 0 & 0.1 & 0.2 & 0.3 & 0.4 & 0.5 & 0.6 & 0.7 & 0.8 & 0.9 & 1.0 & 1 & 0.9 & 0.8 & 0.7 & 0.6 & 0.5 & 0.4 & 0.3 & 0.2 & 0.1 & 0.0 \\
\hline \multirow{4}{*}{1} & a1 & 60 & 61 & 62 & 63 & 64 & 65 & 66 & 67 & 68 & 69 & 70 & 70 & 71 & 72 & 73 & 74 & 75 & 76 & 77 & 78 & 79 & 80 \\
\hline & $\mathrm{b} 1$ & 50 & 51 & 52 & 53 & 54 & 55 & 56 & 57 & 58 & 59 & 60 & 60 & 61 & 62 & 63 & 64 & 65 & 66 & 67 & 68 & 69 & 70 \\
\hline & $\mathrm{c} 1$ & 60 & 61 & 62 & 63 & 64 & 65 & 66 & 67 & 68 & 69 & 70 & 70 & 71 & 72 & 73 & 74 & 75 & 76 & 77 & 78 & 79 & 80 \\
\hline & $\mathrm{d} 1$ & 60 & 61 & 62 & 63 & 64 & 65 & 66 & 67 & 68 & 69 & 70 & 70 & 71 & 72 & 73 & 74 & 75 & 76 & 77 & 78 & 79 & 80 \\
\hline \multirow{4}{*}{2} & a1 & 60 & 61 & 62 & 63 & 64 & 65 & 66 & 67 & 68 & 69 & 70 & 70 & 71 & 72 & 73 & 74 & 75 & 76 & 77 & 78 & 79 & 80 \\
\hline & b1 & 50 & 51 & 52 & 53 & 54 & 55 & 56 & 57 & 58 & 59 & 60 & 60 & 61 & 62 & 63 & 64 & 65 & 66 & 67 & 68 & 69 & 70 \\
\hline & $\mathrm{c} 1$ & 60 & 61 & 62 & 63 & 64 & 65 & 66 & 67 & 68 & 69 & 70 & 70 & 71 & 72 & 73 & 74 & 75 & 76 & 77 & 78 & 79 & 80 \\
\hline & $\mathrm{d} 2$ & 70 & 71 & 72 & 73 & 74 & 75 & 76 & 77 & 78 & 79 & 80 & 80 & 81 & 82 & 83 & 84 & 85 & 86 & 87 & 88 & 89 & 90 \\
\hline \multirow{3}{*}{3} & a1 & 60 & 61 & 62 & 63 & 64 & 65 & 66 & 67 & 68 & 69 & 70 & 70 & 71 & 72 & 73 & 74 & 75 & 76 & 77 & 78 & 79 & 80 \\
\hline & b1 & 50 & 51 & 52 & 53 & 54 & 55 & 56 & 57 & 58 & 59 & 60 & 60 & 61 & 62 & 63 & 64 & 65 & 66 & 67 & 68 & 69 & 70 \\
\hline & c2 & 70 & 71 & 72 & 73 & 74 & 75 & 76 & 77 & 78 & 79 & 80 & 80 & 81 & 82 & 83 & 84 & 85 & 86 & 87 & 88 & 89 & 90 \\
\hline \multirow{4}{*}{4} & a1 & 60 & 61 & 62 & 63 & 64 & 65 & 66 & 67 & 68 & 69 & 70 & 70 & 71 & 72 & 73 & 74 & 75 & 76 & 77 & 78 & 79 & 80 \\
\hline & b1 & 50 & 51 & 52 & 53 & 54 & 55 & 56 & 57 & 58 & 59 & 60 & 60 & 61 & 62 & 63 & 64 & 65 & 66 & 67 & 68 & 69 & 70 \\
\hline & c2 & 70 & 71 & 72 & 73 & 74 & 75 & 76 & 77 & 78 & 79 & 80 & 80 & 81 & 82 & 83 & 84 & 85 & 86 & 87 & 88 & 89 & 90 \\
\hline & $\mathrm{d} 2$ & 70 & 71 & 72 & 73 & 74 & 75 & 76 & 77 & 78 & 79 & 80 & 80 & 81 & 82 & 83 & 84 & 85 & 86 & 87 & 88 & 89 & 90 \\
\hline \multirow{4}{*}{5} & $\mathrm{a} 1$ & 60 & 61 & 62 & 63 & 64 & 65 & 66 & 67 & 68 & 69 & 70 & 70 & 71 & 72 & 73 & 74 & 75 & 76 & 77 & 78 & 79 & 80 \\
\hline & b2 & 60 & 61 & 62 & 63 & 64 & 65 & 66 & 67 & 68 & 69 & 70 & 70 & 71 & 72 & 73 & 74 & 75 & 76 & 77 & 78 & 79 & 80 \\
\hline & c1 & 60 & 61 & 62 & 63 & 64 & 65 & 66 & 67 & 68 & 69 & 70 & 70 & 71 & 72 & 73 & 74 & 75 & 76 & 77 & 78 & 79 & 80 \\
\hline & $\mathrm{d} 1$ & 60 & 61 & 62 & 63 & 64 & 65 & 66 & 67 & 68 & 69 & 70 & 70 & 71 & 72 & 73 & 74 & 75 & 76 & 77 & 78 & 79 & 80 \\
\hline \multirow{4}{*}{6} & a1 & 60 & 61 & 62 & 63 & 64 & 65 & 66 & 67 & 68 & 69 & 70 & 70 & 71 & 72 & 73 & 74 & 75 & 76 & 77 & 78 & 79 & 80 \\
\hline & b2 & 60 & 61 & 62 & 63 & 64 & 65 & 66 & 67 & 68 & 69 & 70 & 70 & 71 & 72 & 73 & 74 & 75 & 76 & 77 & 78 & 79 & 80 \\
\hline & $\mathrm{c} 1$ & 60 & 61 & 62 & 63 & 64 & 65 & 66 & 67 & 68 & 69 & 70 & 70 & 71 & 72 & 73 & 74 & 75 & 76 & 77 & 78 & 79 & 80 \\
\hline & $\mathrm{d} 2$ & 70 & 71 & 72 & 73 & 74 & 75 & 76 & 77 & 78 & 79 & 80 & 80 & 81 & 82 & 83 & 84 & 85 & 86 & 87 & 88 & 89 & 90 \\
\hline \multirow{4}{*}{7} & a1 & 60 & 61 & 62 & 63 & 64 & 65 & 66 & 67 & 68 & 69 & 70 & 70 & 71 & 72 & 73 & 74 & 75 & 76 & 77 & 78 & 79 & 80 \\
\hline & b2 & 60 & 61 & 62 & 63 & 64 & 65 & 66 & 67 & 68 & 69 & 70 & 70 & 71 & 72 & 73 & 74 & 75 & 76 & 77 & 78 & 79 & 80 \\
\hline & c2 & 70 & 71 & 72 & 73 & 74 & 75 & 76 & 77 & 78 & 79 & 80 & 80 & 81 & 82 & 83 & 84 & 85 & 86 & 87 & 88 & 89 & 90 \\
\hline & $\mathrm{d} 1$ & 60 & 61 & 62 & 63 & 64 & 65 & 66 & 67 & 68 & 69 & 70 & 70 & 71 & 72 & 73 & 74 & 75 & 76 & 77 & 78 & 79 & 80 \\
\hline
\end{tabular}


Table A2. Cont.

\begin{tabular}{|c|c|c|c|c|c|c|c|c|c|c|c|c|c|c|c|c|c|c|c|c|c|c|c|}
\hline \multirow{3}{*}{$\begin{array}{c}\text { No. of } \\
\text { Combination }\end{array}$} & \multirow{3}{*}{$\begin{array}{c}\text { Element } \\
\text { Combination }\end{array}$} & \multicolumn{22}{|c|}{ The Lower and Upper Boundary } \\
\hline & & \multicolumn{11}{|c|}{$\left(\boldsymbol{R}_{E L}\right)_{\alpha}^{L}$} & \multicolumn{11}{|c|}{$\left(\boldsymbol{R}_{E L}\right)_{\alpha}^{U}$} \\
\hline & & \multicolumn{11}{|c|}{$\alpha-\mathrm{Cut}$} & \multicolumn{11}{|c|}{$\alpha$-Cut } \\
\hline \multirow{4}{*}{8} & a1 & 60 & 61 & 62 & 63 & 64 & 65 & 66 & 67 & 68 & 69 & 70 & 70 & 71 & 72 & 73 & 74 & 75 & 76 & 77 & 78 & 79 & 80 \\
\hline & $\mathrm{b} 2$ & 60 & 61 & 62 & 63 & 64 & 65 & 66 & 67 & 68 & 69 & 70 & 70 & 71 & 72 & 73 & 74 & 75 & 76 & 77 & 78 & 79 & 80 \\
\hline & $\mathrm{c} 2$ & 70 & 71 & 72 & 73 & 74 & 75 & 76 & 77 & 78 & 79 & 80 & 80 & 81 & 82 & 83 & 84 & 85 & 86 & 87 & 88 & 89 & 90 \\
\hline & $\mathrm{d} 2$ & 70 & 71 & 72 & 73 & 74 & 75 & 76 & 77 & 78 & 79 & 80 & 80 & 81 & 82 & 83 & 84 & 85 & 86 & 87 & 88 & 89 & 90 \\
\hline \multirow{4}{*}{9} & a1 & 60 & 61 & 62 & 63 & 64 & 65 & 66 & 67 & 68 & 69 & 70 & 70 & 71 & 72 & 73 & 74 & 75 & 76 & 77 & 78 & 79 & 80 \\
\hline & b3 & 70 & 71 & 72 & 73 & 74 & 75 & 76 & 77 & 78 & 79 & 80 & 80 & 81 & 82 & 83 & 84 & 85 & 86 & 87 & 88 & 89 & 90 \\
\hline & c1 & 60 & 61 & 62 & 63 & 64 & 65 & 66 & 67 & 68 & 69 & 70 & 70 & 71 & 72 & 73 & 74 & 75 & 76 & 77 & 78 & 79 & 80 \\
\hline & $\mathrm{d} 1$ & 60 & 61 & 62 & 63 & 64 & 65 & 66 & 67 & 68 & 69 & 70 & 70 & 71 & 72 & 73 & 74 & 75 & 76 & 77 & 78 & 79 & 80 \\
\hline \multirow{4}{*}{10} & a1 & 60 & 61 & 62 & 63 & 64 & 65 & 66 & 67 & 68 & 69 & 70 & 70 & 71 & 72 & 73 & 74 & 75 & 76 & 77 & 78 & 79 & 80 \\
\hline & b3 & 70 & 71 & 72 & 73 & 74 & 75 & 76 & 77 & 78 & 79 & 80 & 80 & 81 & 82 & 83 & 84 & 85 & 86 & 87 & 88 & 89 & 90 \\
\hline & c1 & 60 & 61 & 62 & 63 & 64 & 65 & 66 & 67 & 68 & 69 & 70 & 70 & 71 & 72 & 73 & 74 & 75 & 76 & 77 & 78 & 79 & 80 \\
\hline & $\mathrm{d} 2$ & 70 & 71 & 72 & 73 & 74 & 75 & 76 & 77 & 78 & 79 & 80 & 80 & 81 & 82 & 83 & 84 & 85 & 86 & 87 & 88 & 89 & 90 \\
\hline \multirow{3}{*}{11} & b3 & 70 & 71 & 72 & 73 & 74 & 75 & 76 & 77 & 78 & 79 & 80 & 80 & 81 & 82 & 83 & 84 & 85 & 86 & 87 & 88 & 89 & 90 \\
\hline & c2 & 70 & 71 & 72 & 73 & 74 & 75 & 76 & 77 & 78 & 79 & 80 & 80 & 81 & 82 & 83 & 84 & 85 & 86 & 87 & 88 & 89 & 90 \\
\hline & $\mathrm{d} 1$ & 60 & 61 & 62 & 63 & 64 & 65 & 66 & 67 & 68 & 69 & 70 & 70 & 71 & 72 & 73 & 74 & 75 & 76 & 77 & 78 & 79 & 80 \\
\hline \multirow{4}{*}{12} & a1 & 60 & 61 & 62 & 63 & 64 & 65 & 66 & 67 & 68 & 69 & 70 & 70 & 71 & 72 & 73 & 74 & 75 & 76 & 77 & 78 & 79 & 80 \\
\hline & b3 & 70 & 71 & 72 & 73 & 74 & 75 & 76 & 77 & 78 & 79 & 80 & 80 & 81 & 82 & 83 & 84 & 85 & 86 & 87 & 88 & 89 & 90 \\
\hline & c2 & 70 & 71 & 72 & 73 & 74 & 75 & 76 & 77 & 78 & 79 & 80 & 80 & 81 & 82 & 83 & 84 & 85 & 86 & 87 & 88 & 89 & 90 \\
\hline & $\mathrm{d} 2$ & 70 & 71 & 72 & 73 & 74 & 75 & 76 & 77 & 78 & 79 & 80 & 80 & 81 & 82 & 83 & 84 & 85 & 86 & 87 & 88 & 89 & 90 \\
\hline \multirow{4}{*}{13} & a2 & 70 & 71 & 72 & 73 & 74 & 75 & 76 & 77 & 78 & 79 & 80 & 80 & 81 & 82 & 83 & 84 & 85 & 86 & 87 & 88 & 89 & 90 \\
\hline & b1 & 50 & 51 & 52 & 53 & 54 & 55 & 56 & 57 & 58 & 59 & 60 & 60 & 61 & 62 & 63 & 64 & 65 & 66 & 67 & 68 & 69 & 70 \\
\hline & $\mathrm{c} 1$ & 60 & 61 & 62 & 63 & 64 & 65 & 66 & 67 & 68 & 69 & 70 & 70 & 71 & 72 & 73 & 74 & 75 & 76 & 77 & 78 & 79 & 80 \\
\hline & $\mathrm{d} 1$ & 60 & 61 & 62 & 63 & 64 & 65 & 66 & 67 & 68 & 69 & 70 & 70 & 71 & 72 & 73 & 74 & 75 & 76 & 77 & 78 & 79 & 80 \\
\hline \multirow{4}{*}{14} & a2 & 70 & 71 & 72 & 73 & 74 & 75 & 76 & 77 & 78 & 79 & 80 & 80 & 81 & 82 & 83 & 84 & 85 & 86 & 87 & 88 & 89 & 90 \\
\hline & b1 & 50 & 51 & 52 & 53 & 54 & 55 & 56 & 57 & 58 & 59 & 60 & 60 & 61 & 62 & 63 & 64 & 65 & 66 & 67 & 68 & 69 & 70 \\
\hline & c1 & 60 & 61 & 62 & 63 & 64 & 65 & 66 & 67 & 68 & 69 & 70 & 70 & 71 & 72 & 73 & 74 & 75 & 76 & 77 & 78 & 79 & 80 \\
\hline & $\mathrm{d} 2$ & 70 & 71 & 72 & 73 & 74 & 75 & 76 & 77 & 78 & 79 & 80 & 80 & 81 & 82 & 83 & 84 & 85 & 86 & 87 & 88 & 89 & 90 \\
\hline
\end{tabular}


Table A2. Cont.

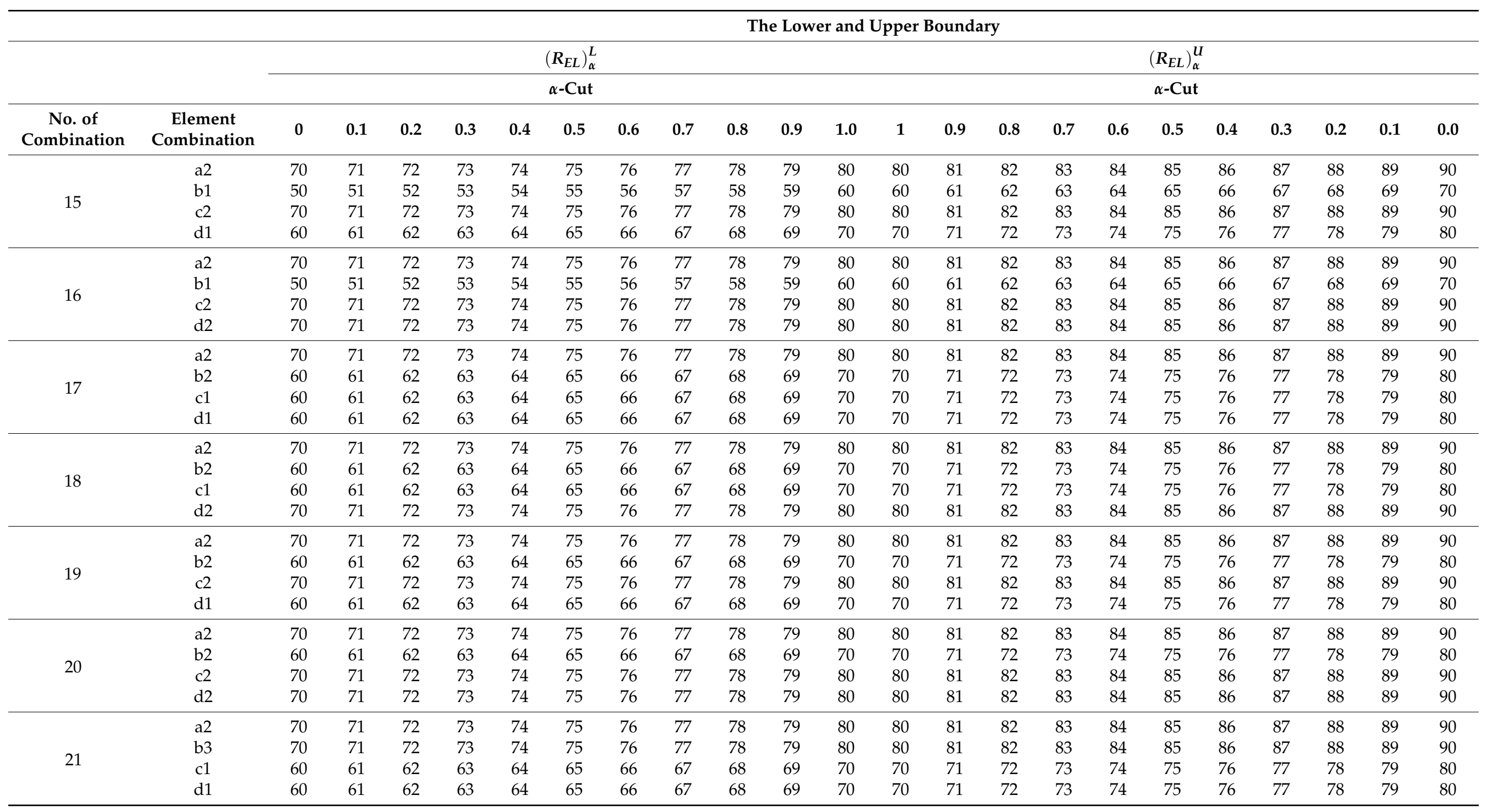


Table A2. Cont.

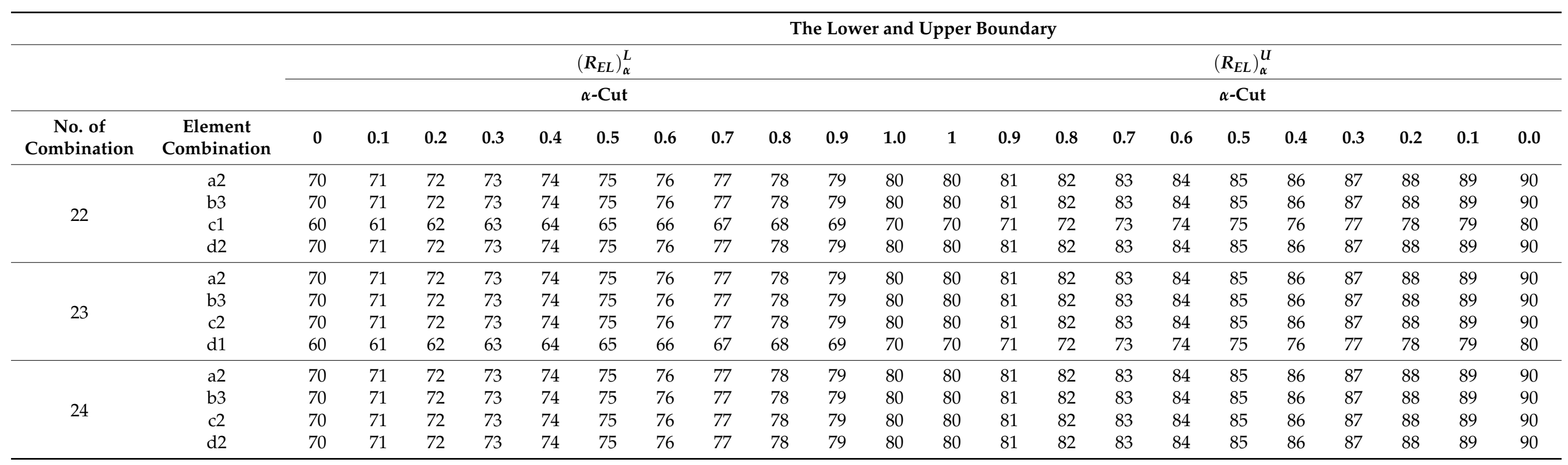

Table A3. The $\alpha$-cut sets of elements fuzzy structural importance according to each combination (extended version of Table 7).

\begin{tabular}{|c|c|c|c|c|c|c|c|c|c|c|c|c|c|}
\hline & & Boundary & & & & & & $\alpha-$ Cut & & & & & \\
\hline \multirow{2}{*}{$\begin{array}{c}\text { No. of } \\
\text { Combination }\end{array}$} & \multirow{2}{*}{$\begin{array}{c}\text { Element } \\
\text { Combination }\end{array}$} & $\left(w_{E L}\right)_{\alpha}^{L}$ & 0 & 0.1 & 0.2 & 0.3 & 0.4 & 0.5 & 0.6 & 0.7 & 0.8 & 0.9 & 1 \\
\hline & & $\left(w_{E L}\right)_{\alpha}^{U}$ & 1 & 0.9 & 0.8 & 0.7 & 0.6 & 0.5 & 0.4 & 0.3 & 0.2 & 0.1 & 0 \\
\hline \multirow{8}{*}{1} & a1 & \multirow{4}{*}{$\left(w_{E L}\right)_{\alpha}^{L}$} & 0.3000 & 0.3250 & 0.3500 & 0.3750 & 0.4000 & 0.4250 & 0.4500 & 0.4750 & 0.5000 & 0.5250 & 0.5500 \\
\hline & b1 & & 0.6000 & 0.6250 & 0.6500 & 0.6750 & 0.7000 & 0.7250 & 0.7500 & 0.7750 & 0.8000 & 0.8250 & 0.8500 \\
\hline & c1 & & 0.3000 & 0.3250 & 0.3500 & 0.3750 & 0.4000 & 0.4250 & 0.4500 & 0.4750 & 0.5000 & 0.5250 & 0.5500 \\
\hline & $\mathrm{d} 1$ & & 0.300 & 0.3250 & 0.3500 & 0.3750 & 0.4000 & 0.4250 & 0.4500 & 0.4750 & 0.5000 & 0.5250 & 0.5500 \\
\hline & a1 & \multirow{4}{*}{$\left(w_{E L}\right)_{\alpha}^{U}$} & 0.5500 & 0.5750 & 0.6000 & 0.6250 & 0.6500 & 0.6750 & 0.7000 & 0.7250 & 0.7500 & 0.7750 & 0.8000 \\
\hline & b1 & & 0.8500 & 0.8650 & 0.8800 & 0.8950 & 0.9100 & 0.9250 & 0.940 & 0.9550 & 0.970 & 0.9850 & 1.000 \\
\hline & $\mathrm{c} 1$ & & 0.5500 & 0.5950 & 0.6400 & 0.6850 & 0.7300 & 0.7750 & 0.8200 & 0.8650 & 0.9100 & 0.9550 & 1.0000 \\
\hline & $\mathrm{d} 1$ & & 0.5500 & 0.5050 & 0.4600 & 0.4150 & 0.3700 & 0.3250 & 0.2800 & 0.2350 & 0.190 & 0.1450 & 0.1000 \\
\hline
\end{tabular}


Table A3. Cont.

\begin{tabular}{|c|c|c|c|c|c|c|c|c|c|c|c|c|c|}
\hline \multirow{3}{*}{$\begin{array}{c}\text { No. of } \\
\text { Combination }\end{array}$} & \multirow{3}{*}{$\begin{array}{c}\text { Element } \\
\text { Combination }\end{array}$} & \multirow{2}{*}{$\begin{array}{c}\text { Boundary } \\
\left(w_{E L}\right)_{\alpha}^{L}\end{array}$} & \multicolumn{11}{|c|}{$\alpha-\mathrm{Cut}$} \\
\hline & & & 0 & 0.1 & 0.2 & 0.3 & 0.4 & 0.5 & 0.6 & 0.7 & 0.8 & 0.9 & 1 \\
\hline & & $\left(w_{E L}\right)_{\alpha}^{U}$ & 1 & 0.9 & 0.8 & 0.7 & 0.6 & 0.5 & 0.4 & 0.3 & 0.2 & 0.1 & 0 \\
\hline \multirow{7}{*}{2} & $\mathrm{~b} 1$ & \multirow{3}{*}{$\left(w_{E L}\right)_{\alpha}^{L}$} & 0.6000 & 0.6250 & 0.6500 & 0.6750 & 0.7000 & 0.7250 & 0.7500 & 0.7750 & 0.8000 & 0.8250 & 0.8500 \\
\hline & $\mathrm{c} 1$ & & 0.3000 & 0.3250 & 0.3500 & 0.3750 & 0.4000 & 0.4250 & 0.4500 & 0.4750 & 0.5000 & 0.5250 & 0.5500 \\
\hline & $\mathrm{d} 2$ & & 0.1500 & 0.1750 & 0.2000 & 0.2250 & 0.2500 & 0.2750 & 0.3000 & 0.3250 & 0.3500 & 0.3750 & 0.4000 \\
\hline & a1 & \multirow{4}{*}{$\left(w_{E L}\right)_{\alpha}^{U}$} & 0.5500 & 0.5750 & 0.6000 & 0.6250 & 0.6500 & 0.6750 & 0.7000 & 0.7250 & 0.7500 & 0.7750 & 0.8000 \\
\hline & b1 & & 0.8500 & 0.8650 & 0.8800 & 0.8950 & 0.9100 & 0.9250 & 0.9400 & 0.9550 & 0.9700 & 0.9850 & 1.0000 \\
\hline & $\mathrm{c} 1$ & & 0.5500 & 0.5950 & 0.6400 & 0.6850 & 0.7300 & 0.7750 & 0.8200 & 0.8650 & 0.9100 & 0.9550 & 1.0000 \\
\hline & $\mathrm{d} 2$ & & 0.4000 & 0.4250 & 0.4500 & 0.4750 & 0.5000 & 0.5250 & 0.5500 & 0.5750 & 0.6000 & 0.6250 & 0.6500 \\
\hline \multirow{7}{*}{3} & a1 & \multirow{4}{*}{$\left(w_{E L}\right)_{\alpha}^{L}$} & 0.3000 & 0.3250 & 0.3500 & 0.3750 & 0.4000 & 0.4250 & 0.4500 & 0.4750 & 0.5000 & 0.5250 & 0.5500 \\
\hline & $\mathrm{b} 1$ & & 0.6000 & 0.6250 & 0.6500 & 0.6750 & 0.7000 & 0.7250 & 0.7500 & 0.7750 & 0.8000 & 0.8250 & 0.8500 \\
\hline & c2 & & 0.1500 & 0.1750 & 0.2000 & 0.2250 & 0.2500 & 0.2750 & 0.3000 & 0.3250 & 0.3500 & 0.3750 & 0.4000 \\
\hline & $\mathrm{d} 1$ & & 0.3000 & 0.3250 & 0.3500 & 0.3750 & 0.4000 & 0.4250 & 0.4500 & 0.4750 & 0.5000 & 0.5250 & 0.5500 \\
\hline & a1 & \multirow{3}{*}{$\left(w_{E L}\right)_{\alpha}^{U}$} & 0.5500 & 0.5750 & 0.6000 & 0.6250 & 0.6500 & 0.6750 & 0.7000 & 0.7250 & 0.7500 & 0.7750 & 0.8000 \\
\hline & $\mathrm{b} 1$ & & 0.8500 & 0.8650 & 0.8800 & 0.8950 & 0.9100 & 0.9250 & 0.9400 & 0.9550 & 0.9700 & 0.9850 & 1.0000 \\
\hline & $\mathrm{d} 1$ & & 0.5500 & 0.5050 & 0.4600 & 0.4150 & 0.3700 & 0.3250 & 0.2800 & 0.2350 & 0.1900 & 0.1450 & 0.1000 \\
\hline \multirow{8}{*}{4} & a1 & \multirow{4}{*}{$\left(w_{E L}\right)_{\alpha}^{L}$} & 0.3000 & 0.3250 & 0.3500 & 0.3750 & 0.4000 & 0.4250 & 0.4500 & 0.4750 & 0.5000 & 0.5250 & 0.5500 \\
\hline & b1 & & 0.6000 & 0.6250 & 0.6500 & 0.6750 & 0.7000 & 0.7250 & 0.7500 & 0.7750 & 0.8000 & 0.8250 & 0.8500 \\
\hline & c2 & & 0.1500 & 0.1750 & 0.2000 & 0.2250 & 0.2500 & 0.2750 & 0.3000 & 0.3250 & 0.3500 & 0.3750 & 0.4000 \\
\hline & $\mathrm{d} 2$ & & 0.1500 & 0.1750 & 0.2000 & 0.2250 & 0.2500 & 0.2750 & 0.3000 & 0.3250 & 0.3500 & 0.3750 & 0.4000 \\
\hline & a1 & \multirow{4}{*}{$\left(w_{E L}\right)_{\alpha}^{U}$} & 0.5500 & 0.5750 & 0.6000 & 0.6250 & 0.6500 & 0.6750 & 0.7000 & 0.7250 & 0.7500 & 0.7750 & 0.8000 \\
\hline & $\mathrm{b} 1$ & & 0.8500 & 0.8650 & 0.8800 & 0.8950 & 0.9100 & 0.9250 & 0.9400 & 0.9550 & 0.9700 & 0.9850 & 1.0000 \\
\hline & c2 & & 0.4000 & 0.4250 & 0.4500 & 0.4750 & 0.5000 & 0.5250 & 0.5500 & 0.5750 & 0.6000 & 0.6250 & 0.6500 \\
\hline & $\mathrm{d} 2$ & & 0.4000 & 0.4250 & 0.4500 & 0.4750 & 0.5000 & 0.5250 & 0.5500 & 0.5750 & 0.6000 & 0.6250 & 0.6500 \\
\hline \multirow{4}{*}{5} & a1 & \multirow{4}{*}{$\left(w_{E L}\right)_{\alpha}^{L}$} & 0.3000 & 0.3250 & 0.3500 & 0.3750 & 0.4000 & 0.4250 & 0.4500 & 0.4750 & 0.5000 & 0.5250 & 0.5500 \\
\hline & b2 & & 0.3000 & 0.3250 & 0.3500 & 0.3750 & 0.4000 & 0.4250 & 0.4500 & 0.4750 & 0.5000 & 0.5250 & 0.5500 \\
\hline & $\mathrm{c} 1$ & & 0.3000 & 0.3250 & 0.3500 & 0.3750 & 0.4000 & 0.4250 & 0.4500 & 0.4750 & 0.5000 & 0.5250 & 0.5500 \\
\hline & $\mathrm{d} 1$ & & 0.3000 & 0.3250 & 0.3500 & 0.3750 & 0.4000 & 0.4250 & 0.4500 & 0.4750 & 0.5000 & 0.5250 & 0.5500 \\
\hline
\end{tabular}


Table A3. Cont.

\begin{tabular}{|c|c|c|c|c|c|c|c|c|c|c|c|c|c|}
\hline \multirow{3}{*}{$\begin{array}{c}\text { No. of } \\
\text { Combination }\end{array}$} & \multirow{3}{*}{$\begin{array}{c}\text { Element } \\
\text { Combination }\end{array}$} & \multirow{2}{*}{$\begin{array}{c}\text { Boundary } \\
\left(w_{E L}\right)_{\alpha}^{L}\end{array}$} & \multicolumn{11}{|c|}{$\alpha$-Cut } \\
\hline & & & 0 & 0.1 & 0.2 & 0.3 & 0.4 & 0.5 & 0.6 & 0.7 & 0.8 & 0.9 & 1 \\
\hline & & $\left(w_{E L}\right)_{\alpha}^{U}$ & 1 & 0.9 & 0.8 & 0.7 & 0.6 & 0.5 & 0.4 & 0.3 & 0.2 & 0.1 & 0 \\
\hline & $\mathrm{b} 2$ & & 0.5500 & 0.5750 & 0.6000 & 0.6250 & 0.6500 & 0.6750 & 0.7000 & 0.7250 & 0.7500 & 0.7750 & 0.8000 \\
\hline & $\mathrm{c} 1$ & $\left(w_{E L}\right)_{\alpha}$ & 0.5500 & 0.5950 & 0.6400 & 0.6850 & 0.7300 & 0.7750 & 0.8200 & 0.8650 & 0.9100 & 0.9550 & 1.0000 \\
\hline & $\mathrm{d} 1$ & & 0.5500 & 0.5050 & 0.4600 & 0.4150 & 0.3700 & 0.3250 & 0.2800 & 0.2350 & 0.1900 & 0.1450 & 0.1000 \\
\hline \multirow{8}{*}{6} & a1 & \multirow{4}{*}{$\left(w_{E L}\right)_{\alpha}^{L}$} & 0.3000 & 0.3250 & 0.3500 & 0.3750 & 0.4000 & 0.4250 & 0.4500 & 0.4750 & 0.5000 & 0.5250 & 0.5500 \\
\hline & $\mathrm{b} 2$ & & 0.3000 & 0.3250 & 0.3500 & 0.3750 & 0.4000 & 0.4250 & 0.4500 & 0.4750 & 0.5000 & 0.5250 & 0.5500 \\
\hline & c1 & & 0.3000 & 0.3250 & 0.3500 & 0.3750 & 0.4000 & 0.4250 & 0.4500 & 0.4750 & 0.5000 & 0.5250 & 0.5500 \\
\hline & $\mathrm{d} 2$ & & 0.1500 & 0.1750 & 0.2000 & 0.2250 & 0.2500 & 0.2750 & 0.3000 & 0.3250 & 0.3500 & 0.3750 & 0.4000 \\
\hline & a1 & \multirow{4}{*}{$\left(w_{E L}\right)_{\alpha}^{U}$} & 0.5500 & 0.5750 & 0.6000 & 0.6250 & 0.6500 & 0.6750 & 0.7000 & 0.7250 & 0.7500 & 0.7750 & 0.8000 \\
\hline & $\mathrm{b} 2$ & & 0.5500 & 0.5750 & 0.6000 & 0.6250 & 0.6500 & 0.6750 & 0.7000 & 0.7250 & 0.7500 & 0.7750 & 0.8000 \\
\hline & $\mathrm{c} 1$ & & 0.5500 & 0.5950 & 0.6400 & 0.6850 & 0.7300 & 0.7750 & 0.8200 & 0.8650 & 0.9100 & 0.9550 & 1.0000 \\
\hline & $\mathrm{d} 2$ & & 0.4000 & 0.4250 & 0.4500 & 0.4750 & 0.5000 & 0.5250 & 0.5500 & 0.5750 & 0.6000 & 0.6250 & 0.6500 \\
\hline \multirow{7}{*}{7} & a1 & \multirow{3}{*}{$\left(w_{E L}\right)_{\alpha}^{L}$} & 0.3000 & 0.3250 & 0.3500 & 0.3750 & 0.4000 & 0.4250 & 0.4500 & 0.4750 & 0.5000 & 0.5250 & 0.5500 \\
\hline & b2 & & 0.3000 & 0.3250 & 0.3500 & 0.3750 & 0.4000 & 0.4250 & 0.4500 & 0.4750 & 0.5000 & 0.5250 & 0.5500 \\
\hline & $\mathrm{d} 1$ & & 0.3000 & 0.3250 & 0.3500 & 0.3750 & 0.4000 & 0.4250 & 0.4500 & 0.4750 & 0.5000 & 0.5250 & 0.5500 \\
\hline & a1 & \multirow{4}{*}{$\left(w_{E L}\right)_{\alpha}^{U}$} & 0.5500 & 0.5750 & 0.6000 & 0.6250 & 0.6500 & 0.6750 & 0.7000 & 0.7250 & 0.7500 & 0.7750 & 0.8000 \\
\hline & b2 & & 0.5500 & 0.5750 & 0.6000 & 0.6250 & 0.6500 & 0.6750 & 0.7000 & 0.7250 & 0.7500 & 0.7750 & 0.8000 \\
\hline & c2 & & 0.4000 & 0.4250 & 0.4500 & 0.4750 & 0.5000 & 0.5250 & 0.5500 & 0.5750 & 0.6000 & 0.6250 & 0.6500 \\
\hline & $\mathrm{d} 1$ & & 0.5500 & 0.5050 & 0.4600 & 0.4150 & 0.3700 & 0.3250 & 0.2800 & 0.2350 & 0.1900 & 0.1450 & 0.1000 \\
\hline \multirow{8}{*}{8} & a1 & \multirow{4}{*}{$\left(w_{E L}\right)_{\alpha}^{L}$} & 0.3000 & 0.3250 & 0.3500 & 0.3750 & 0.4000 & 0.4250 & 0.4500 & 0.4750 & 0.5000 & 0.5250 & 0.5500 \\
\hline & b2 & & 0.3000 & 0.3250 & 0.3500 & 0.3750 & 0.4000 & 0.4250 & 0.4500 & 0.4750 & 0.5000 & 0.5250 & 0.5500 \\
\hline & c2 & & 0.1500 & 0.1750 & 0.2000 & 0.2250 & 0.2500 & 0.2750 & 0.3000 & 0.3250 & 0.3500 & 0.3750 & 0.4000 \\
\hline & $\mathrm{d} 2$ & & 0.1500 & 0.1750 & 0.2000 & 0.2250 & 0.2500 & 0.2750 & 0.3000 & 0.3250 & 0.3500 & 0.3750 & 0.4000 \\
\hline & a1 & \multirow{4}{*}{$\left(w_{E L}\right)_{\alpha}^{U}$} & 0.5500 & 0.5750 & 0.6000 & 0.6250 & 0.6500 & 0.6750 & 0.7000 & 0.7250 & 0.7500 & 0.7750 & 0.8000 \\
\hline & b2 & & 0.5500 & 0.5750 & 0.6000 & 0.6250 & 0.6500 & 0.6750 & 0.7000 & 0.7250 & 0.7500 & 0.7750 & 0.8000 \\
\hline & $\mathrm{c} 2$ & & 0.4000 & 0.4250 & 0.4500 & 0.4750 & 0.5000 & 0.5250 & 0.5500 & 0.5750 & 0.6000 & 0.6250 & 0.6500 \\
\hline & $\mathrm{d} 2$ & & 0.4000 & 0.4250 & 0.4500 & 0.4750 & 0.5000 & 0.5250 & 0.5500 & 0.5750 & 0.6000 & 0.6250 & 0.6500 \\
\hline
\end{tabular}


Table A3. Cont.

\begin{tabular}{|c|c|c|c|c|c|c|c|c|c|c|c|c|c|}
\hline \multirow{3}{*}{$\begin{array}{c}\text { No. of } \\
\text { Combination }\end{array}$} & \multirow{3}{*}{$\begin{array}{c}\text { Element } \\
\text { Combination }\end{array}$} & \multirow{2}{*}{$\begin{array}{c}\text { Boundary } \\
\left(w_{E L}\right)_{\alpha}^{L}\end{array}$} & \multicolumn{11}{|c|}{$\alpha-\mathrm{Cut}$} \\
\hline & & & 0 & 0.1 & 0.2 & 0.3 & 0.4 & 0.5 & 0.6 & 0.7 & 0.8 & 0.9 & 1 \\
\hline & & $\left(w_{E L}\right)_{\alpha}^{U}$ & 1 & 0.9 & 0.8 & 0.7 & 0.6 & 0.5 & 0.4 & 0.3 & 0.2 & 0.1 & 0 \\
\hline \multirow{7}{*}{9} & b3 & \multirow{3}{*}{$\left(w_{E L}\right)_{\alpha}^{L}$} & 0.1500 & 0.1750 & 0.2000 & 0.2250 & 0.2500 & 0.2750 & 0.3000 & 0.3250 & 0.3500 & 0.3750 & 0.4000 \\
\hline & $\mathrm{c} 1$ & & 0.3000 & 0.3250 & 0.3500 & 0.3750 & 0.4000 & 0.4250 & 0.4500 & 0.4750 & 0.5000 & 0.5250 & 0.5500 \\
\hline & $\mathrm{d} 1$ & & 0.3000 & 0.3250 & 0.3500 & 0.3750 & 0.4000 & 0.4250 & 0.4500 & 0.4750 & 0.5000 & 0.5250 & 0.5500 \\
\hline & a1 & \multirow{4}{*}{$\left(w_{E L}\right)_{\alpha}^{U}$} & 0.5500 & 0.5750 & 0.6000 & 0.6250 & 0.6500 & 0.6750 & 0.7000 & 0.7250 & 0.7500 & 0.7750 & 0.8000 \\
\hline & b3 & & 0.4000 & 0.4250 & 0.4500 & 0.4750 & 0.5000 & 0.5250 & 0.5500 & 0.5750 & 0.6000 & 0.6250 & 0.6500 \\
\hline & $\mathrm{c} 1$ & & 0.5500 & 0.5950 & 0.6400 & 0.6850 & 0.7300 & 0.7750 & 0.8200 & 0.8650 & 0.9100 & 0.9550 & 1.0000 \\
\hline & $\mathrm{d} 1$ & & 0.5500 & 0.5050 & 0.4600 & 0.4150 & 0.3700 & 0.3250 & 0.2800 & 0.2350 & 0.1900 & 0.1450 & 0.1000 \\
\hline \multirow{7}{*}{10} & a1 & \multirow{4}{*}{$\left(w_{E L}\right)_{\alpha}^{L}$} & 0.3000 & 0.3250 & 0.3500 & 0.3750 & 0.4000 & 0.4250 & 0.4500 & 0.4750 & 0.5000 & 0.5250 & 0.5500 \\
\hline & b3 & & 0.1500 & 0.1750 & 0.2000 & 0.2250 & 0.2500 & 0.2750 & 0.3000 & 0.3250 & 0.3500 & 0.3750 & 0.4000 \\
\hline & c1 & & 0.3000 & 0.3250 & 0.3500 & 0.3750 & 0.4000 & 0.4250 & 0.4500 & 0.4750 & 0.5000 & 0.5250 & 0.5500 \\
\hline & $\mathrm{d} 2$ & & 0.1500 & 0.1750 & 0.2000 & 0.2250 & 0.2500 & 0.2750 & 0.3000 & 0.3250 & 0.3500 & 0.3750 & 0.4000 \\
\hline & a1 & \multirow{3}{*}{$\left(w_{E L}\right)_{\alpha}^{U}$} & 0.5500 & 0.5750 & 0.6000 & 0.6250 & 0.6500 & 0.6750 & 0.7000 & 0.7250 & 0.7500 & 0.7750 & 0.8000 \\
\hline & b3 & & 0.4000 & 0.4250 & 0.4500 & 0.4750 & 0.5000 & 0.5250 & 0.5500 & 0.5750 & 0.6000 & 0.6250 & 0.6500 \\
\hline & $\mathrm{d} 2$ & & 0.4000 & 0.4250 & 0.4500 & 0.4750 & 0.5000 & 0.5250 & 0.5500 & 0.5750 & 0.6000 & 0.6250 & 0.6500 \\
\hline \multirow{8}{*}{11} & a1 & \multirow{4}{*}{$\left(w_{E L}\right)_{\alpha}^{L}$} & 0.3000 & 0.3250 & 0.3500 & 0.3750 & 0.4000 & 0.4250 & 0.4500 & 0.4750 & 0.5000 & 0.5250 & 0.5500 \\
\hline & b3 & & 0.1500 & 0.1750 & 0.2000 & 0.2250 & 0.2500 & 0.2750 & 0.3000 & 0.3250 & 0.3500 & 0.3750 & 0.4000 \\
\hline & $c 2$ & & 0.1500 & 0.1750 & 0.2000 & 0.2250 & 0.2500 & 0.2750 & 0.3000 & 0.3250 & 0.3500 & 0.3750 & 0.4000 \\
\hline & $\mathrm{d} 1$ & & 0.3000 & 0.3250 & 0.3500 & 0.3750 & 0.4000 & 0.4250 & 0.4500 & 0.4750 & 0.5000 & 0.5250 & 0.5500 \\
\hline & a1 & \multirow{4}{*}{$\left(w_{E L}\right)_{\alpha}^{U}$} & 0.5500 & 0.5750 & 0.6000 & 0.6250 & 0.6500 & 0.6750 & 0.7000 & 0.7250 & 0.7500 & 0.7750 & 0.8000 \\
\hline & b3 & & 0.4000 & 0.4250 & 0.4500 & 0.4750 & 0.5000 & 0.5250 & 0.5500 & 0.5750 & 0.6000 & 0.6250 & 0.6500 \\
\hline & c2 & & 0.4000 & 0.4250 & 0.4500 & 0.4750 & 0.5000 & 0.5250 & 0.5500 & 0.5750 & 0.6000 & 0.6250 & 0.6500 \\
\hline & $\mathrm{d} 1$ & & 0.5500 & 0.5050 & 0.4600 & 0.4150 & 0.3700 & 0.3250 & 0.2800 & 0.2350 & 0.1900 & 0.1450 & 0.1000 \\
\hline \multirow{4}{*}{12} & a1 & \multirow{4}{*}{$\left(w_{E L}\right)_{\alpha}^{L}$} & 0.3000 & 0.3250 & 0.3500 & 0.3750 & 0.4000 & 0.4250 & 0.4500 & 0.4750 & 0.5000 & 0.5250 & 0.5500 \\
\hline & b3 & & 0.1500 & 0.1750 & 0.2000 & 0.2250 & 0.2500 & 0.2750 & 0.3000 & 0.3250 & 0.3500 & 0.3750 & 0.4000 \\
\hline & $\mathrm{c} 2$ & & 0.1500 & 0.1750 & 0.2000 & 0.2250 & 0.2500 & 0.2750 & 0.3000 & 0.3250 & 0.3500 & 0.3750 & 0.4000 \\
\hline & $\mathrm{d} 2$ & & 0.1500 & 0.1750 & 0.2000 & 0.2250 & 0.2500 & 0.2750 & 0.3000 & 0.3250 & 0.3500 & 0.3750 & 0.4000 \\
\hline
\end{tabular}


Table A3. Cont.

\begin{tabular}{|c|c|c|c|c|c|c|c|c|c|c|c|c|c|}
\hline \multirow{3}{*}{$\begin{array}{c}\text { No. of } \\
\text { Combination }\end{array}$} & \multirow{3}{*}{$\begin{array}{c}\text { Element } \\
\text { Combination }\end{array}$} & \multirow{2}{*}{$\frac{\text { Boundary }}{\left(w_{E L}\right)_{\alpha}^{L}}$} & \multicolumn{11}{|c|}{$\alpha$-Cut } \\
\hline & & & 0 & 0.1 & 0.2 & 0.3 & 0.4 & 0.5 & 0.6 & 0.7 & 0.8 & 0.9 & 1 \\
\hline & & $\left(w_{E L}\right)_{\alpha}^{U}$ & 1 & 0.9 & 0.8 & 0.7 & 0.6 & 0.5 & 0.4 & 0.3 & 0.2 & 0.1 & 0 \\
\hline & b3 & & 0.4000 & 0.4250 & 0.4500 & 0.4750 & 0.5000 & 0.5250 & 0.5500 & 0.5750 & 0.6000 & 0.6250 & 0.6500 \\
\hline & $\mathrm{c} 2$ & $\left(w_{E L}\right)_{\alpha}$ & 0.4000 & 0.4250 & 0.4500 & 0.4750 & 0.5000 & 0.5250 & 0.5500 & 0.5750 & 0.6000 & 0.6250 & 0.6500 \\
\hline & $\mathrm{d} 2$ & & 0.4000 & 0.4250 & 0.4500 & 0.4750 & 0.5000 & 0.5250 & 0.5500 & 0.5750 & 0.6000 & 0.6250 & 0.6500 \\
\hline \multirow{8}{*}{13} & a2 & \multirow{4}{*}{$\left(w_{E L}\right)_{\alpha}^{L}$} & 0.1500 & 0.1750 & 0.2000 & 0.2250 & 0.2500 & 0.2750 & 0.3000 & 0.3250 & 0.3500 & 0.3750 & 0.4000 \\
\hline & b1 & & 0.6000 & 0.6250 & 0.6500 & 0.6750 & 0.7000 & 0.7250 & 0.7500 & 0.7750 & 0.8000 & 0.8250 & 0.8500 \\
\hline & c1 & & 0.3000 & 0.3250 & 0.3500 & 0.3750 & 0.4000 & 0.4250 & 0.4500 & 0.4750 & 0.5000 & 0.5250 & 0.5500 \\
\hline & $\mathrm{d} 1$ & & 0.3000 & 0.3250 & 0.3500 & 0.3750 & 0.4000 & 0.4250 & 0.4500 & 0.4750 & 0.5000 & 0.5250 & 0.5500 \\
\hline & a2 & \multirow{4}{*}{$\left(w_{E L}\right)_{\alpha}^{U}$} & 0.4000 & 0.4250 & 0.4500 & 0.4750 & 0.5000 & 0.5250 & 0.5500 & 0.5750 & 0.6000 & 0.6250 & 0.6500 \\
\hline & b1 & & 0.8500 & 0.8650 & 0.8800 & 0.8950 & 0.9100 & 0.9250 & 0.9400 & 0.9550 & 0.9700 & 0.9850 & 1.0000 \\
\hline & $\mathrm{c} 1$ & & 0.5500 & 0.5950 & 0.6400 & 0.6850 & 0.7300 & 0.7750 & 0.8200 & 0.8650 & 0.9100 & 0.9550 & 1.0000 \\
\hline & $\mathrm{d} 1$ & & 0.5500 & 0.5050 & 0.4600 & 0.4150 & 0.3700 & 0.3250 & 0.2800 & 0.2350 & 0.1900 & 0.1450 & 0.1000 \\
\hline \multirow{7}{*}{14} & a2 & \multirow{3}{*}{$\left(w_{E L}\right)_{\alpha}^{L}$} & 0.1500 & 0.1750 & 0.2000 & 0.2250 & 0.2500 & 0.2750 & 0.3000 & 0.3250 & 0.3500 & 0.3750 & 0.4000 \\
\hline & b1 & & 0.6000 & 0.6250 & 0.6500 & 0.6750 & 0.7000 & 0.7250 & 0.7500 & 0.7750 & 0.8000 & 0.8250 & 0.8500 \\
\hline & $\mathrm{d} 2$ & & 0.1500 & 0.1750 & 0.2000 & 0.2250 & 0.2500 & 0.2750 & 0.3000 & 0.3250 & 0.3500 & 0.3750 & 0.4000 \\
\hline & a2 & \multirow{4}{*}{$\left(w_{E L}\right)_{\alpha}^{U}$} & 0.4000 & 0.4250 & 0.4500 & 0.4750 & 0.5000 & 0.5250 & 0.5500 & 0.5750 & 0.6000 & 0.6250 & 0.6500 \\
\hline & b1 & & 0.8500 & 0.8650 & 0.8800 & 0.8950 & 0.9100 & 0.9250 & 0.9400 & 0.9550 & 0.9700 & 0.9850 & 1.0000 \\
\hline & c1 & & 0.5500 & 0.5950 & 0.6400 & 0.6850 & 0.7300 & 0.7750 & 0.8200 & 0.8650 & 0.9100 & 0.9550 & 1.0000 \\
\hline & $\mathrm{d} 2$ & & 0.4000 & 0.4250 & 0.4500 & 0.4750 & 0.5000 & 0.5250 & 0.5500 & 0.5750 & 0.6000 & 0.6250 & 0.6500 \\
\hline \multirow{8}{*}{15} & a2 & \multirow{4}{*}{$\left(w_{E L}\right)_{\alpha}^{L}$} & 0.1500 & 0.1750 & 0.2000 & 0.2250 & 0.2500 & 0.2750 & 0.3000 & 0.3250 & 0.3500 & 0.3750 & 0.4000 \\
\hline & b1 & & 0.6000 & 0.6250 & 0.6500 & 0.6750 & 0.7000 & 0.7250 & 0.7500 & 0.7750 & 0.8000 & 0.8250 & 0.8500 \\
\hline & c2 & & 0.1500 & 0.1750 & 0.2000 & 0.2250 & 0.2500 & 0.2750 & 0.3000 & 0.3250 & 0.3500 & 0.3750 & 0.4000 \\
\hline & $\mathrm{d} 1$ & & 0.3000 & 0.3250 & 0.3500 & 0.3750 & 0.4000 & 0.4250 & 0.4500 & 0.4750 & 0.5000 & 0.5250 & 0.5500 \\
\hline & a2 & \multirow{4}{*}{$\left(w_{E L}\right)_{\alpha}^{U}$} & 0.4000 & 0.4250 & 0.4500 & 0.4750 & 0.5000 & 0.5250 & 0.5500 & 0.5750 & 0.6000 & 0.6250 & 0.6500 \\
\hline & b1 & & 0.8500 & 0.8650 & 0.8800 & 0.8950 & 0.9100 & 0.9250 & 0.9400 & 0.9550 & 0.9700 & 0.9850 & 1.0000 \\
\hline & c2 & & 0.4000 & 0.4250 & 0.4500 & 0.4750 & 0.5000 & 0.5250 & 0.5500 & 0.5750 & 0.6000 & 0.6250 & 0.6500 \\
\hline & $\mathrm{d} 1$ & & 0.5500 & 0.5050 & 0.4600 & 0.4150 & 0.3700 & 0.3250 & 0.2800 & 0.2350 & 0.1900 & 0.1450 & 0.1000 \\
\hline
\end{tabular}


Table A3. Cont.

\begin{tabular}{|c|c|c|c|c|c|c|c|c|c|c|c|c|c|}
\hline & & Boundary & & & & & & $\alpha$-Cut & & & & & \\
\hline \multirow{2}{*}{$\begin{array}{c}\text { No. of } \\
\text { Combination }\end{array}$} & \multirow{2}{*}{$\begin{array}{c}\text { Element } \\
\text { Combination }\end{array}$} & $\left(w_{E L}\right)_{\alpha}^{L}$ & 0 & 0.1 & 0.2 & 0.3 & 0.4 & 0.5 & 0.6 & 0.7 & 0.8 & 0.9 & 1 \\
\hline & & $\left(w_{E L}\right)_{\alpha}^{U}$ & 1 & 0.9 & 0.8 & 0.7 & 0.6 & 0.5 & 0.4 & 0.3 & 0.2 & 0.1 & 0 \\
\hline \multirow{7}{*}{16} & $\mathrm{~b} 1$ & \multirow{3}{*}{$\left(w_{E L}\right)_{\alpha}^{L}$} & 0.6000 & 0.6250 & 0.6500 & 0.6750 & 0.7000 & 0.7250 & 0.7500 & 0.7750 & 0.8000 & 0.8250 & 0.8500 \\
\hline & c2 & & 0.1500 & 0.1750 & 0.2000 & 0.2250 & 0.2500 & 0.2750 & 0.3000 & 0.3250 & 0.3500 & 0.3750 & 0.4000 \\
\hline & $\mathrm{d} 2$ & & 0.1500 & 0.1750 & 0.2000 & 0.2250 & 0.2500 & 0.2750 & 0.3000 & 0.3250 & 0.3500 & 0.3750 & 0.4000 \\
\hline & a2 & \multirow{4}{*}{$\left(w_{E L}\right)_{\alpha}^{U}$} & 0.4000 & 0.4250 & 0.4500 & 0.4750 & 0.5000 & 0.5250 & 0.5500 & 0.5750 & 0.6000 & 0.6250 & 0.6500 \\
\hline & b1 & & 0.8500 & 0.8650 & 0.8800 & 0.8950 & 0.9100 & 0.9250 & 0.9400 & 0.9550 & 0.9700 & 0.9850 & 1.0000 \\
\hline & $\mathrm{c} 2$ & & 0.4000 & 0.4250 & 0.4500 & 0.4750 & 0.5000 & 0.5250 & 0.5500 & 0.5750 & 0.6000 & 0.6250 & 0.6500 \\
\hline & $\mathrm{d} 2$ & & 0.4000 & 0.4250 & 0.4500 & 0.4750 & 0.5000 & 0.5250 & 0.5500 & 0.5750 & 0.6000 & 0.6250 & 0.6500 \\
\hline \multirow{7}{*}{17} & a2 & \multirow{4}{*}{$\left(w_{E L}\right)_{\alpha}^{L}$} & 0.1500 & 0.1750 & 0.2000 & 0.2250 & 0.2500 & 0.2750 & 0.3000 & 0.3250 & 0.3500 & 0.3750 & 0.4000 \\
\hline & $\mathrm{b} 2$ & & 0.3000 & 0.3250 & 0.3500 & 0.3750 & 0.4000 & 0.4250 & 0.4500 & 0.4750 & 0.5000 & 0.5250 & 0.5500 \\
\hline & $\mathrm{c} 1$ & & 0.3000 & 0.3250 & 0.3500 & 0.3750 & 0.4000 & 0.4250 & 0.4500 & 0.4750 & 0.5000 & 0.5250 & 0.5500 \\
\hline & $\mathrm{d} 1$ & & 0.3000 & 0.3250 & 0.3500 & 0.3750 & 0.4000 & 0.4250 & 0.4500 & 0.4750 & 0.5000 & 0.5250 & 0.5500 \\
\hline & a2 & \multirow{3}{*}{$\left(w_{E L}\right)_{\alpha}^{U}$} & 0.4000 & 0.4250 & 0.4500 & 0.4750 & 0.5000 & 0.5250 & 0.5500 & 0.5750 & 0.6000 & 0.6250 & 0.6500 \\
\hline & b2 & & 0.5500 & 0.5750 & 0.6000 & 0.6250 & 0.6500 & 0.6750 & 0.7000 & 0.7250 & 0.7500 & 0.7750 & 0.8000 \\
\hline & $\mathrm{d} 1$ & & 0.5500 & 0.5050 & 0.4600 & 0.4150 & 0.3700 & 0.3250 & 0.2800 & 0.2350 & 0.1900 & 0.1450 & 0.1000 \\
\hline \multirow{8}{*}{18} & a2 & \multirow{4}{*}{$\left(w_{E L}\right)_{\alpha}^{L}$} & 0.1500 & 0.1750 & 0.2000 & 0.2250 & 0.2500 & 0.2750 & 0.3000 & 0.3250 & 0.3500 & 0.3750 & 0.4000 \\
\hline & b2 & & 0.3000 & 0.3250 & 0.3500 & 0.3750 & 0.4000 & 0.4250 & 0.4500 & 0.4750 & 0.5000 & 0.5250 & 0.5500 \\
\hline & c1 & & 0.3000 & 0.3250 & 0.3500 & 0.3750 & 0.4000 & 0.4250 & 0.4500 & 0.4750 & 0.5000 & 0.5250 & 0.5500 \\
\hline & $\mathrm{d} 2$ & & 0.1500 & 0.1750 & 0.2000 & 0.2250 & 0.2500 & 0.2750 & 0.3000 & 0.3250 & 0.3500 & 0.3750 & 0.4000 \\
\hline & a2 & \multirow{4}{*}{$\left(w_{E L}\right)_{\alpha}^{U}$} & 0.4000 & 0.4250 & 0.4500 & 0.4750 & 0.5000 & 0.5250 & 0.5500 & 0.5750 & 0.6000 & 0.6250 & 0.6500 \\
\hline & b2 & & 0.5500 & 0.5750 & 0.6000 & 0.6250 & 0.6500 & 0.6750 & 0.7000 & 0.7250 & 0.7500 & 0.7750 & 0.8000 \\
\hline & $\mathrm{c} 1$ & & 0.5500 & 0.5950 & 0.6400 & 0.6850 & 0.7300 & 0.7750 & 0.8200 & 0.8650 & 0.9100 & 0.9550 & 1.0000 \\
\hline & $\mathrm{d} 2$ & & 0.4000 & 0.4250 & 0.4500 & 0.4750 & 0.5000 & 0.5250 & 0.5500 & 0.5750 & 0.6000 & 0.6250 & 0.6500 \\
\hline \multirow{4}{*}{19} & a2 & \multirow{4}{*}{$\left(w_{E L}\right)_{\alpha}^{L}$} & 0.1500 & 0.1750 & 0.2000 & 0.2250 & 0.2500 & 0.2750 & 0.3000 & 0.3250 & 0.3500 & 0.3750 & 0.4000 \\
\hline & b2 & & 0.3000 & 0.3250 & 0.3500 & 0.3750 & 0.4000 & 0.4250 & 0.4500 & 0.4750 & 0.5000 & 0.5250 & 0.5500 \\
\hline & $\mathrm{c} 2$ & & 0.1500 & 0.1750 & 0.2000 & 0.2250 & 0.2500 & 0.2750 & 0.3000 & 0.3250 & 0.3500 & 0.3750 & 0.4000 \\
\hline & $\mathrm{d} 1$ & & 0.3000 & 0.3250 & 0.3500 & 0.3750 & 0.4000 & 0.4250 & 0.4500 & 0.4750 & 0.5000 & 0.5250 & 0.5500 \\
\hline
\end{tabular}


Table A3. Cont.

\begin{tabular}{|c|c|c|c|c|c|c|c|c|c|c|c|c|c|}
\hline \multirow{3}{*}{$\begin{array}{c}\text { No. of } \\
\text { Combination }\end{array}$} & \multirow{3}{*}{$\begin{array}{c}\text { Element } \\
\text { Combination }\end{array}$} & \multirow{2}{*}{$\frac{\text { Boundary }}{\left(w_{E L}\right)_{\alpha}^{L}}$} & \multicolumn{11}{|c|}{$\alpha$-Cut } \\
\hline & & & 0 & 0.1 & 0.2 & 0.3 & 0.4 & 0.5 & 0.6 & 0.7 & 0.8 & 0.9 & 1 \\
\hline & & $\left(w_{E L}\right)_{\alpha}^{U}$ & 1 & 0.9 & 0.8 & 0.7 & 0.6 & 0.5 & 0.4 & 0.3 & 0.2 & 0.1 & 0 \\
\hline & $\mathrm{b} 2$ & & 0.5500 & 0.5750 & 0.6000 & 0.6250 & 0.6500 & 0.6750 & 0.7000 & 0.7250 & 0.7500 & 0.7750 & 0.8000 \\
\hline & c2 & $\left(w_{E L}\right)_{\alpha}^{u}$ & 0.4000 & 0.4250 & 0.4500 & 0.4750 & 0.5000 & 0.5250 & 0.5500 & 0.5750 & 0.6000 & 0.6250 & 0.6500 \\
\hline & $\mathrm{d} 1$ & & 0.5500 & 0.5050 & 0.4600 & 0.4150 & 0.3700 & 0.3250 & 0.2800 & 0.2350 & 0.1900 & 0.1450 & 0.1000 \\
\hline \multirow{8}{*}{20} & $\mathrm{a} 2$ & \multirow{4}{*}{$\left(w_{E L}\right)_{\alpha}^{L}$} & 0.1500 & 0.1750 & 0.2000 & 0.2250 & 0.2500 & 0.2750 & 0.3000 & 0.3250 & 0.3500 & 0.3750 & 0.4000 \\
\hline & $\mathrm{b} 2$ & & 0.3000 & 0.3250 & 0.3500 & 0.3750 & 0.4000 & 0.4250 & 0.4500 & 0.4750 & 0.5000 & 0.5250 & 0.5500 \\
\hline & $\mathrm{c} 2$ & & 0.1500 & 0.1750 & 0.2000 & 0.2250 & 0.2500 & 0.2750 & 0.3000 & 0.3250 & 0.3500 & 0.3750 & 0.4000 \\
\hline & $\mathrm{d} 2$ & & 0.1500 & 0.1750 & 0.2000 & 0.2250 & 0.2500 & 0.2750 & 0.3000 & 0.3250 & 0.3500 & 0.3750 & 0.4000 \\
\hline & a2 & \multirow{4}{*}{$\left(w_{E L}\right)_{\alpha}^{U}$} & 0.4000 & 0.4250 & 0.4500 & 0.4750 & 0.5000 & 0.5250 & 0.5500 & 0.5750 & 0.6000 & 0.6250 & 0.6500 \\
\hline & $\mathrm{b} 2$ & & 0.5500 & 0.5750 & 0.6000 & 0.6250 & 0.6500 & 0.6750 & 0.7000 & 0.7250 & 0.7500 & 0.7750 & 0.8000 \\
\hline & $c 2$ & & 0.4000 & 0.4250 & 0.4500 & 0.4750 & 0.5000 & 0.5250 & 0.5500 & 0.5750 & 0.6000 & 0.6250 & 0.6500 \\
\hline & $\mathrm{d} 2$ & & 0.4000 & 0.4250 & 0.4500 & 0.4750 & 0.5000 & 0.5250 & 0.5500 & 0.5750 & 0.6000 & 0.6250 & 0.6500 \\
\hline \multirow{7}{*}{21} & a2 & \multirow{3}{*}{$\left(w_{E L}\right)_{\alpha}^{L}$} & 0.1500 & 0.1750 & 0.2000 & 0.2250 & 0.2500 & 0.2750 & 0.3000 & 0.3250 & 0.3500 & 0.3750 & 0.4000 \\
\hline & b3 & & 0.1500 & 0.1750 & 0.2000 & 0.2250 & 0.2500 & 0.2750 & 0.3000 & 0.3250 & 0.3500 & 0.3750 & 0.4000 \\
\hline & $\mathrm{d} 1$ & & 0.3000 & 0.3250 & 0.3500 & 0.3750 & 0.4000 & 0.4250 & 0.4500 & 0.4750 & 0.5000 & 0.5250 & 0.5500 \\
\hline & a2 & \multirow{4}{*}{$\left(w_{E L}\right)_{\alpha}^{U}$} & 0.4000 & 0.4250 & 0.4500 & 0.4750 & 0.5000 & 0.5250 & 0.5500 & 0.5750 & 0.6000 & 0.6250 & 0.6500 \\
\hline & b3 & & 0.4000 & 0.4250 & 0.4500 & 0.4750 & 0.5000 & 0.5250 & 0.5500 & 0.5750 & 0.6000 & 0.6250 & 0.6500 \\
\hline & c1 & & 0.5500 & 0.5950 & 0.6400 & 0.6850 & 0.7300 & 0.7750 & 0.8200 & 0.8650 & 0.9100 & 0.9550 & 1.0000 \\
\hline & $\mathrm{d} 1$ & & 0.5500 & 0.5050 & 0.4600 & 0.4150 & 0.3700 & 0.3250 & 0.2800 & 0.2350 & 0.1900 & 0.1450 & 0.1000 \\
\hline \multirow{8}{*}{22} & a2 & \multirow{4}{*}{$\left(w_{E L}\right)_{\alpha}^{L}$} & 0.1500 & 0.1750 & 0.2000 & 0.2250 & 0.2500 & 0.2750 & 0.3000 & 0.3250 & 0.3500 & 0.3750 & 0.4000 \\
\hline & b3 & & 0.1500 & 0.1750 & 0.2000 & 0.2250 & 0.2500 & 0.2750 & 0.3000 & 0.3250 & 0.3500 & 0.3750 & 0.4000 \\
\hline & $\mathrm{c} 1$ & & 0.3000 & 0.3250 & 0.3500 & 0.3750 & 0.4000 & 0.4250 & 0.4500 & 0.4750 & 0.5000 & 0.5250 & 0.5500 \\
\hline & $\mathrm{d} 2$ & & 0.1500 & 0.1750 & 0.2000 & 0.2250 & 0.2500 & 0.2750 & 0.3000 & 0.3250 & 0.3500 & 0.3750 & 0.4000 \\
\hline & a2 & \multirow{4}{*}{$\left(w_{E L}\right)_{\alpha}^{U}$} & 0.4000 & 0.4250 & 0.4500 & 0.4750 & 0.5000 & 0.5250 & 0.5500 & 0.5750 & 0.6000 & 0.6250 & 0.6500 \\
\hline & b3 & & 0.4000 & 0.4250 & 0.4500 & 0.4750 & 0.5000 & 0.5250 & 0.5500 & 0.5750 & 0.6000 & 0.6250 & 0.6500 \\
\hline & $\mathrm{c} 1$ & & 0.5500 & 0.5950 & 0.6400 & 0.6850 & 0.7300 & 0.7750 & 0.8200 & 0.8650 & 0.9100 & 0.9550 & 1.0000 \\
\hline & $\mathrm{d} 2$ & & 0.4000 & 0.4250 & 0.4500 & 0.4750 & 0.5000 & 0.5250 & 0.5500 & 0.5750 & 0.6000 & 0.6250 & 0.6500 \\
\hline
\end{tabular}


Table A3. Cont.

\begin{tabular}{|c|c|c|c|c|c|c|c|c|c|c|c|c|c|}
\hline \multirow{3}{*}{$\begin{array}{c}\text { No. of } \\
\text { Combination }\end{array}$} & \multirow{3}{*}{$\begin{array}{c}\text { Element } \\
\text { Combination }\end{array}$} & \multirow{2}{*}{$\begin{array}{c}\text { Boundary } \\
\left(w_{E L}\right)_{\alpha}^{L}\end{array}$} & \multicolumn{11}{|c|}{$\alpha$-Cut } \\
\hline & & & 0 & 0.1 & 0.2 & 0.3 & 0.4 & 0.5 & 0.6 & 0.7 & 0.8 & 0.9 & 1 \\
\hline & & $\left(w_{E L}\right)_{\alpha}^{U}$ & 1 & 0.9 & 0.8 & 0.7 & 0.6 & 0.5 & 0.4 & 0.3 & 0.2 & 0.1 & 0 \\
\hline \multirow{7}{*}{23} & b3 & \multirow{3}{*}{$\left(w_{E L}\right)_{\alpha}^{L}$} & 0.1500 & 0.1750 & 0.2000 & 0.2250 & 0.2500 & 0.2750 & 0.3000 & 0.3250 & 0.3500 & 0.3750 & 0.4000 \\
\hline & c2 & & 0.1500 & 0.1750 & 0.2000 & 0.2250 & 0.2500 & 0.2750 & 0.3000 & 0.3250 & 0.3500 & 0.3750 & 0.4000 \\
\hline & $\mathrm{d} 1$ & & 0.3000 & 0.3250 & 0.3500 & 0.3750 & 0.4000 & 0.4250 & 0.4500 & 0.4750 & 0.5000 & 0.5250 & 0.5500 \\
\hline & a2 & \multirow{4}{*}{$\left(w_{E L}\right)_{\alpha}^{U}$} & 0.4000 & 0.4250 & 0.4500 & 0.4750 & 0.5000 & 0.5250 & 0.5500 & 0.5750 & 0.6000 & 0.6250 & 0.6500 \\
\hline & b3 & & 0.4000 & 0.4250 & 0.4500 & 0.4750 & 0.5000 & 0.5250 & 0.5500 & 0.5750 & 0.6000 & 0.6250 & 0.6500 \\
\hline & $\mathrm{c} 2$ & & 0.4000 & 0.4250 & 0.4500 & 0.4750 & 0.5000 & 0.5250 & 0.5500 & 0.5750 & 0.6000 & 0.6250 & 0.6500 \\
\hline & $\mathrm{d} 1$ & & 0.5500 & 0.5050 & 0.4600 & 0.4150 & 0.3700 & 0.3250 & 0.2800 & 0.2350 & 0.1900 & 0.1450 & 0.1000 \\
\hline \multirow{6}{*}{24} & a2 & \multirow{4}{*}{$\left(w_{E L}\right)_{\alpha}^{L}$} & 0.1500 & 0.1750 & 0.2000 & 0.2250 & 0.2500 & 0.2750 & 0.3000 & 0.3250 & 0.3500 & 0.3750 & 0.4000 \\
\hline & b3 & & 0.1500 & 0.1750 & 0.2000 & 0.2250 & 0.2500 & 0.2750 & 0.3000 & 0.3250 & 0.3500 & 0.3750 & 0.4000 \\
\hline & $\mathrm{c} 2$ & & 0.1500 & 0.1750 & 0.2000 & 0.2250 & 0.2500 & 0.2750 & 0.3000 & 0.3250 & 0.3500 & 0.3750 & 0.4000 \\
\hline & $\mathrm{d} 2$ & & 0.1500 & 0.1750 & 0.2000 & 0.2250 & 0.2500 & 0.2750 & 0.3000 & 0.3250 & 0.3500 & 0.3750 & 0.4000 \\
\hline & a2 & \multirow{2}{*}{$\left(w_{E L}\right)_{\alpha}^{U}$} & 0.4000 & 0.4250 & 0.4500 & 0.4750 & 0.5000 & 0.5250 & 0.5500 & 0.5750 & 0.6000 & 0.6250 & 0.6500 \\
\hline & $\mathrm{d} 2$ & & 0.4000 & 0.4250 & 0.4500 & 0.4750 & 0.5000 & 0.5250 & 0.5500 & 0.5750 & 0.6000 & 0.6250 & 0.6500 \\
\hline
\end{tabular}


Table A4. The rating value of the superstructure component for all combinations (extended version of Table 8).

\begin{tabular}{|c|c|c|c|c|c|c|c|c|c|c|c|c|}
\hline \multirow[b]{2}{*}{$\alpha$-Cut } & \multicolumn{12}{|c|}{ Number of Combination } \\
\hline & 1 & 2 & 3 & 4 & 5 & 6 & 7 & 8 & 9 & 10 & 11 & 12 \\
\hline 0.0 & 55.78 & 56.29 & 56.29 & 56.92 & 60.00 & 61.34 & 61.34 & 63.16 & 61.34 & 63.16 & 63.16 & 65.81 \\
\hline 0.1 & 56.88 & 57.51 & 57.51 & 58.30 & 61.00 & 62.43 & 62.43 & 64.33 & 62.43 & 64.33 & 64.33 & 67.00 \\
\hline 0.2 & 57.97 & 58.71 & 58.71 & 59.63 & 62.00 & 63.50 & 63.50 & 65.46 & 63.50 & 65.46 & 65.46 & 68.14 \\
\hline 0.3 & 59.05 & 59.89 & 59.89 & 60.92 & 63.00 & 64.57 & 64.57 & 66.58 & 64.57 & 66.58 & 66.58 & 69.26 \\
\hline 0.4 & 60.12 & 61.05 & 61.05 & 62.17 & 64.00 & 65.62 & 65.62 & 67.68 & 65.62 & 67.68 & 67.68 & 70.36 \\
\hline 0.5 & 61.18 & 62.19 & 62.19 & 63.40 & 65.00 & 66.67 & 66.67 & 68.76 & 66.67 & 68.76 & 68.76 & 71.44 \\
\hline 0.6 & 62.24 & 63.32 & 63.32 & 64.60 & 66.00 & 67.71 & 67.71 & 69.83 & 67.71 & 69.83 & 69.83 & 72.51 \\
\hline 0.7 & 63.29 & 64.43 & 64.43 & 65.78 & 67.00 & 68.75 & 68.75 & 70.90 & 68.75 & 70.90 & 70.90 & 73.57 \\
\hline 0.8 & 64.34 & 65.54 & 65.54 & 66.95 & 68.00 & 69.79 & 69.79 & 71.95 & 69.79 & 71.95 & 71.95 & 74.62 \\
\hline 0.9 & 65.38 & 66.64 & 66.64 & 68.10 & 69.00 & 70.82 & 70.82 & 73.00 & 70.82 & 73.00 & 73.00 & 75.67 \\
\hline 1.0 & 66.43 & 67.73 & 67.73 & 69.23 & 70.00 & 71.85 & 71.85 & 74.05 & 71.85 & 74.05 & 74.05 & 76.71 \\
\hline 1.0 & 66.43 & 67.73 & 67.73 & 69.23 & 70.00 & 71.85 & 71.85 & 74.05 & 71.85 & 74.05 & 74.05 & 76.71 \\
\hline 0.9 & 67.42 & 68.86 & 68.78 & 70.40 & 71.00 & 72.86 & 72.94 & 75.09 & 72.92 & 75.05 & 75.24 & 77.75 \\
\hline 0.8 & 68.42 & 69.98 & 69.83 & 71.56 & 72.00 & 73.86 & 74.02 & 76.13 & 73.99 & 76.05 & 76.43 & 78.78 \\
\hline 0.7 & 69.42 & 71.09 & 70.88 & 72.71 & 73.00 & 74.87 & 75.11 & 77.16 & 75.05 & 77.05 & 77.61 & 79.81 \\
\hline 0.6 & 70.41 & 72.20 & 71.94 & 73.85 & 74.00 & 75.88 & 76.19 & 78.19 & 76.11 & 78.05 & 78.79 & 80.84 \\
\hline 0.5 & 71.41 & 73.30 & 72.99 & 74.97 & 75.00 & 76.88 & 77.27 & 79.22 & 77.17 & 79.05 & 79.97 & 81.87 \\
\hline 0.4 & 72.41 & 74.39 & 74.04 & 76.09 & 76.00 & 77.89 & 78.35 & 80.25 & 78.23 & 80.05 & 81.13 & 82.89 \\
\hline 0.3 & 73.41 & 75.47 & 75.09 & 77.21 & 77.00 & 78.89 & 79.43 & 81.27 & 79.29 & 81.05 & 82.30 & 83.91 \\
\hline 0.2 & 74.40 & 76.55 & 76.14 & 78.31 & 78.00 & 79.90 & 80.50 & 82.30 & 80.34 & 82.05 & 83.46 & 84.93 \\
\hline 0.1 & 75.40 & 77.62 & 77.18 & 79.41 & 79.00 & 80.90 & 81.58 & 83.32 & 81.39 & 83.05 & 84.61 & 85.95 \\
\hline \multirow[t]{2}{*}{0.0} & 76.40 & 78.69 & 78.23 & 80.51 & 80.00 & 81.91 & 82.65 & 84.34 & 82.44 & 84.05 & 85.77 & 86.97 \\
\hline & \multicolumn{12}{|c|}{ Number of Combination } \\
\hline$\alpha$-Cut & 13 & 14 & 15 & 16 & 17 & 18 & 19 & 20 & 21 & 22 & 23 & 24 \\
\hline 0.0 & 56.29 & 56.92 & 56.92 & 57.76 & 61.34 & 63.16 & 63.16 & 65.81 & 63.16 & 65.81 & 65.81 & 70.00 \\
\hline 0.1 & 57.51 & 58.30 & 58.30 & 59.32 & 62.43 & 64.33 & 64.33 & 67.00 & 64.33 & 67.00 & 67.00 & 71.00 \\
\hline 0.2 & 58.71 & 59.63 & 59.63 & 60.79 & 63.50 & 65.46 & 65.46 & 68.14 & 65.46 & 68.14 & 68.14 & 72.00 \\
\hline 0.3 & 59.89 & 60.92 & 60.92 & 62.20 & 64.57 & 66.58 & 66.58 & 69.26 & 66.58 & 69.26 & 69.26 & 73.00 \\
\hline 0.4 & 61.05 & 62.17 & 62.17 & 63.56 & 65.62 & 67.68 & 67.68 & 70.36 & 67.68 & 70.36 & 70.36 & 74.00 \\
\hline 0.5 & 62.19 & 63.40 & 63.40 & 64.87 & 66.67 & 68.76 & 68.76 & 71.44 & 68.76 & 71.44 & 71.44 & 75.00 \\
\hline 0.6 & 63.32 & 64.60 & 64.60 & 66.15 & 67.71 & 69.83 & 69.83 & 72.51 & 69.83 & 72.51 & 72.51 & 76.00 \\
\hline 0.7 & 64.43 & 65.78 & 65.78 & 67.40 & 68.75 & 70.90 & 70.90 & 73.57 & 70.90 & 73.57 & 73.57 & 77.00 \\
\hline 0.8 & 65.54 & 66.95 & 66.95 & 68.62 & 69.79 & 71.95 & 71.95 & 74.62 & 71.95 & 74.62 & 74.62 & 78.00 \\
\hline 0.9 & 66.64 & 68.10 & 68.10 & 69.82 & 70.82 & 73.00 & 73.00 & 75.67 & 73.00 & 75.67 & 75.67 & 79.00 \\
\hline 1.0 & 67.73 & 69.23 & 69.23 & 71.00 & 71.85 & 74.05 & 74.05 & 76.71 & 74.05 & 76.71 & 76.71 & 80.00 \\
\hline 1.0 & 67.73 & 69.23 & 69.23 & 71.00 & 71.85 & 74.05 & 74.05 & 76.71 & 74.05 & 76.71 & 76.71 & 80.00 \\
\hline 0.9 & 68.80 & 70.41 & 70.39 & 72.23 & 72.92 & 75.05 & 75.24 & 77.75 & 75.20 & 77.67 & 78.03 & 81.00 \\
\hline 0.8 & 69.87 & 71.57 & 71.53 & 73.43 & 73.99 & 76.05 & 76.43 & 78.78 & 76.34 & 78.64 & 79.33 & 82.00 \\
\hline 0.7 & 70.94 & 72.72 & 72.68 & 74.63 & 75.05 & 77.05 & 77.61 & 79.81 & 77.47 & 79.61 & 80.63 & 83.00 \\
\hline 0.6 & 72.00 & 73.85 & 73.83 & 75.80 & 76.11 & 78.05 & 78.79 & 80.84 & 78.60 & 80.59 & 81.92 & 84.00 \\
\hline 0.5 & 73.06 & 74.97 & 74.97 & 76.97 & 77.17 & 79.05 & 79.97 & 81.87 & 79.73 & 81.56 & 83.20 & 85.00 \\
\hline 0.4 & 74.13 & 76.09 & 76.11 & 78.12 & 78.23 & 80.05 & 81.13 & 82.89 & 80.85 & 82.54 & 84.47 & 86.00 \\
\hline 0.3 & 75.19 & 77.20 & 77.25 & 79.27 & 79.29 & 81.05 & 82.30 & 83.91 & 81.96 & 83.52 & 85.74 & 87.00 \\
\hline 0.2 & 76.25 & 78.30 & 78.39 & 80.40 & 80.34 & 82.05 & 83.46 & 84.93 & 83.07 & 84.51 & 86.99 & 88.00 \\
\hline 0.1 & 77.30 & 79.39 & 79.52 & 81.53 & 81.39 & 83.05 & 84.61 & 85.95 & 84.17 & 85.49 & 88.24 & 89.00 \\
\hline 0.0 & 78.36 & 80.48 & 80.66 & 82.65 & 82.44 & 84.05 & 85.77 & 86.97 & 85.27 & 86.48 & 89.48 & 90.00 \\
\hline
\end{tabular}




\section{References}

1. Puž, G.; Radić, J.; Tenžera, D. Predicting the condition of bridges to optimize maintenance. Građevinar 2013, 65, 1079-1088.

2. Tenžera, D.; Puž, G.; Radić, J. Visual inspection as an aid to assess the condition of bridges. Građevinar 2012, 64, 717-726.

3. Frangopol, D.; Liu, M. Bridge Management Based on Multiple-objective Optimization. In Proceedings of the 5th International Conference on Bridge Management, Bridge Management 5: Inspection, Maintenance, Assessment and Repair, Surrey, UK, 11-13 April 2005; pp. 235-242.

4. Rashidi, M.; Lemass, B. Holistic Decision Support for Bridge Remediation. In Proceedings of the 4th International Conference on Construction Engineering and Project Management (ICCEPM), Sydney, Australia, 16-18 February 2011.

5. Dabous, S.A. A Decision Support Methodology for Rehabilitation Management of Concrete Bridges. Ph.D. Thesis, University of Concordia, Montreal, QC, Canada, 2008.

6. ARRB. Local Roads Bridge Manual; Transport Research Ltd.: Berkshire, UK, 2000.

7. Chassiakos, A.; Vagiotas, P.; Theodorakopoulos, D. A knowledge based system for maintenance planning of highway concrete bridges. Adv. Eng. Softw. 2005, 36, 740-749. [CrossRef]

8. De Brito, J.; Branco, F. Computer Aided Lifecycle Costs Prediction in Concrete Bridges. Eng. Model. 1998, 11, 97-106.

9. Radić, J. Prosudba Utjecaja na Trajnost Mostova u Hrvatskoj. (Assessment of the Impact on the Durability of Bridges in Croatia). In Proceedings of the Prvog Znanstvenog Kolokvija "Mostovi", Society of Croatian Strucutral Constructors, Brijuni, Croatia, 18-21 September 1991; pp. 219-232.

10. Yanev, B. Bridge Management; John Wiley \& Sons: Hoboken, NJ, USA, 2007.

11. Moore, D.; Refaat, M.; de Fleuriot, E.; Nordengen, P. Implementation of a Bridge Maintenance Management System for Dubai, United Arab Emirates. In Proceedings of the Austroads 8th Bridge Conference, Sydney, Australia, 31 October-5 November 2011.

12. Elbehairy, H. Bridge Management System with Integrated Life Cycle Cost Optimization. Ph.D. Thesis, University of Waterloo, Waterloo, ON, Canada, 2007.

13. Watson, S.; Everett, S. RTA bridge Inspection Records for Sustainability. In Proceedings of the Austroads 8th Bridge Conference, Sydney, New South Wales, Australia, 31 October-5 November 2011.

14. Rashidi, M.; Lemass, B.; Gibson, P. A Decision Support System for Concrete Bridge Maintenance. In Proceedings of the 2nd International Symposium on Computational Mechanics and the 12th International Conference on the Enhancement and Promotion of Computational Methods in Engineering and Science, Hong Kong-Macau, China, 30 November-3 December 2009; American Institute of Physics (AIP): Melville, NY, USA, 2010.

15. Radić, J.; Mandić, A.; Augustinović, I. Ocjenjivanje postojećih konstrukcija. Građevinar 2009, 61, 901-912.

16. Al-Radaideh, A.; Al-Ali, A.R.; Bheiry, S.; Alawnah, S. A Wireless Sensor Network Monitoring System for Highway Bridges. In Proceedings of the 2015 International Conference on Electrical and Information Technologies (ICEIT), Marrakech, Morocco, 25-27 March 2015; pp. 119-124. [CrossRef]

17. Bolar, A.; Tesfamariam, S.; Sadiq, R. Condition assessment for bridges: A hierarchical evidential reasoning (HER) framework. Struct. Infrastruct. Eng. 2010, 9, 648-666. [CrossRef]

18. Zanini, M.A.; Faleschini, F.; Casas, J.R. State-Of-Research on Performance Indicators for Bridge Quality Control and Management. Front. Built Env. 2019, 5, 22. [CrossRef]

19. Forde, M.C. International practice using NDE for the inspection of concrete and masonry arch bridges. Bridge Struct. 2010, 6, 25-34. [CrossRef]

20. Braga, F.; Buratti, G.; Cosentinob, A.; Dall'Asta, A.; De Matteis, G. Multi-level Approach for the Assessment of Bridge and Viaducts within Road Networks. In XVIII Convegno Anidis Ascoli Pi Ceno; Pisa University Press: Pisa, Italy, $2019 ;$ pp. 17-31.

21. Wang, Z.W.; Zhou, M.; Slabaugh, G.G.; Zhai, J.; Fang, T. Automatic Detection of Bridge Deck Condition From Ground Penetrating Radar Images. IEEE Trans. Autom. Sci. Eng. 2011, 8, 633-640. [CrossRef]

22. Rashidi, M.; Samali, B.; Sharafi, P. A new model for bridge management: Part A: Condition assessment and priority ranking of bridges. Aus. J. Civil Eng. 2016, 14, 35-45. [CrossRef]

23. Lima, M.; Alipour Limaei, S.A. Structural Health Monitoring of Concrete Bridges in Rudbar-Manjil Region in Iran Mehdi. In Proceedings of the International Conference on Intelligent Building and Management Proc IACSIT Press, Singapore, 2-4 May 2011.

24. Zambon, I.; Vidović, A.; Strauss, A.; Matos, J. Condition Prediction of Existing Concrete Bridges as a Combination of Visual Inspection and Analytical Models of Deterioration. Appl. Sci. 2019, 9, 148. [CrossRef]

25. Stochino, F.; Fadda, L.; Mistretta, F. Low cost condition assessment method for existing RC bridges. Eng. Fail. Anal. 2018, 86, 56-71. [CrossRef]

26. Srinivas, V.; Sasmal, S.; Karusala, R. Fuzzy Based Decision Support System for Condition Assessment and Rating of Bridges. J. Inst. Eng. India Ser. A 2016, 97, 261-272. [CrossRef]

27. Ismail, N.; Ismail, A.; Atig, R. An Overview of Expert Systems in Pavement Management. Eur. J. Sci. Res. 2009, $30,99-111$.

28. Ramos, C.; Augusto, J.C.; Shapiro, D. Ambient Intelligence-The Next Step for Artificial Intelligence. IEEE Intell. Syst. 2008, 23, 15-18. [CrossRef]

29. De Kock, E. Decentralising the Codification of Rules in a Decision Support Expert Knowledge Base. Ph.D. Thesis, University of Pretoria, Pretoria, Južnoafrička Republika, 2003.

30. Zadeh, L.A. Fuzzy sets. Inf. Control 1965, 8, 338-353. [CrossRef] 
31. Penadés-Plà, V.; García-Segura, T.; Martí, J.V. A Review of Multi-Criteria Decision-Making Methods Applied to the Sustainable Bridge Design. Sustainability 2016, 8, 1295. [CrossRef]

32. Zavadskas, E.K.; Liias, R.; Turskis, Z. Multi-attribute decision-making methods for assessment of quality in bridges and road construction: State-of-the-art surveys. Baltic J. Road Bridge Eng. 2008, 3, 152-160. [CrossRef]

33. Sasmal, S.; Ramanjaneyulu, K. Condition evaluation of existing reinforced concrete bridges using fuzzy based analytic hierarchy approach. Exp. Syst. Appl. 2008, 35, 1430-1443. [CrossRef]

34. Nguyen, P.; Tran, D.; Lines, B. Identifying Common Groups of Highway Projects Using Fuzzy Cluster Analysis. In Construction Research Congress 2020: Project Management and Controls, Materials, and Contracts; American Society of Civil Engineers: Reston, VA, USA, 2020. [CrossRef]

35. Tarighat, A.; Miyamoto, A. Fuzzy concrete bridge deck condition rating method for practical bridge management system. Exp. Syst. Appl. 2009, 36, 12077-12088. [CrossRef]

36. Zhao, Z.; Chen, C. Concrete bridge deterioration diagnosis using fuzzy inference system. Adv. Eng. Softw. 2001, 32, 317-325. [CrossRef]

37. Yongping, W. Expert system for comprehensive assessment to bridge service property using Fuzzy theory. J. Northeast For. Univ. 1996, 7, 88-99.

38. Liu, H.; Wang, X.; Jiao, Y.; He, X.; Wang, B. Condition evaluation for existing reinforced concrete bridge superstructure using fuzzy clustering improved by particle swarm optimisation. Struct. Infrastruct. Eng 2007, 13, 955-965. [CrossRef]

39. Symans, M.D.; Kelly, S.W. Fuzzy logic control of bridge structures using intelligent semi-active seismic isolation systems. J. Earthq. Eng. Struct. Dyn. 1999, 28, 37-60. [CrossRef]

40. Pan, N.F. Forecasting bridge deck conditions using fuzzy regression analysis. J. Chin. Inst. Eng. 2007, 30, 593-603. [CrossRef]

41. Kandel, A. Fuzzy Expert Systems; CRC Press: Boca Raton, FL, USA, 1991.

42. Kumar, M.B.; Parameshwaran, R. Fuzzy weighted geometric mean approach-based FMEA to prioritise lean failure modes in manufacturing industries. Int. J. Manuf. Technol. Manag. 2019, 33, 398-427. [CrossRef]

43. Wang, Y.M.; Lou, Y. Generalised fuzzy weighted mean and its applications. Int. J. Gen. Syst. 2009, 38, 533-546. [CrossRef]

44. Krejči, J.; Stoklasa, J. Aggregation in the analytic hierarchy process: Why weighted geometric mean should be used instead of weighted arithmetic mean. Exp. Syst. Appl. 2018, 114, 97-106. [CrossRef]

45. Gu, Y.K.; Luo, X.C.; Tang, S.Y. Risk Priority Analysis for Engine Based on Fuzzy Weighted Geometric Mean. Adv. Mater. Res. 2012, 463-464, 1160-1164. [CrossRef]

46. Shen, G.-x.; Fan, S.-h.; Zhang, Y.-z.; Wei, L.h.; Jia, Y.-z. Risk Evaluation of NC Machine Tools Based on Fuzzy Weighted Geometric Mean. In Proceedings of the 2010 IEEE International Conference on Industrial Engineering and Engineering Management, Macao, China, 7-10 December 2010; pp. 2384-2388. [CrossRef]

47. Dabous, S.A.; Alkass, S. Managing bridge infrastructure under budget constraints: A decision support methodology. Can. J. Civil Eng. 2012, 38, 1227-1237. [CrossRef]

48. Yehia, S.; Abudayyeh, O.; Fazal, I.; Randolph, D. A decision support system for concrete bridge deck maintenance. Adv. Eng. Softw. 2008, 39, 202-210. [CrossRef]

49. Wang, Y.-M.; Chin, K.-S.; Poon, G.K.K.; Yang, J.-B. Risk evaluation in failure mode and effects analysis using fuzzy weighted geometric mean. Exp. Syst. Appl. 2009, 36, 1195-1207. [CrossRef]

50. Saaty, T.L. The Analytic Hierarchy Process; McGraw-Hill: New York, NY, USA, 1980.

51. Saaty, T.L. The Analytic Hierarchy and Analytic Network Processes for the Measurement of Intangible Criteria and for Decision-making; Fiigueira, J., Fiigueira, J., Greco, S., Greco, S., Ehrgott, M., Ehrgott, M., Eds.; Springer: New York, NY, USA, 2005.

52. Rashidi, M.; Samali, B.; Sharafi, P. A new model for bridge management: Part B: Decision support system for remediation planning. Aus. J. Civil Eng. 2006, 14, 46-53. [CrossRef]

53. Rashidi, M.; Ghodrat, M.; Samali, B.; Kendall, B.; Zhang, C. Remedial Modelling of Steel Bridges through Application of Analytical Hierarchy Process (AHP). Appl. Sci. 2017, 7, 168. [CrossRef] 